University of Rhode Island

DigitalCommons@URI

Open Access Dissertations

2020

\title{
THE INFLUENCE OF POLYMETHYL METHACRYLATE INTERFACES ON THE FLUORESCENCE OF RHODAMINE 6G THIN FILMS
}

Navid Chapman

University of Rhode Island, navid.chapman@gmail.com

Follow this and additional works at: https://digitalcommons.uri.edu/oa_diss

Recommended Citation

Chapman, Navid, "THE INFLUENCE OF POLYMETHYL METHACRYLATE INTERFACES ON THE

FLUORESCENCE OF RHODAMINE 6G THIN FILMS" (2020). Open Access Dissertations. Paper 1213.

https://digitalcommons.uri.edu/oa_diss/1213

This Dissertation is brought to you for free and open access by DigitalCommons@URI. It has been accepted for inclusion in Open Access Dissertations by an authorized administrator of DigitalCommons@URI. For more information, please contact digitalcommons-group@uri.edu. 
THE INFLUENCE OF POLYMETHYL METHACRYLATE INTERFACES ON THE FLUORESCENCE OF RHODAMINE 6G THIN FILMS

BY

NAVID CHAPMAN

\begin{abstract}
A DISSERTATION SUBMITTED IN PARTIAL FULFILLMENT OF THE REQUIREMENTS FOR THE DEGREE OF DOCTOR OF PHILOSOPHY IN
\end{abstract}

ANALYTICAL CHEMISTRY

UNIVERSITY OF RHODE ISLAND

2020 


\section{DOCTOR OF PHILOSOPHY DISSERTATION}

OF

Navid Chapman

\section{APPROVED:}

Dissertation Committee:

Major Professor William B. Euler

Dugan K. Hayes

Daniel Roxbury

David. R. Heskett

Brenton DeBoef

DEAN OF THE GRADUATE SCHOOL

\section{UNIVERSITY OF RHODE ISLAND}




\begin{abstract}
A three-layer fluorescence sensing platform is described. The sensor consists of an ultra-thin fluorophore layer of Rhodamine $6 \mathrm{G}$ (Rh6G) on top of a sub-micron polymer film of polymethyl methacrylate (PMMA) on top of a rigid glass support. Both fluorophore and polymer layers are prepared by spin-coating, a common industrial process for repeatable deposition of thin films of uniform thickness. First, we study the preparation of PMMA films. Using an accepted equation of state, we closely examine spin-coating dynamics and show that casting solution concentration and spin speed process parameters can be used to modulate the final thickness and surface morphology of dry PMMA films. Then, we apply the fluorophore layer. Using absorbance, excitation, and emission spectroscopy, we study the photophysics of Rh6G and demonstrate that interfacial roughness can help enhance fluorescence by disrupting the formation of weakly emissive dimer and aggregate absorbing species. Additionally, light trapping within the dielectric polymer layer can enhance fluorescence by promoting photon reabsorption at the polymer-fluorophore interface.
\end{abstract}




\section{ACKNOWLEDGMENTS}

I would like to express my gratitude to Professor William Euler for advising me throughout my graduate school career. I am grateful to have Professor Euler as well as Professor Dugan Hayes, Professor Daniel Roxbury, and Professor David Heskett to have taken the time out of their busy schedules to review my dissertation. I would like to also acknowledge Rhodes Pharmaceuticals and Purdue Pharmaceuticals for providing financial support for this work. A very special thanks for Stefan Nyarady, Qi Hong, Gerard Frunzi, Akwete Lex Adjei, Ping Chang, Deb Shell, James Doyle, and Vincent Mancinelli for their encouragement, invaluable input, and support of this work.

Finally, my deepest and most sincere appreciation goes to my exceptionally

clever, beautiful, and caring wife, Mingyu Chapman, for believing in me throughout my graduate school career. This work is an extension of her work and I appreciate her years of research that made this study possible. 


\section{DEDICATION}

For my parents 


\section{PREFACE}

This dissertation is written in manuscript format. The first manuscript is prepared for submission to the Journal of Applied Physics. The second manuscript is prepared for submission to Langmuir. The third manuscript is prepared for submission to the Journal of Physical Chemistry C. 


\section{TABLE OF CONTENTS}

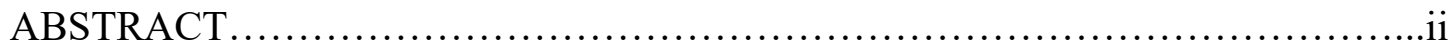

ACKNOWLEDGMENTS ......................................................ii

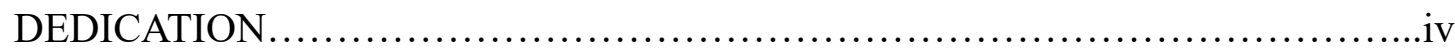

PREFACE ......................................................................

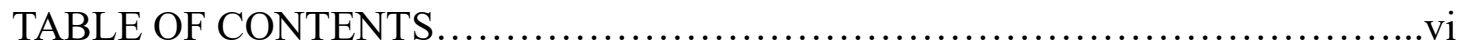

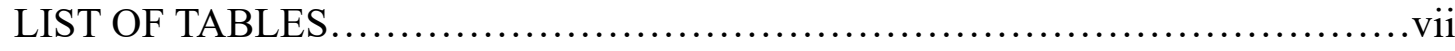

LIST OF FIGURES .....................................................viii

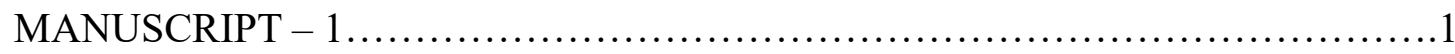

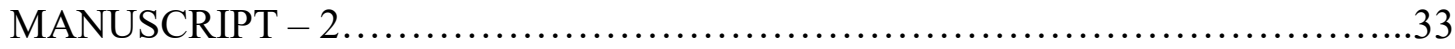

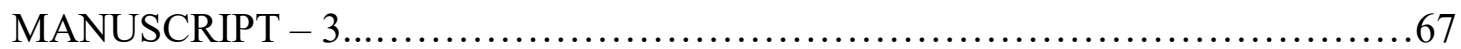

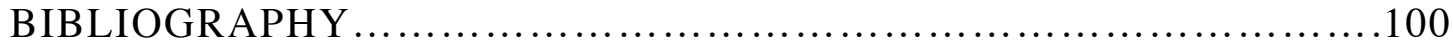




\section{LIST OF TABLES}

Table 1-1. PMMA intrinsic viscosity estimated from Mark-Houwink parameters...... 11

Table 1-2. Hansen solubility for PMMA and toluene. .......................................... 13

Table 2-S1. Slope, slope error, and $\mathrm{R}^{2}$ of global fit from figure 2-8 (A).................. 63

Table 3-1. Deconvolution Gaussian Peaks for the Absorption Spectra. ..................... 78

Table 3-2. Deconvolution Gaussian Peaks for the Emission Spectra ......................... 86 


\section{LIST OF FIGURES}

Figure 1-1. Huggin's plot for intrinsic viscosity determination of PMMA in toluene. 10

Figure 1-2. Scatter plot of dynamic viscosity as a function of spin-coating solution concentration

Figure 1-3. TGA thermogram showing isothermal evaporation of pure toluene and a $10 \mathrm{~g} / \mathrm{dL}$ PMMA-toluene solution

Figure 1-4. Derivative TGA thermogram of solvent and polymer solution at ambient temperature with polymer mass fraction. 15

Figure 1-5. TGA thermogram of bulk PMMA and spin-cast film at $10{ }^{\circ} \mathrm{C} / \mathrm{min}$ 17

Figure 1-6. FTIR spectra of bulk PMMA and spin-cast film 18

Figure 1-7. Scatter plot describing UV-Vis and reflectance measurement reproducibility 20

Figure 1-8. Difference scatter plot describing UV-Vis and reflectance measurement reproducibility

Figure 1-9. Scatter plot for initial solution properties contribution to film thickness. Scatter plot of final film height by physical fluid properties scaled by Eq. 1-4

Figure 1-10. Scatter plot of spin speed contribution to film thickness. Scatter plot of final film height by spin speed scaled by Eq. 1-4

Figure 1-11. Scatterplot for system calibration of evaporation rate contribution to film

thickness. 24 
Figure 1-12. Difference scatter plot describing bias between measured and calculated heights. 26

Figure 1-13. Contour plot of thickness by spin speed and solution concentration. ..... 27

Figure 2-1. Schematic of temperature-concentration gradient on volatile fluid droplets

Figure 2-2. Surface plots of commonly observed arrangements of convective flow

cells

Figure 2-3. Optical micrographs showing surface morphology at the spinning center of PMMA films prepared from various concentrations and spin speeds 45

Figure 2-4. Optical micrograph showing surface morphology at the spinning center of PMMA film produced from $8.0 \mathrm{~g} / \mathrm{dL}$ and $1000 \mathrm{RPM}$ 47

Figure 2-5. One-dimensional line profiles of PMMA surfaces at locations where convection rolls are present. 48

Figure 2-6. Scatterplot comparing PMMA wrinkle measurements by one- and twodimensional analysis methods. 50

Figure 2-7. Surface wrinkle wavelengths and amplitudes formed on PMMA films cast from different concentrations at a constant spin speed of 1200 RPM 51

Figure 2-8. PMMA surface wrinkle wavelength and wrinkle amplitude as a function of final film thickness. 53

Figure 2-9. PMMA surface skewness as a function of final film thickness 55

Figure 2-10. Optical micrographs of PMMA thin films cast at different spin speeds from chosen solution concentrations 56 
Figure 2-11. PMMA surface wrinkle wavelength and wrinkle amplitude as a function

of solvent drying rate. 57

Figure 2-S1. Line scan profiles of the wrinkled PMMA surfaces for films cast from 2.5 $\mathrm{g} / \mathrm{dL}$ 62

Figure 2-S2. Line scan profiles of the wrinkled PMMA surfaces for films cast at 2000

RPM 63

Figure 3-1. Scheme for three-layer sensor. 70

Figure 3-2. (A) Absorption spectra of different Rh6G on constant PMMA substrate, $t_{\text {PMMA }}=318 \pm 30 \mathrm{~nm}$; (B) Height normalized plot of (A); (C) Scatterplot of Rh6G thickness as a function of casting solution concentration for glass and PMMA supports; inset shows the lower concentration range; (D) Scatterplot of absorbance maximum wavelength and Rh6G thickness for Rh6G on PMMA substrate 76

Figure 3-3. Absorption spectra of Rh6G monolayer on PMMA.............................. 80

Figure 3-4. Absorption spectra of different Rh6G on constant PMMA substrate, $t_{\text {PMMA }}$ $=780 \pm 30 \mathrm{~nm}$ 82

Figure 3-5. (A) Steady state emission spectra of Rh6G on PMMA, tPMMA $=318 \pm 30$ nm. (B). Height normalized plot of (A). (C) Scatterplot comparing emission maximum wavelength with Rh6G thickness on a PMMA substrate of constant thickness. (D) Emission intensity as a function of tRh6G for glass and PMMA substrates 83 
Figure 3-6. Normalized absorbance (black), excitation (red), emission (green) spectra of different Rh6G thicknesses on PMMA of constant thickness, tPMMA $=318$

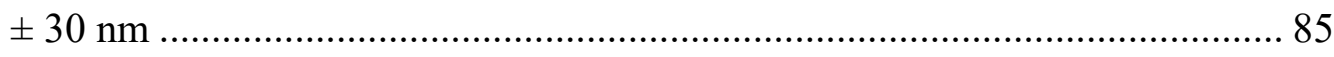

Figure 3-7. (A) Rh6G steady state emission spectra on PMMA of changing thickness, tRh6G $=1.0 \mathrm{~nm}$. (B) Rh6G emissive wavelength dependence of PMMA thickness. (C) Rh6G Emission intensity as a function of Rh6G thickness and PMMA thickness.

Figure 3-8. (A) Lifetime emission of different thicknesses of Rh6G on PMMA of constant thickness; tPMMA $=318 \mathrm{~nm}$. (B). Pre-exponential factor as a function of Rh6G thickness............................................................... 88

Figure 3-S1. Absorption spectra of constant Rh6G thickness on different PMMA thicknesses...................................................95

Figure 3-S2. Example fit for deconvolution of Rh6G spectral absorption............96

Figure 3-S3. Example fit for deconvolution of Rh6G spectral emission..............97 


\title{
MANUSCRIPT - I
}

Prepared for submission to Journal of Applied Physics

Modeling of Polymethyl Methacrylate Viscous Thin Films by Spin-coating

\author{
Navid Chapman, Mingyu Chapman, and William B. Euler \\ Chemistry, University of Rhode Island, Kingston, RI, USA
}

Corresponding Author: William B. Euler, Ph.D.

Chemistry

University of Rhode Island

140 Flagg Road

Kingston, RI, 02881, USA

Email address: wueler@chm.uri.edu 


\begin{abstract}
A predictive film thickness model based on an accepted equation of state is applied to the spin-coating of sub-micron polymethyl methacrylate viscous thin films from toluene. Concentration effects on density and dynamic viscosity of the spincoating solution are closely examined. Film thickness model is calibrated with a system specific film drying rate and was observed to scale with the square root of spin speed. Process mapping is used to generate a three-dimensional design space for control of film thickness.
\end{abstract}




\section{INTRODUCTION}

In this work we report methods for controlled deposition of polymethyl methacrylate (PMMA) coatings on glass slides. Control of polymer film thickness is critical to sensor efficiency and performance. ${ }^{1}$ Coatings were applied by spin-coating, a common academic and industrial process for repeatable deposition of films of uniform thickness and surface roughness. When used as solid fluorophore host, PMMA has demonstrated increased fluorophore stability against thermal and photo degradation. ${ }^{2}$ Toluene is frequently used as solvent to dissolve PMMA in fundamental spin-coating studies..$^{3-5}$ The PMMA-toluene solution is of moderate volatility, miscible at all concentrations, and relatively weak in solvent-solute interactions. ${ }^{6-8}$ Newtonian fluid behavior has been demonstrated with linear shear stress and shear rates over a large concentration range. ${ }^{9}$

Foundations for the spin-coating model were laid by Emslie, Bonner, and Peck in their study of hydrodynamic flow of a non-volatile Newtonian fluid. ${ }^{10}$ They proposed that influence from gravitational and Coriolis acceleration could be neglected when the thinning fluid possesses a disproportionate viscosity to thickness ratio and is rotated at speeds of 100 RPM or more. With these conditions met, fluid thinning could be described as a force balance between viscous drag and rotational acceleration dependent upon radial and hydrodynamic forces as described by the parameter:

$$
K=\frac{\omega^{2}}{(3 v)}
$$

where $\omega$ is rotational velocity and $v$ is kinematic viscosity. 
Meyerhofer adapted this approach to incorporate a volatile solvent. Considerations were provided for evaporation and fluid dynamics while assuming a lubrication approximation (no slip due to sufficient substrate wetting) and negligible impacts from surface tension or substrate acceleration. ${ }^{11}$ Viscous film thinning is described as a two-stage sequential domination of hydrodynamic and evaporative forces. Initial fluid thinning is directed by radial outflow and continues until solute enrichment reaches a critical point where fluid viscosity retards flow and solvent evaporation becomes the dominant force. Final stages of film formation continue at a constant evaporation rate until a solid film has formed. From the transition point onward, the contributions to thinning due to radial outflow are negligible in comparison to evaporation.

The rate of film thinning per unit area could be described by

$$
\frac{d h}{d t}=-2 K h^{3}-E
$$

where $h$ is the vertical thickness of the fluid. The parameter $E$ was proposed for evaporation and captures an observed scaling of the static evaporation rate, $e$, by rotation speed:

$$
E=e \omega^{-1 / 2}
$$

Haas reported that the rate of solvent evaporation is reliant on solvent partial pressure. Solvent mass transfer to the vapor phase is inhibited by diffusion within the film at low partial pressure and resisted by the saturated environment above the film at high partial pressure. The evaporation rate is a static system specific parameter that encompasses solvent vapor pressure effects and diffusivity into the overlying gas. ${ }^{12}$ 
Using a highspeed imaging techniques, Danglad-Flores refined Meyerhofer's models and proposed a first-order approach to quantitative predictions of final film thickness. ${ }^{3}$ This simple method requires only a few initial fluid properties, spin speed, and a calibration experiment to determine the system specific evaporation rate.

$$
h_{f}=(3 \Theta / 2)^{1 / 3} \chi_{0}\left(\eta_{0} / \rho_{0}\right)^{1 / 3} \omega^{-1 / 2}
$$

where $\chi_{0}$ is the polymer mass fraction, $\eta_{0}$ is the dynamic viscosity, and $\rho_{0}$ is the density.

Solution density and viscosity properties are closely related to polymer concentration. Viscous behavior of the polymer solutions can be described with the reduced specific viscosity, $\eta_{r}$ :

$$
\eta_{r}=\left(\frac{\eta_{0}}{\eta_{s}}-1\right) / c
$$

where $\eta_{o}$ is initial viscosity of the polymer solution, $\eta_{s}$ is viscosity of the pure solvent, and $c$ is the concentration of the polymer in the spin-coating solution. Dynamic viscosity relates with solution concentration as per the Martin equation: ${ }^{13}$

$$
\eta_{r}=[\eta] e^{c K_{H}[\eta]}
$$

where $[\eta]$ is intrinsic viscosity and $K_{H}$ is Huggin's viscosity constant. The value of $K_{H}$ is expected near 0.4, which is the reciprocal of the Einstein-Stokes constant in an ideal dilute solution where the probability of interactions between polymer chains is negligible. Matsuoka and Cowman have reported a systematic overestimation of $K_{H}$ during analysis of high molecular weight compounds at low concentrations. This error has been attributed to straight line approximations which can be accommodated for by restricting $K_{H}$ to $0.4 \pm 0.1$. Application of Eq. 1-6 is limited to dilute through medium 
concentrated solutions. The deviation at higher concentrations are associated with interactions from overlapping polymer coils. Matsuoka and Cowman propose that the viscous behavior arising from polar, ionic, and hydrogen bonding interactions can be better approximated by expanding Eq. 1-6 into a Taylor series:

$$
\eta_{r} \approx[\eta] \sum_{i=0}^{\infty} \frac{\left(c K_{H}[\eta]\right)^{i}}{i !}
$$

A conservative approximation of entanglement effects is made by truncating expansion after the third term. ${ }^{14}$

The previous studies examined polymer solutions of dilute to medium concentrations and thin films up to a few microns in thickness. The focus of this study is to analyze materials and fluid properties for process mapping of a predictive spincoating model for depositing sub-micron polymer layers. 


\section{EXPERIMENTAL}

Glass microscope slides $(\sim 1 \mathrm{~mm}$ thick) were cut into 37.5 x $25 \mathrm{~mm}$ sections. Slides were cleaned and treated by submersion in ethanol (EtOH, 95\%, PharmacoAaper), followed by 15 minutes of sonication, then rinsed with purified water, submerged in purified water, sonicated for an additional 15 minutes, and dried under $\mathrm{N}_{2}$.

Atactic PMMA (Mw 120,000, PDI 2.0-2.4) was obtained from Sigma-Aldrich and used without further purification. A $20 \mathrm{~g} / \mathrm{dL}$ stock solution was prepared in toluene (Honeywell, HPLC grade). Polymer stock solution was sonicated for 8 hours with intermittent shaking to ensure full solvation. Resulting solution was optically clear. Dilutions ranging from 0.75 to $10.00 \mathrm{~g} / \mathrm{dL}$ were prepared directly from the stock.

Dynamic viscosity of polymer solutions was measured with cylindrical spindles and a Brookfield DV2T spring-torque rotational viscometer at shear rates of $200 \mathrm{~s}^{-1}$. Sample temperature was measured by thermocouple attached to the sample chamber and observed at $20.0^{\circ} \mathrm{C}$.

A Laurell Technologies spin-coater was used for spin-coating films. An ultrathin PMMA film was applied to the glass slides in dry conditions $(<20 \%$ Relative Humidity) by depositing a $250-\mu \mathrm{L}$ aliquot of polymer solution to the center of a slide and then spin-coating for 45 seconds, accelerated at $1080 \mathrm{~s}^{-2}$, and maximum rotation speed in the range of 400 to 8000 RPM. Spin-coating was carried out under a constant flow of compressed air. Films were air dried for 15 minutes and then transferred to an oven set at $60^{\circ} \mathrm{C}$ for 2 minutes to facilitate residual solvent removal. 
Fourier transform infrared (FTIR) spectra were obtained with a Perkin Elmer Spectrum 100 fitted with a diamond ATR crystal. Background and sample spectra were collected with 128 scans and resolution of $4 \mathrm{~cm}^{-1}$.

Thermal mass loss experiments were performed with a TA instruments thermogravimetric analyzer (TGA). Static evaporation rate $(\omega=0)$ investigations were conducted in open cylindrical aluminum pans $(20-\mu \mathrm{L}$ capacity, $5 \mathrm{~mm}$ diameter). Samples were held isothermally at ambient temperature. Dry compressed air purge of balance and sample at a flow rate of $25 \mathrm{~mL} / \mathrm{min}$. A second investigation for polymer characterization was conducted with open aluminum sample pans $(80-\mu \mathrm{L})$. Samples were first equilibrated at $30{ }^{\circ} \mathrm{C}$ and then heated to $500{ }^{\circ} \mathrm{C}$ at a rate of $10{ }^{\circ} \mathrm{C} / \mathrm{min}$. Dry nitrogen purge of balance and sample at respective flow rates of 40 and $30 \mathrm{~mL} / \mathrm{min}$.

Reflection spectra of polymer films was acquired with a Filmetrics F40 microscope thin film analyzer. Reflectance in the range of 400-900 nm was generated by a tungsten-halogen light source. PMMA thin film optical constants for the refractive index, $\mathrm{n}$, and absorption coefficient, $\mathrm{k}$, were obtained from literature. ${ }^{15}$ Spectral fitting and film thickness calculations were performed with the Filmeasure software. Transmittance spectra of polymer films were collected with a Perkin Elmer Lambda $1050 \mathrm{UV} / \mathrm{V}$ is spectrometer. The slit width and integration time were set at $2 \mathrm{~nm}$ and 0.20 seconds respectively. Wavelengths generated from tungsten-halogen and deuterium lamps were collected in the 1100 to $300 \mathrm{~nm}$ range. 


\section{RESULTS AND DISCUSSION}

Polymer coating solutions prepared at concentrations ranging from 0.125 to 20.0 $\mathrm{g} / \mathrm{dL}$ were observed to be clear and free flowing. Optical transparency for all solutions was identical to the pure solvent. Polymer mass fraction and solution density determinations were conducted at an ambient temperature of $20^{\circ} \mathrm{C}$. Both mass fraction and density increased linearly with polymer concentration. The relationship between polymer mass fraction and concentration is described by:

$$
\chi_{o}=1.12 \times 10^{-2} c
$$

The relationship between solution density and concentration is described by:

$$
\rho_{o}=2.94 c+\rho_{s}
$$

where $\rho_{s}$ is density of the pure solvent. For both regressions, the coefficient of determination $R^{2}$ was greater than 0.999 .

Dynamic viscosity of fluids was observed between 1.13 and $8.31 \mathrm{mPa}-\mathrm{s}$. Viscosity measurements were taken at constant shear rates of $200 \mathrm{~s}^{-1}$ for semi-dilute polymer to moderately concentrated solutions ( 2.5 to $10.0 \mathrm{~g} / \mathrm{dL}$ ). Solution viscosity was observed to increase exponentially with polymer concentration. 


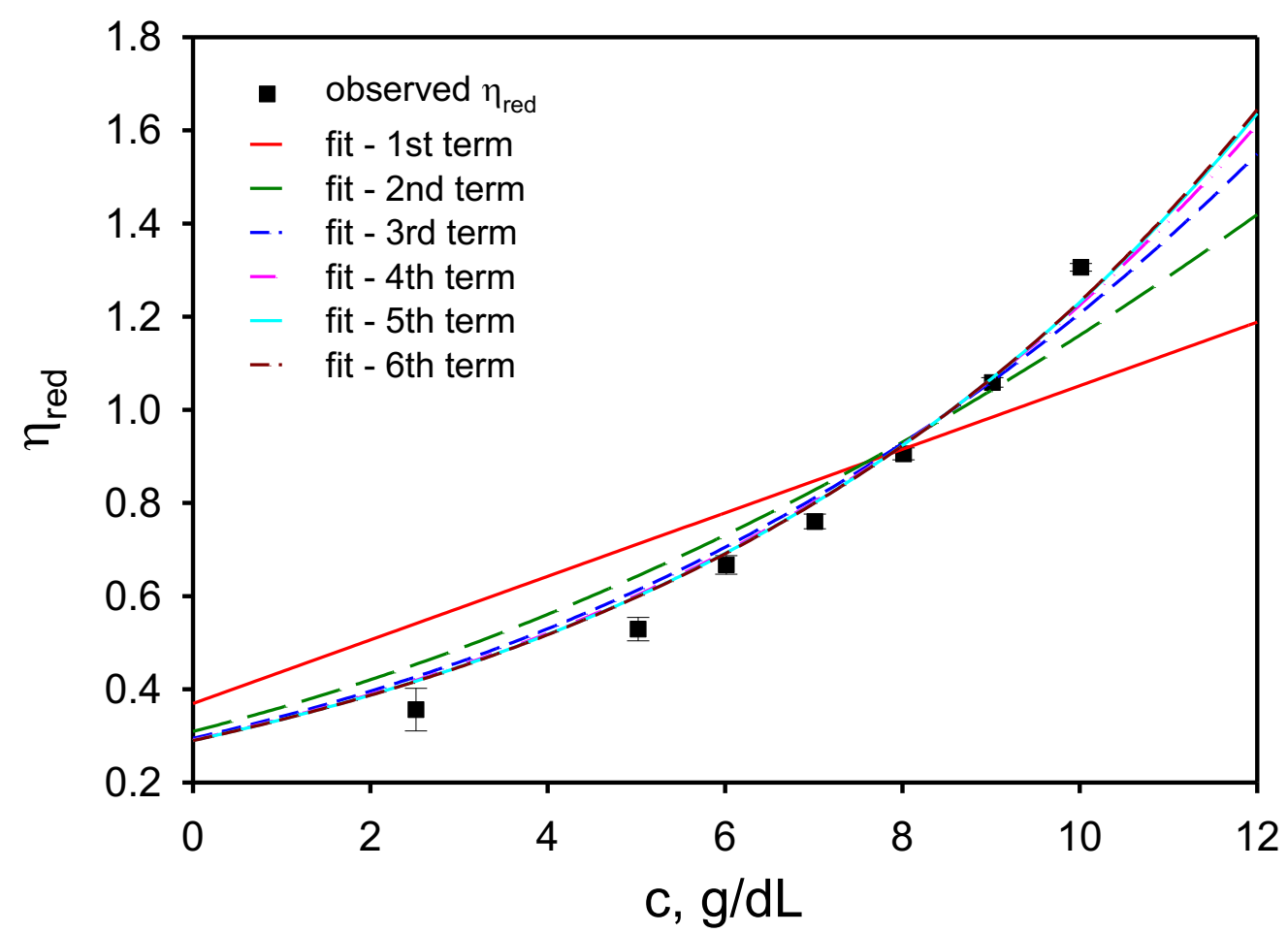

Figure 1-1. Huggin's plot for intrinsic viscosity determination of PMMA in toluene. Huggin's scatter plot of reduced specific viscosity against polymer concentration. Nonlinear regression by series expansion of Eq. 1-7 and parameters converged by the sixth term for $[\eta]=0.292 \pm 0.031(\mathrm{dL} / \mathrm{g})$ and $\mathrm{K}_{\mathrm{H}}=0.500 \pm 0.101$. Lines for the first six term expansions of Eq. 1-7 have been plotted. Matsuoka and coworkers recommended a maximum three-term expansion to account for viscosity contributions from polymer entanglement. ${ }^{14}$ Fit at the third term expansion is reasonable with $\mathrm{R}^{2}=0.956$. Vertical error bars presented for all points.

Figure 1-1 shows a Huggin's plot of reduced specific viscosity by concentration.

Non-linear regression by Eq. 1-7 was found to converge by the sixth term $([\eta]=0.292$ $\left.\pm 0.031, K_{H}=0.500 \pm 0.101, \mathrm{R}^{2}=0.96\right)$. Potentially due to differences in fractional polydispersity ${ }^{16}$ or systematic fitting errors ${ }^{14}$ a wide range of literature values have been reported for $[\eta]$ and $K_{H}$ combinations. ${ }^{17}$ For this reason, experimental intrinsic viscosity determinations were compared to estimations made with the Mark-Houwink equation:

$$
[\eta]=K_{M H} M^{a}
$$


where $M$ is PMMA molecular weight. Calculations were made with reported Mark-Houwink coefficients $\left(K_{M H}, a\right)$ and results are listed in Table 1-1. ${ }^{18-20}$ Experimentally determined intrinsic viscosity for PMMA is also shown in Table 1-1 and is in good agreement with estimates calculated from literature values. Limitations of the fitting regression are observed by the assignment of $K_{H}$ at the upper limit which was implemented to avoid erroneous straight line approximations. ${ }^{14}$ When the fitting was performed without variable constraints, $K_{H}$ and $[\eta]$ converged near $\sim 0.7$ and $\sim 0.18$ dL/g respectively. The higher than expected $K_{H}$ tendency suggests that the solution rheology may be impacted by undetermined polymer-solvent dynamics or synergistic effects.

$\begin{array}{cccccc}{[\boldsymbol{\eta}]} & \begin{array}{c}\boldsymbol{K}_{\boldsymbol{M H}} \\ \left(10^{-3} \mathrm{~mL} / \mathrm{g}\right)\end{array} & \boldsymbol{a} & \begin{array}{c}\text { temp. } \\ { }^{\circ} \mathrm{C}\end{array} & \text { measurement } & \text { reference } \\ 0.292 \pm 0.031 & - & - & 20 & \text { viscosity } & \\ 0.28 & 7.0 & 0.71 & 30 & \text { viscosity } & {[28]} \\ 0.33 & 8.12 & 0.71 & 25 & \text { membrane osmometry } & {[29]} \\ 0.27 & 7.79 & 0.697 & 25 & \text { light scattering } & {[30]}\end{array}$

Table 1-1. PMMA intrinsic viscosity estimated from Mark-Houwink parameters. Intrinsic viscosity estimates determined from Eq. 1-10. Coefficients, $K_{M H}$ and $a$, were obtained from studies that utilized different analytical techniques. Presented results and referenced studies were performed at comparable temperatures.

Figure 1-2 shows a plot between dynamic viscosity and concentration. This relationship is fit reasonably well by Eq. $1-7$ truncated at the third term $\left(\mathrm{R}^{2}=0.97\right.$, error: \pm 0.34 ) with the largest deviations occurring at the highest concentrations. 


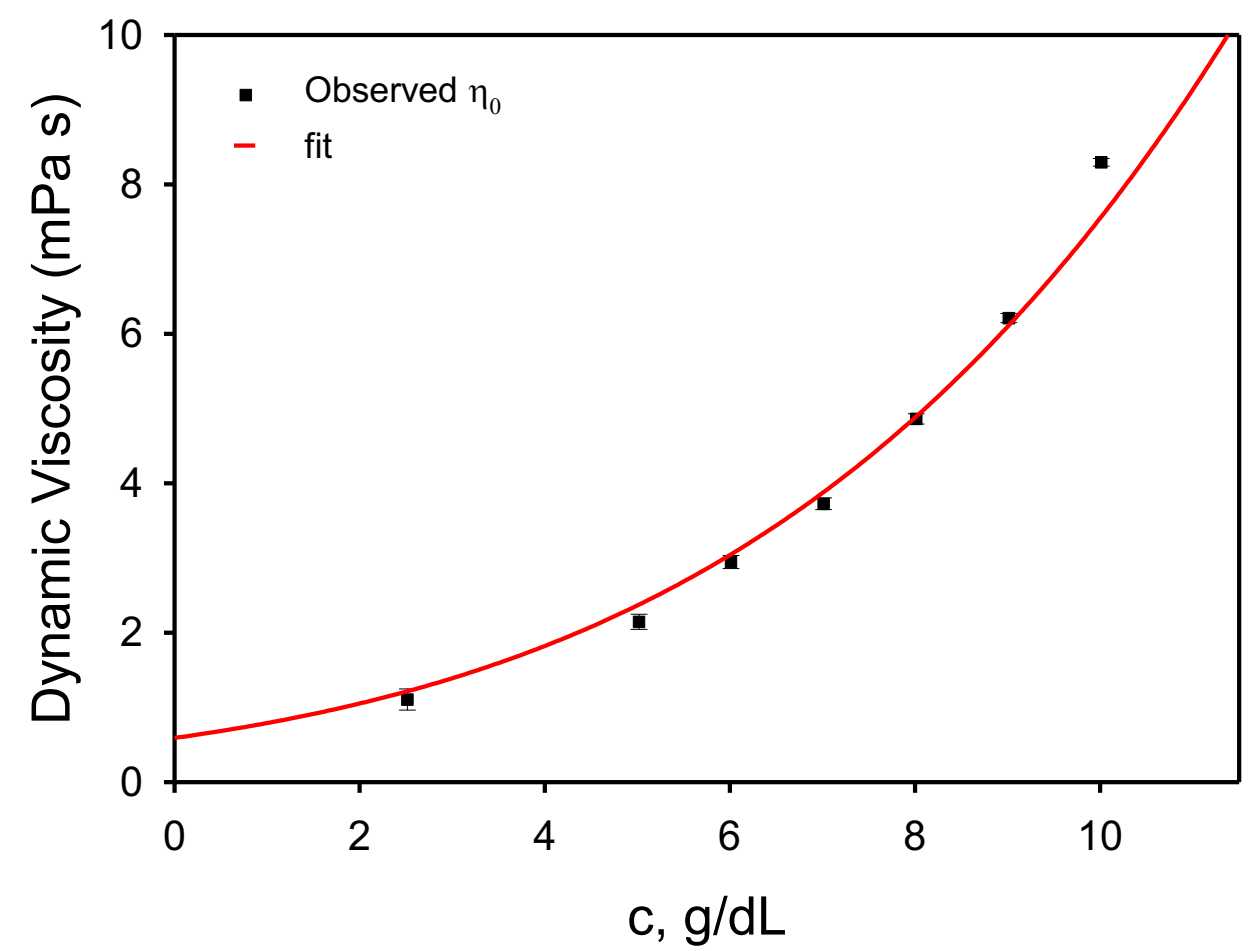

Figure 1-2. Scatter plot of dynamic viscosity as a function of spin-coating solution concentration.

Line of fit was determined by combining Eq. 1-5 with Eq. 1-7 (truncated at the third term) and solving for $\eta_{0}$. Fit was comparable to the Huggin's plot with $\mathrm{R}^{2}$ $=0.973$ and standard error \pm 0.34 . Vertical error bars presented for all points. $\eta_{\text {solution }} \approx \eta_{\text {solvent }}\left\{1+c[\eta] \sum_{i=0}^{3} \frac{\left(c K_{H}[\eta]\right)^{i}}{i !}\right\}$

A theoretical examination of solvent-polymer interactions can be approached by Hansen's three-component solubility parameter envelope:

$$
R_{a}=\left[4\left(\delta_{D 2}-\delta_{D 1}\right)^{2}+\left(\delta_{P 2}-\delta_{P 1}\right)^{2}+\left(\delta_{H 2}-\delta_{H 1}\right)^{2}\right]^{1 / 2}
$$

where the interaction radius is relative to three solubility parameters: $\delta_{D}$, dispersion; $\delta_{P}$, polar; and $\delta_{H}$, hydrogen bonding. Table 1-2 displays the calculated parameters for PMMA and toluene. ${ }^{21,22}$ Hansen solubility parameter (HSP) theory describes relative energy difference (RED) as the ratio of HSP distance, $\mathrm{R}_{\mathrm{a}}$, to the interaction radius, $\mathrm{R}_{0}$. Solubility is expected when $\mathrm{RED}<1$ and partial solubility when 
RED is at unity. While the calculated RED value of 0.96 correctly predicts full solubility, it suggests relatively weak solute-solvent interactions.

$\begin{array}{cccccc}\text { Material } & \begin{array}{c}\delta_{\mathrm{D}} \\ \left(\mathrm{MPa}^{1 / 2}\right)\end{array} & \begin{array}{c}\delta_{\mathrm{P}} \\ \left(\mathrm{MPa}^{1 / 2}\right)\end{array} & \begin{array}{c}\delta_{\mathrm{H}} \\ \left(\mathrm{MPa}^{1 / 2}\right)\end{array} & \mathrm{R}_{\mathrm{a}} & \mathrm{R}_{0} \\ \text { PMMA } & 19.74 & 4.92 & 11.5 & 10.7 & 11.1 \\ \text { Toluene } & 18.0 & 1.4 & 2.0 & 10.7\end{array}$

Table 1-2. Hansen solubility for PMMA and toluene.

Toluene and PMMA dispersion $\left(\delta_{\mathrm{D}}\right)$, polar $\left(\delta_{\mathrm{P}}\right)$, hydrogen bonding $\left(\delta_{\mathrm{H}}\right)$, parameters and interaction radius $\left(\mathrm{R}_{0}\right)$ were calculated with HSP software and reported in an application note. ${ }^{23}$ HSP distance $\left(\mathrm{R}_{\mathrm{a}}\right)$ was calculated by Eq. 1-11. Full solubility with relatively weak solute-solvent interactions are suggested by the relative energy difference $\left(R_{a} / R_{0}\right)$. The degree of variance between individual solubility parameters describes interactions as mainly dispersion-van der Waals forces, with some polar interactions, and relatively low hydrogen bonding.

Thermogravimetry was used for screening solute effect on evaporation rate. A slow flow of purged air was used to facilitate solvent vapor removal without encouraging convection. Figure 1-3 shows the mass loss curves and Figure 1-4 shows the static evaporation rates $(\omega=0)$ of toluene and a $10.0 \mathrm{~g} / \mathrm{dL}$ polymer solution. The two mass loss curves are very similar for the first twenty minutes of drying. Beginning around 20 minutes of drying, when PMMA is approximately $\chi \approx 0.2$, the polymer solution begins to dry slower than the pure solvent. As time is increased, the polymer solution continues drying at a slightly slower rate until around 85 minutes $(\chi \approx 0.8)$ 
when the rate of evaporation in the polymer solution is strongly suppressed. In contrast, pure toluene evaporates steadily through depletion.

Solvent evaporation is controlled by diffusivity within the film and solvent partial pressure above the film. The observed decrease in evaporation rate over time contrasts the expected constant evaporation rates that have been reported for the spincoating process. ${ }^{3,24}$ It is likely that surface tension effects help shape evaporation rates. Slow removal of toluene in the final stages of film formation may be indicative of a solvent mass transfer being diffusion rate limited in the enriched polymer environment.

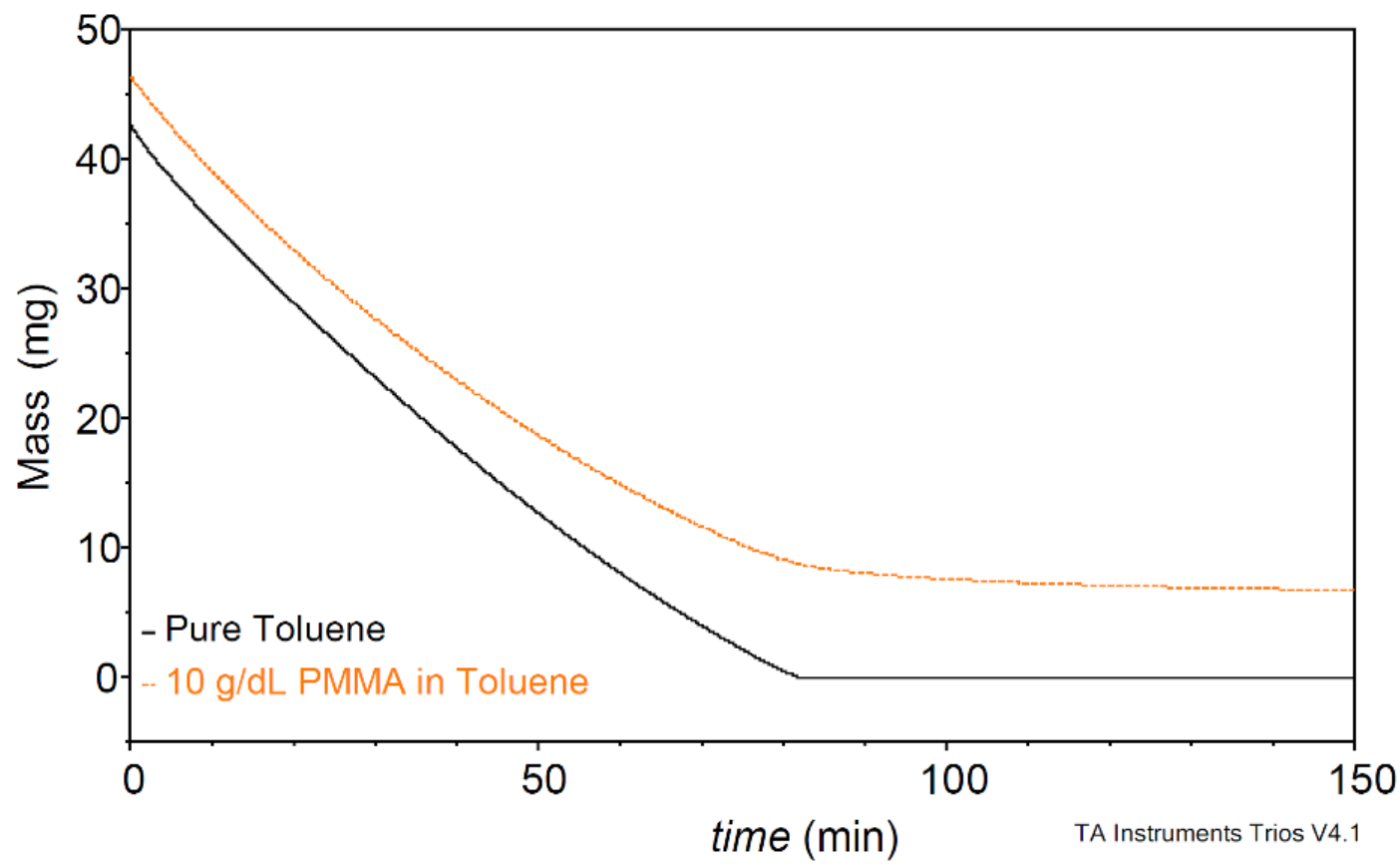

Figure 1-3. TGA thermogram showing isothermal evaporation of pure toluene and a 10 g/dL PMMA-toluene solution.

Ambient temperature isotherm for 150 minutes. Fluids were placed in open cylindrical sample pans and held at ambient temperatures under a slow $\mathrm{N}_{2}$ purge, which was added to limit solvent saturation above the sample. Both solutions were monitored until dry. The residue mass in the $10 \mathrm{~g} / \mathrm{dL}$ PMMA curve represents the dried polymer. 


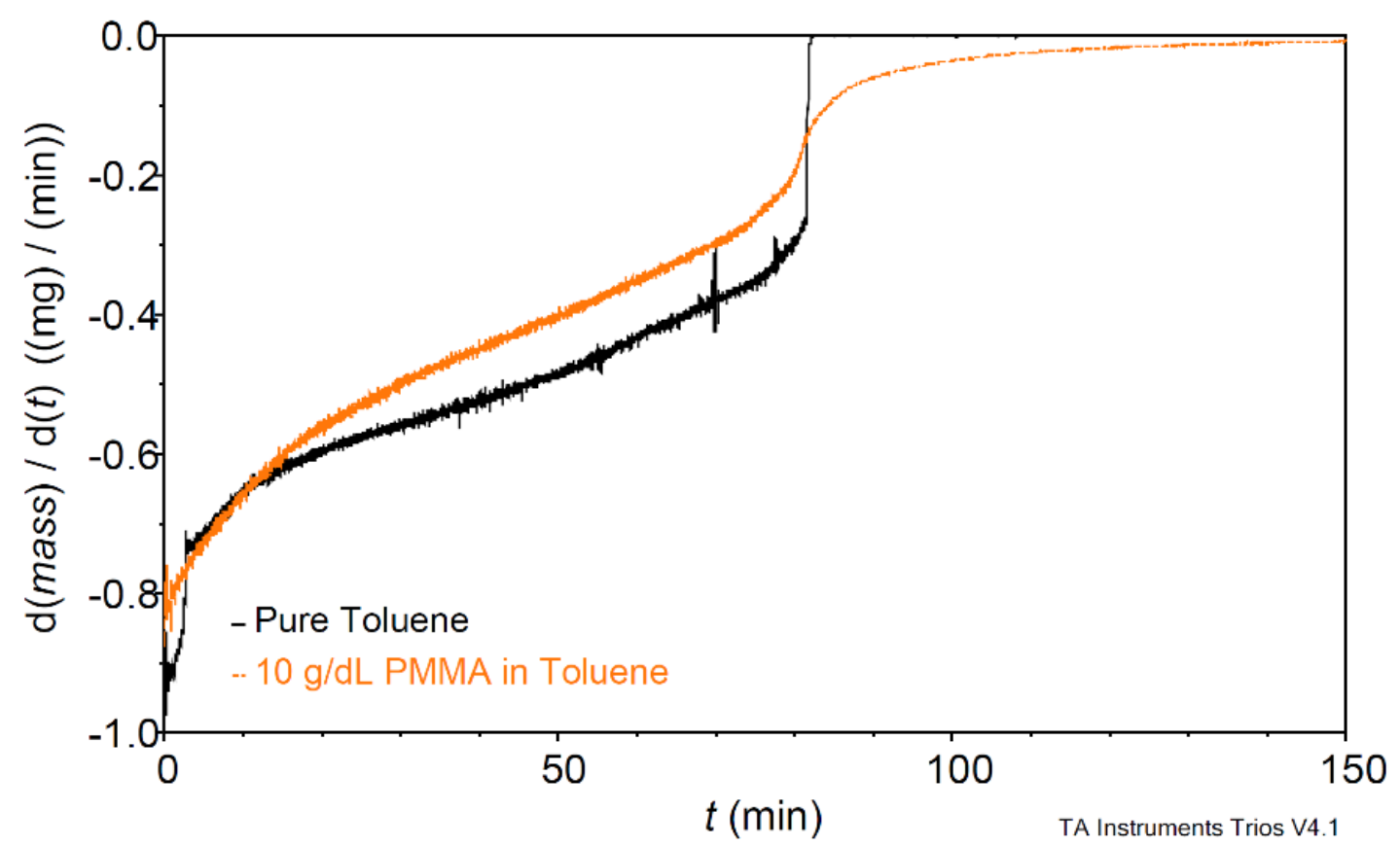

Figure 1-4. Derivative TGA thermogram of solvent and polymer solution at ambient temperature with polymer mass fraction.

Derivative TGA plots are used here to compare toluene evaporation rates in the polymer solution and pure solvent. Evaporation rate of the polymer solution at concentrations less than $0.2 \chi$ are nearly identical to the pure solvent. Evaporation rates are slightly reduced at polymer concentrations less than $0.8 \chi$. Significantly slower evaporation rates are observed at the final stages of polymer enrichment and may be correlated with a glass transition. The observed constant decrease in evaporation rates is possibly a solvent retention effect caused by interactions with the sample container walls. Constant evaporation rates have been reported for the solvent during spincoating. ${ }^{3,24}$ 
TGA is used here on both the PMMA starting material and final dried film to verify that the material was not changed. Figure 1-5 shows mass loss associated with thermal decomposition occurring between ambient temperature and $500^{\circ} \mathrm{C}$. An initial mass loss is observed near $153{ }^{\circ} \mathrm{C}$ and followed by a larger mass loss near $260{ }^{\circ} \mathrm{C}$. These two mass loss stages are generally associated with depolymerization starting from headto-head linkages and unsaturated vinyl ends. The third and largest mass loss shown near $370{ }^{\circ} \mathrm{C}$ is often associated with a methoxycarbonyl side group scission and random scissions of the main chain. ${ }^{25-27}$ Temperature and magnitude of the three mass loss stages strongly correlated with published reports. Minor deviations between degradation curves are likely an artifact related to the limited sample size of the thin film. Highly similar thermal behavior is observed for both samples. 


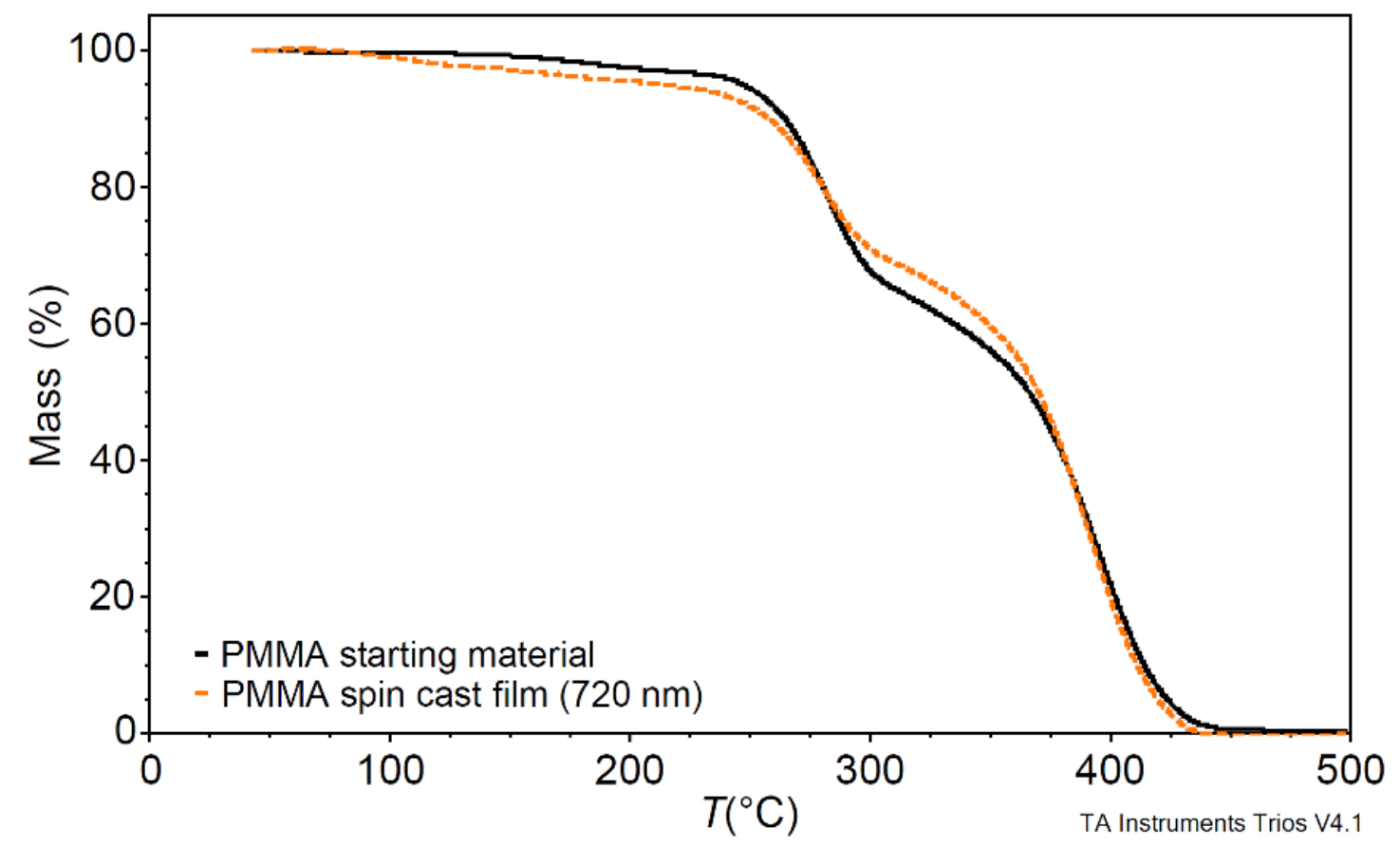

Figure 1-5. TGA thermogram of bulk PMMA and spin-cast film at $10^{\circ} \mathrm{C} / \mathrm{min}$.

$10.95 \mathrm{mg}$ of commercial PMMA and $0.28 \mathrm{mg}$ of spin-cast film removed by scraping from glass slide. TGA thermogram shows mass loss over time for PMMA starting materials and a spin-cast film that was removed from the glass substrate. Materials were heated in open pans at a ramp rate of $10^{\circ} \mathrm{C} / \mathrm{min}$. Variances between the two curves are likely associated with the small thin film sample size. The two thermograms are highly similar, which suggests that the bulk chemical properties of the polymer were not affected by the spin-coating process.

Additional chemical characterization of bulk and spin-cast polymer was carried out by FTIR analysis. Figure 1-6 over lays the infrared absorbance spectra of the two samples from 4000 to $1200 \mathrm{~cm}^{-1}$. Collection was limited in the higher energy region due to strong silicon-oxide absorptions of the glass substrate at frequencies below 1200 $\mathrm{cm}^{-1}$. The observed absorbance bands for methyl, carbonyl, and ester stretching modes at $\sim 2900, \sim 1700$, and $\sim 1450 \mathrm{~cm}^{-1}$ have also been reported in literature for PMMA as a bulk substance and thin film. ${ }^{7,16,28}$ The FTIR spectra of the bulk material and the $720 \mathrm{~nm}$ spin-cast film are highly similar. 


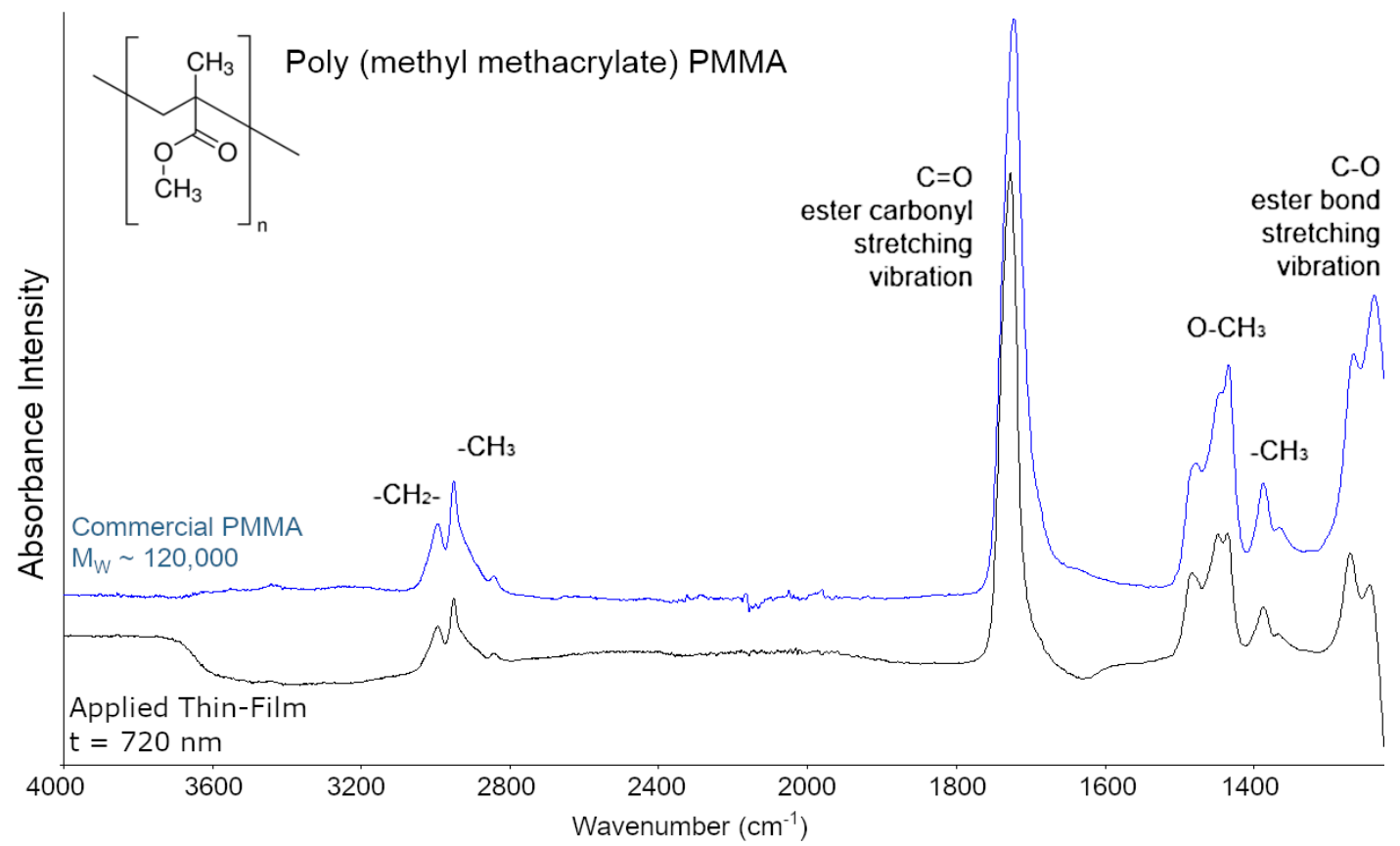

Figure 1-6. FTIR spectra of bulk PMMA and spin-cast film.

FTIR spectra of bulk PMMA and spin-cast film was collected in ATR mode with a diamond crystal. Thin film was not removed from glass substrate prior to measuring spectra. Strong silicate absorbances prevented meaningful collection of thin film spectra at wavenumbers less than $1200 \mathrm{~cm}^{-1}$. The two spectra are highly similar, which supports the TGA characterization conclusions that the bulk chemical properties of the polymer were not affected by the spin-coating process.

Polymer film thickness was calculated from thin film interreference equations based the ultraviolet visible light (UV-Vis) absorption spectral fringing patterns, regression analysis of the reflectance spectra, and the material's optical constants. The thinnest films measurable by UV-Vis were $160 \mathrm{~nm}$. The thinnest films measured by reflectance were $65 \mathrm{~nm}$. The thickest films measured were approximately $1 \mu \mathrm{m}$. No limitations were observed for reflectance measurements. Film thickness measurements for select spin-coating parameters match our previous findings. ${ }^{29}$ Process repeatability was assessed for several solution concentrations from UV-Vis obtained film thickness measurements at 1200 RPM. For films cast from 2,4 , and $7 \mathrm{~g} / \mathrm{dL}$ solutions, the polymer layer was $130 \pm 13 \mathrm{~nm}, 306 \pm 10 \mathrm{~nm}$, and $717 \pm 16 \mathrm{~nm}$ respectively. For all three 
concentrations, film thickness measurements are evenly distributed around a mean value. The coefficient of variance is smallest for films cast from the $4 \mathrm{~g} / \mathrm{dL}$ solution. Standard deviation values not only contribute information for reproducibility of average thickness, but also provide insights about surface uniformity.

Reproducibility of film thickness measurements between the two techniques was assessed using a 'limits of agreement' approach. ${ }^{30}$ Figure 1-7 shows a scatter plot comparing UV-Vis with reflectance thicknesses measurements of the same samples. A line of equality has been drawn where identical measurements would lie. The 'line of equality' marks the location of identical measurement values for the two techniques. Figure 1-8 shows a scatter diagram of measurement differences by the average of the two measurements. Lines have been drawn for the mean difference and $95 \%$ limits of agreement ( \pm 1.96 standard deviations). Results show a normal distribution of differences in measured thickness that extends without bias through the studied thickness range from $\sim 100 \mathrm{~nm}$ to $1 \mu \mathrm{m}$. The $95 \%$ confidence interval was found to be \pm $44 \mathrm{~nm}$ from the mean. Film uniformity is expected to decrease with film thickness and a bias towards larger measurement differences might be expected. While the data does not suggest this to be the case, the sample size at larger thicknesses is too small for this expectation to be ruled out. Thickness variations across a film are expected and the reported confidence interval accounts for the unlikeness of the same of location being measured by both techniques. 


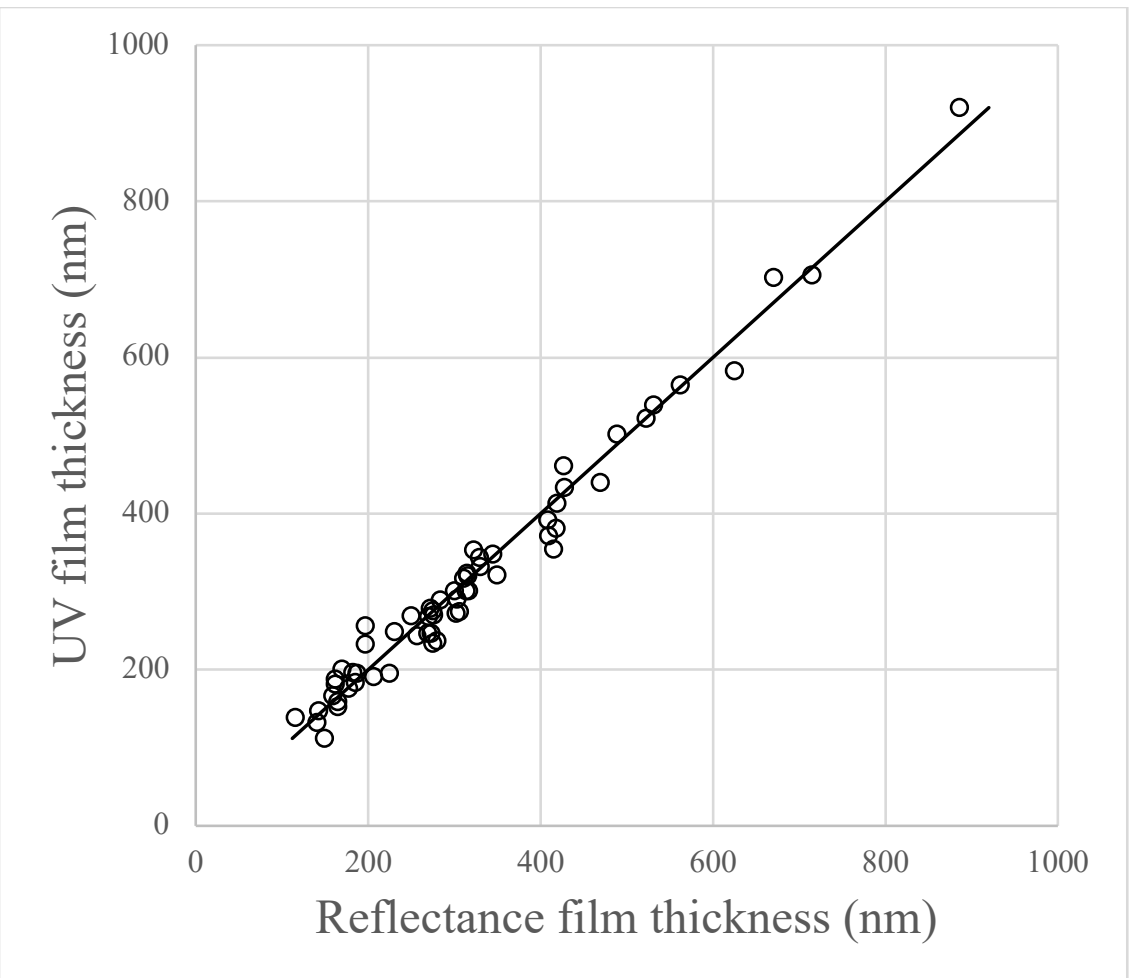

Figure 1-7. Scatter plot describing UV-Vis and reflectance measurement reproducibility. Scatterplot seeking distribution and assessing bias of measurements made by different visible light instruments. The 'line of equivalency' marks the location for identical measurements. 


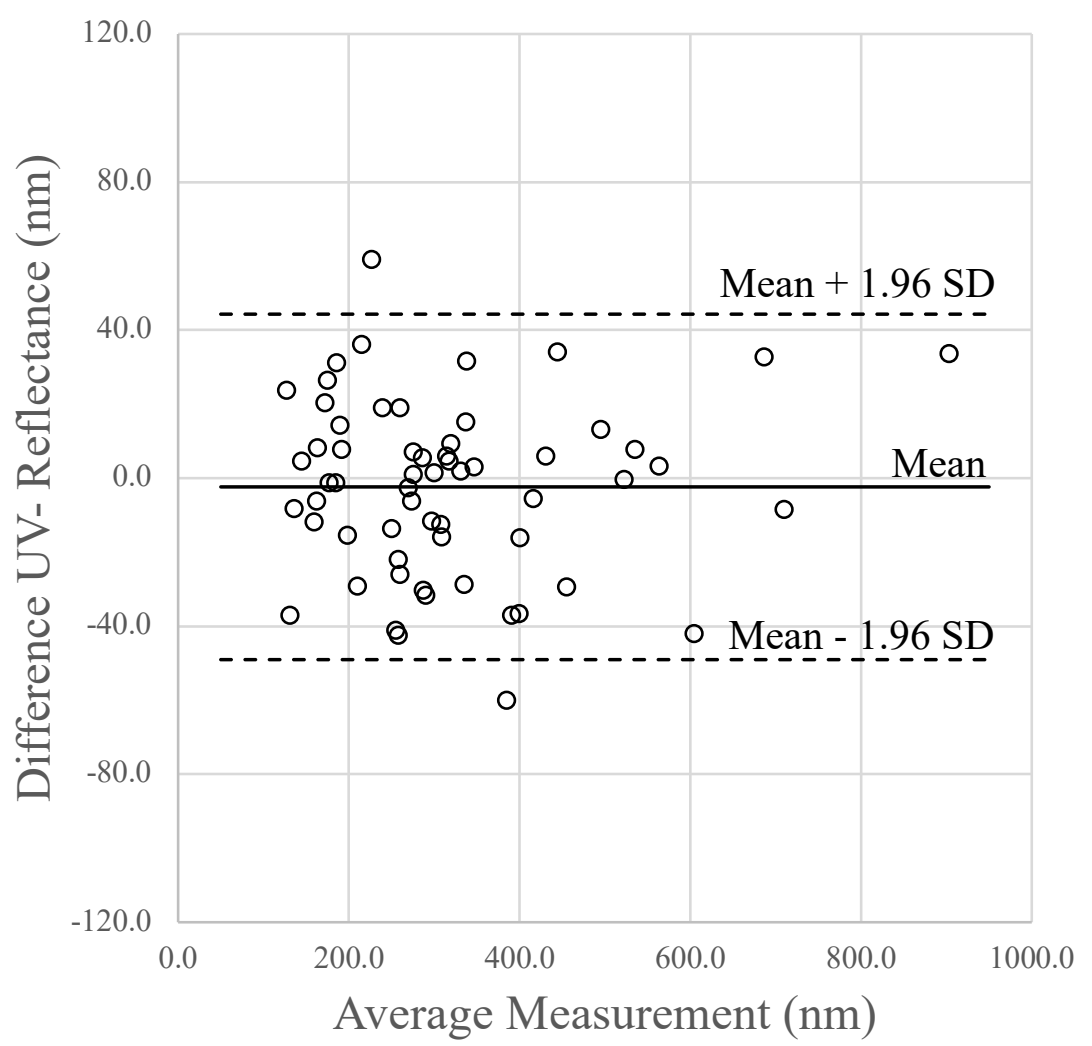

Figure 1-8. Difference scatter plot describing UV-Vis and reflectance measurement reproducibility.

The difference scatterplot is used as a supplemental evaluation of measurement bias from Figure 1-7. The apparent bias for larger reflectance measurements is within the standard error of the mean. Film thickness measurements made by the two techniques are highly similar.

Due to the high molecular weight of the polymer, film thickness is largely dictated by spin-coating parameters related to the transport of the solution over the substrate. The primary and secondary factors with the largest impact on film thickness are initial solution concentration and spin speed ${ }^{31}$ Figure 1-9 is a scatter plot of final film height and combined concentration related variables from Eq. 1-4. At a given spin speed, final film thickness is demonstrated to increase linearly with fluid properties $\chi_{0}\left(\eta_{0} / \rho_{0}\right)^{1 / 3}$. Figure 1-10 plots final film height against spin speed as given in Eq. 1- 
4. At a given initial concentration, final film thickness is demonstrated to increase linearly with the inverse square root of spin speed. Comparison of slopes in figures 1-9 and 1-10 suggest that changes in solution concentration have a greater impact on film thickness than changes in angular velocity.

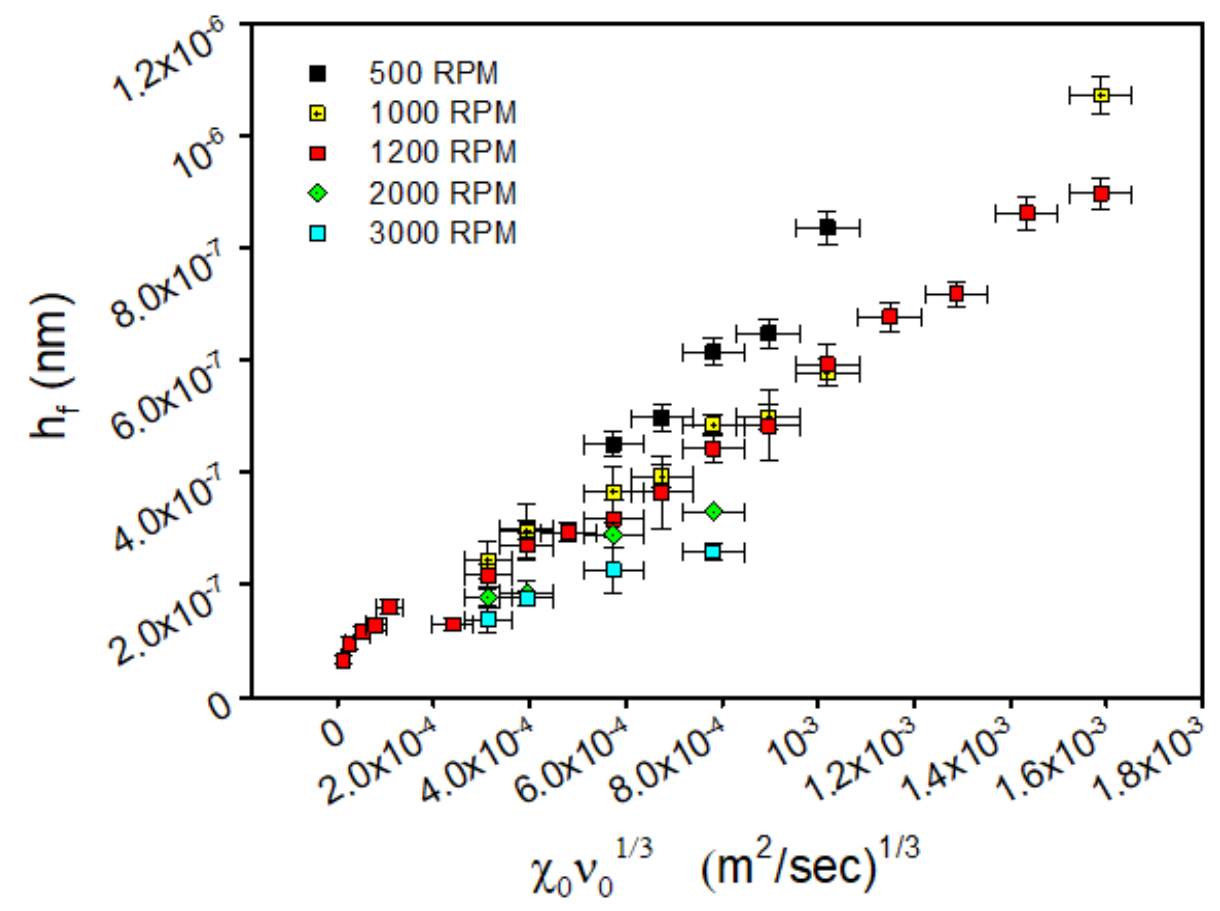

Figure 1-9. Scatter plot for initial solution properties contribution to film thickness. Scatter plot of final film height by physical fluid properties scaled by Eq. 1-4. $v_{0}$ is the kinematic viscosity. 


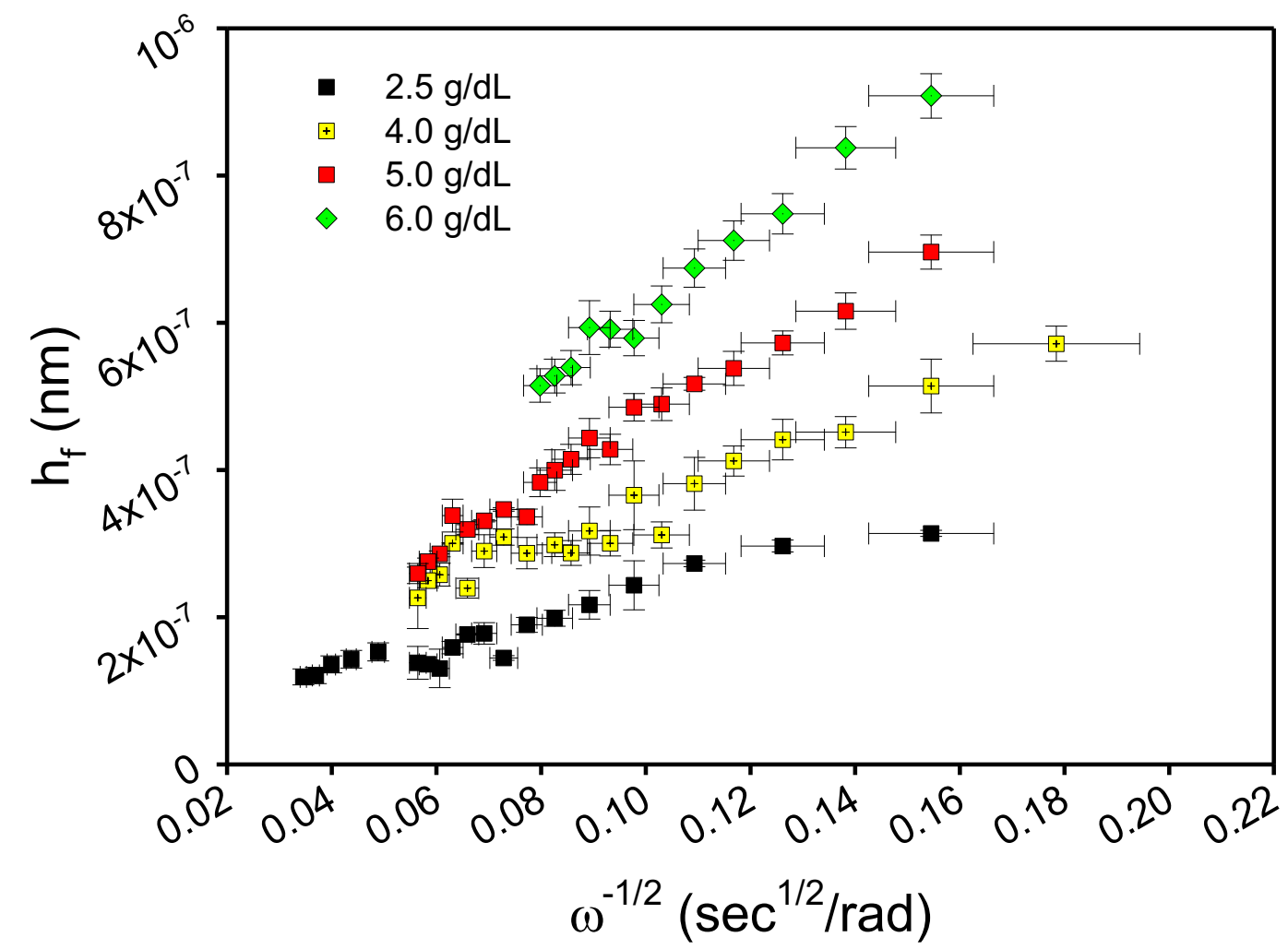

Figure 1-10. Scatter plot of spin speed contribution to film thickness. Scatter plot of final film height by spin speed scaled by Eq. 1-4.

Figure 1-11 combines the two previous plots for system calibration of evaporation rate. Evaporation rate was calculated from the slope of $(3 \mathbb{e} / 2)^{1 / 3}$ and was found to be $\sqrt{\omega} \times 140 \mathrm{~nm} / \mathrm{s}^{1 / 2}$, which is less than $\sqrt{\omega} \times 180 \mathrm{~nm} / \mathrm{s}^{1 / 2}$ reported in similar studies. ${ }^{3,24}$ Possible reasons for this difference may be related several potential factors including environmental temperature, vapor phase composition, and spin speed calibration. Because evaporation rate is a calibrated system specific parameter, minor disagreement with literature values is not significant. 


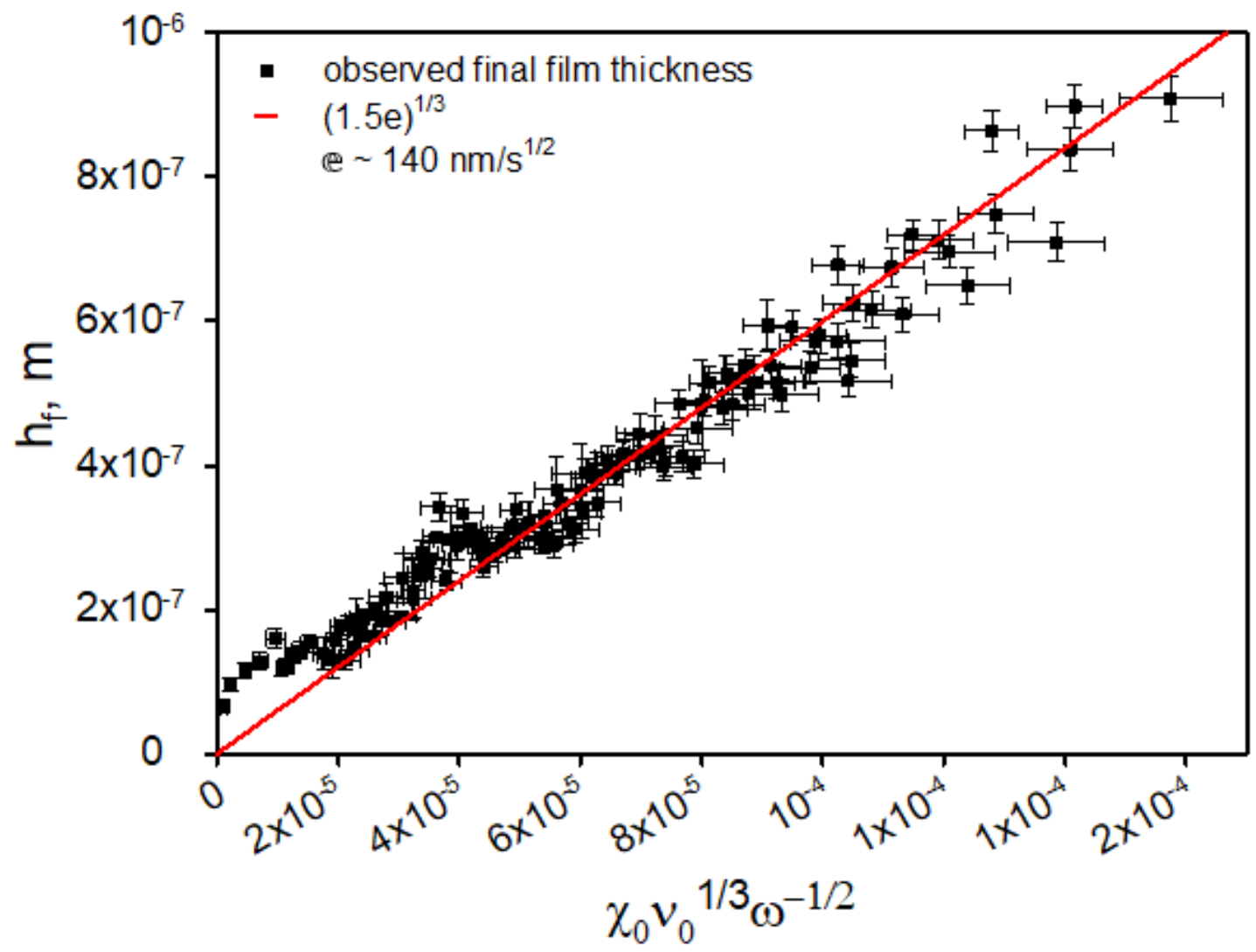

Figure 1-11. Scatterplot for system calibration of evaporation rate contribution to film thickness.

Scatterplot for calibration of system specific evaporation rate parameter for Eq. 1-4; $e \sqrt{\omega}$ describes the rate of vertical solute change.

Figure 1-12 is a scatterplot examining differences between measured and predicted film thicknesses. It is shown that the fit underestimates thinner films and overestimates thicker films. One possibility for deviations could be that viscosity predictions by Eq. 1-7 apply to a limited range. The underlying viscosity equations assume ideal solutions, but polydispersity contributions and viscoelastic behavior changes may need to be accounted for. Meyerhofer's model assumes that film thickness is impacted by solution viscosity for only a fraction of second, which is the duration of the initial hydrodynamic thinning stage. While rheological properties during the late 
evaporative thinning stage may affect film uniformity, it is unlikely to impact average film thickness. However, it is assumed that Newtonian fluid behavior remains at the high spin-coating shear rates and the measured values reflect viscosity behavior at the high shear rates of spin-coating. If non-Newtonian fluid behavior is exhibited during spin-coating, then Eq. 1-7 may describe solution viscosity during the hydrodynamic thinning stage. Perhaps a no slip lubrication approximation has led to an overestimation of radial outflow by not accounting for inertial forces and the initial acceleration.

Figure 1-13 shows a contour plot of film thicknesses predictive model with solution concentration and spin speed as variables. The predictive model is reasonable for thickness estimations. $100 \mathrm{~nm}$ thickness increments are selected to incorporate consideration of the $\pm 44 \mathrm{~nm}$ range for $95 \%$ limit of agreement between measurement techniques. This plot is a design space for selection of polymer solution and spin speed combinations that are likely to generate films of a specified thickness. While each contour represents films of similar mean thickness, it does not imply that the films are identical. It is possible that films within a contour differ in surface quality. 


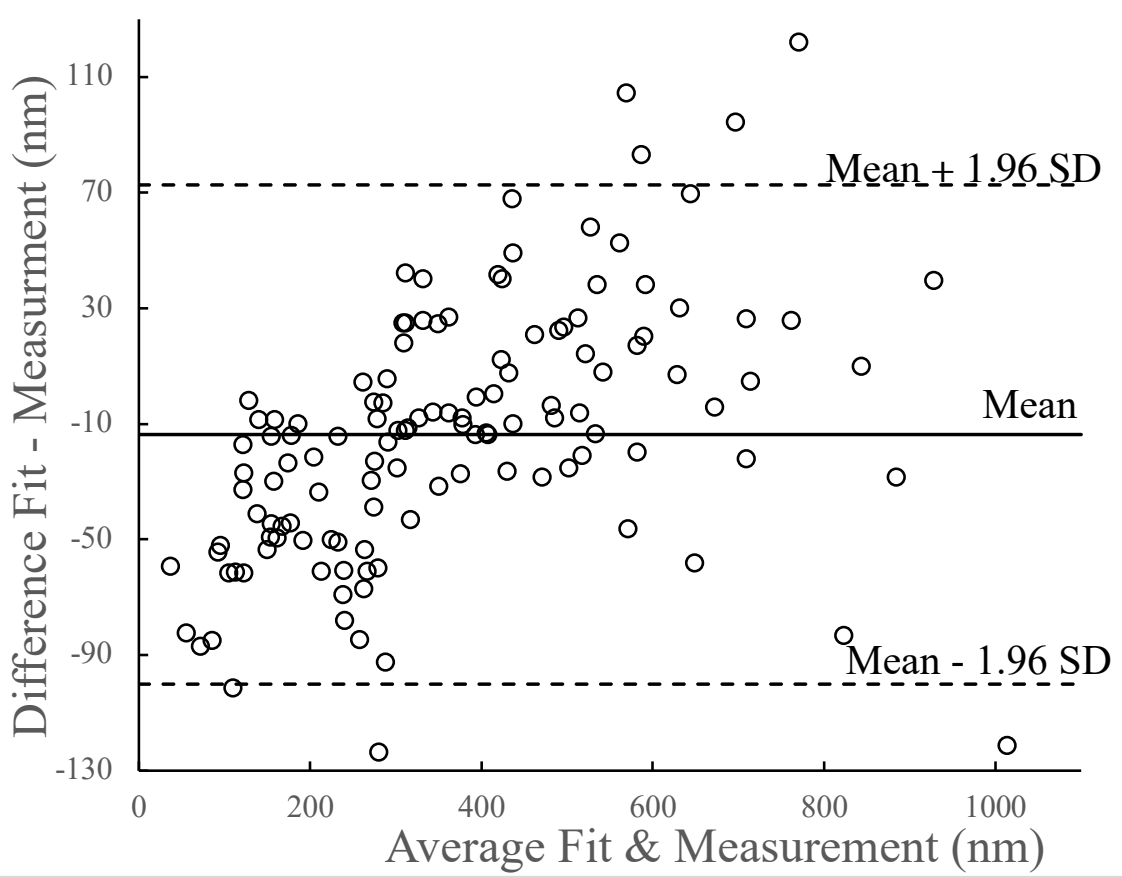

Figure 1-12. Difference scatter plot describing bias between measured and calculated heights.

The difference scatterplot is used to evaluate bias. Predictive thickness model overestimates thickness films and underestimation of thinner films. Bias may be related to inertial effects at the start of the spin-coating process. 


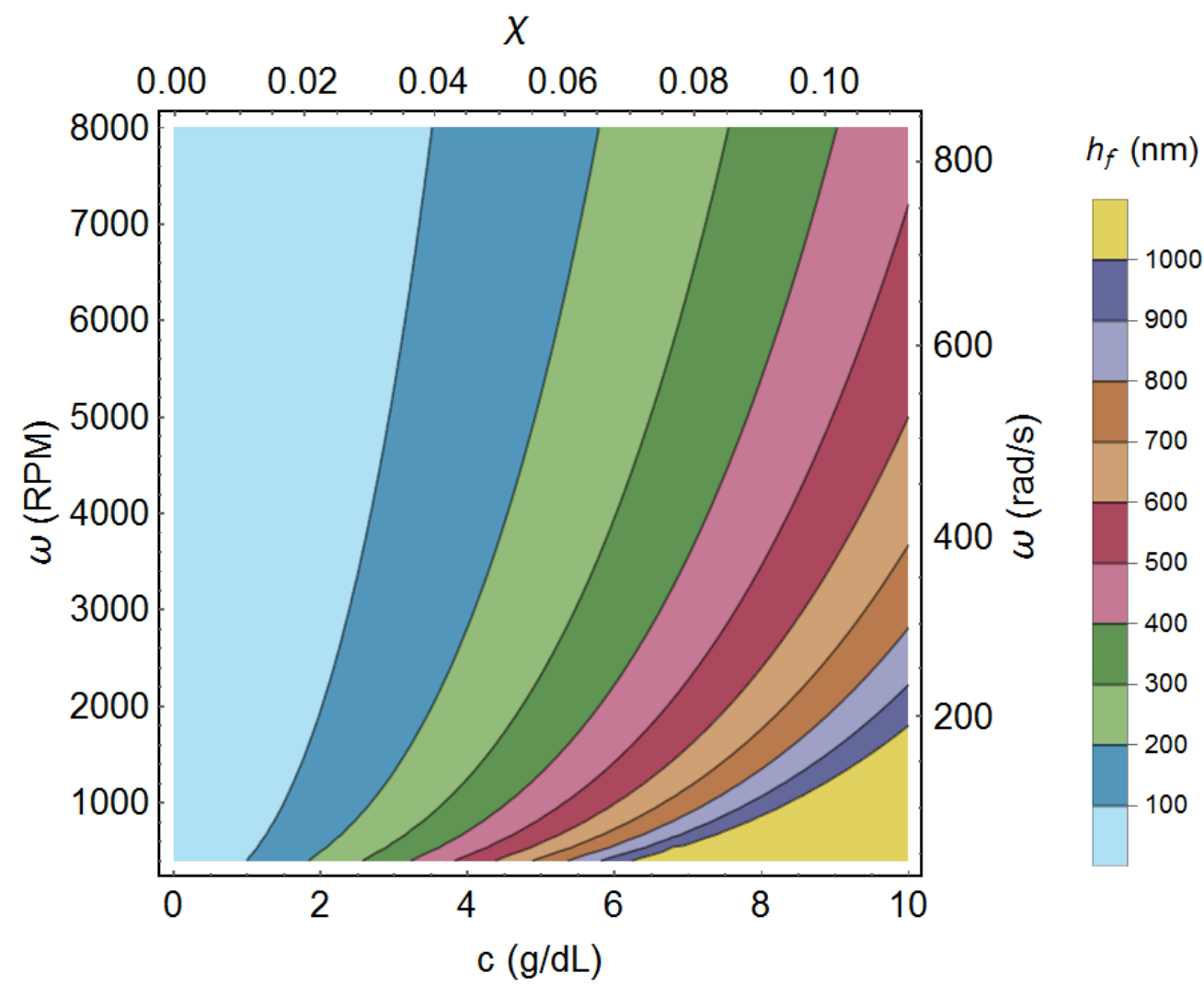

Figure 1-13. Contour plot of thickness by spin speed and solution concentration.

Design space for selection of polymer solution and spin speed combinations that are likely to generate films of a specified thickness. Films grouped within a contour are expected to differ in surface quality. 


\section{CONCLUSION}

A predictive model for thickness of sub-micron PMMA thin films by spincoating from toluene has been calibrated. The bulk chemical properties of the polymer

were demonstrated to be unaffected by the solvation and coating processes. Static solvent evaporation, at zero shear film thinning, was demonstrated to deviate from evaporation of pure solvent beginning at $\sim 0.2 \chi$. Solvent evaporation in the polymer solution was observed to be strongly suppressed from $\sim 0.8 \chi$ and onward. Surface tension effects may help shape evaporation rate. Different visible light spectrometers were used to measure final film thicknesses and a 95\% limit of agreement was determined within $\pm 44 \mathrm{~nm}$. No measurement bias was observed relative to film thickness. Thickness measurement differences between spectroscopic techniques may be related to surface non-uniformity. Coating solution fluid properties were modeled to polymer concentration. Because coating solution properties significantly impact film thickness only during hydrodynamic thinning, relationships between solution properties were limited to concentrations up to $10 \mathrm{~g} / \mathrm{dL}$. Process mapping was used to generate a three-dimensional design space for control of film thickness. 


\section{ACKNOWLEDGEMENT}

This material is based upon work supported by Rhodes Pharmaceuticals L.P. and by the U.S. Department of Homeland Security's Science and Technology

Directorate. The views and conclusions contained in this document are those of the authors and should not be interpreted as necessarily representing the official views and policies, either expressed or implied, of Rhodes Pharmaceuticals L.P. or any of its affiliates, or the U.S. Department of Homeland Security. 


\section{CONFLICT OF INTERESTS}

All authors declare no conflicts of interest in this paper. 


\section{REFERENCES}

${ }^{1}$ A. Lalova, R. Todorov, and A.J. Malinowski, Optical Properties of Thin PMMA Films for Sensor Application (2015).

2 V.M. Martínez, F.L. Arbeloa, J.B. Prieto, and I.L. Arbeloa, J. Phys. Chem. B 109, 7443 (2005).

${ }^{3}$ J. Danglad-Flores, S. Eickelmann, and H. Riegler, Chem. Eng. Sci. 179, 257 (2018).

${ }^{4}$ Y. Mouhamad, P. Mokarian-Tabari, N. Clarke, R.A.L. Jones, and M. Geoghegan, J. Appl. Phys. 116, (2014).

${ }^{5}$ S. Bistac and J. Schultz, Int. J. Adhes. Adhes. 17, 197 (1997).

${ }^{6}$ D.B. Hall, P. Underhill, and J.M. Torkelson, Polym. Eng. Sci. 38, 2039 (1998).

${ }^{7}$ N. Patra, A.C. Barone, and M. Salerno, Adv. Polym. Technol. 30, 12 (2011).

${ }^{8}$ J.W. Van Dyk, H.L. Frisch, and D.T. Wu, Ind. Eng. Chem. Prod. Res. Dev. 24, 473 (1985).

${ }_{9}$ S.R. Vashishtha, N. Chand, and S.A.R. Hashmi, Indian J. Chem. Technol. 9, 316 (2002).

${ }^{10}$ A.G. Emslie, F.T. Bonner, and L.G. Peck, J. Appl. Phys. 29, 858 (1958).

${ }^{11}$ D. Meyerhofer, Cit. J. Appl. Phys. 49, 3993 (1978).

${ }^{12}$ D.E. Haas, J.N. Quijada, S.J. Picone, and D.P. Birnie III, in Sol-Gel Opt. V, edited by B.S. Dunn, E.J.A. Pope, H.K. Schmidt, and M. Yamane (SPIE, Bellingham, 2000), pp. 280-284.

${ }^{13}$ S.G. Weissberg, R. Simha, and S. Rothman, J. Res. Natl. Bur. Stand. (1934). 47, 298 (1951).

${ }^{14}$ S. Matsuoka and M.K. Cowman, Polymer (Guildf). (2002).

${ }^{15}$ A. Penzkofer, E. Drotleff, and W. Holzer, Opt. Commun. 158, 221 (1998).

${ }^{16}$ E. Patrone and U. Bianchi, Die Makromol. Chemie 94, 52 (1966).

17 J. Brandrup, E.H. Immergut, E.A. Grulke, A. Abe, D.R. Bloch, J. Wlley, N.Y. Chichester, W. Brisbane, and S. Toronto, Polymer Handbook, 4th ed. (WileyInterscience, 1999). 
${ }^{18}$ E. Cohn-Ginsberg, T. Fox, and H. Mason, Polymer (Guildf). 3, 97 (1962).

${ }^{19}$ W.R. Moore and R.J. Fort, J. Polym. Sci. Part A Gen. Pap. 1, 929 (1963).

${ }^{20}$ H. Matsuda, K. Yamano, and H. Inagaki, J. Polym. Sci. Part A-2 Polym. Phys. 7, 609 (1969).

${ }^{21}$ H. Yamamoto, (2009).

22 C. Hansen and K. Hansen, in Perform. Prot. Cloth. Second Symp. (ASTM International, 100 Barr Harbor Drive, PO Box C700, West Conshohocken, PA 194282959, 1988), pp. 197-197-12.

${ }^{23}$ C.M. Hansen, Hansen Solubility Parameters : A User's Handbook, 2nd ed. (CRC Press, 2007).

${ }^{24}$ P. Mokarian-Tabari, M. Geoghegan, J.R. Howse, S.Y. Heriot, R.L. Thompson, and R.A.L. Jones, Eur. Phys. J. E 33, 283 (2010).

${ }^{25}$ P. Gałka, J. Kowalonek, and H. Kaczmarek, J. Therm. Anal. Calorim. 115, 1387 (2014).

${ }^{26}$ M. Ferriol, A. Gentilhomme, M. Cochez, N. Oget, and J.L. Mieloszynski, Polym. Degrad. Stab. 79, 271 (2003).

${ }^{27}$ T. Kashiwagi, A. Inaba, J.E. Brown, K. Hatada, T. Kitayama, and E. Masuda, Macromolecules 19, 2160 (1986).

${ }^{28}$ J. Peng, F. Yang, D. Chiang, and S. Lee, Langmuir 32, 4602 (2016).

${ }^{29}$ H.Q. Zhang and W.B. Euler, Sensors Actuators B. Chem. 225, 553 (2016).

${ }^{30}$ J.M. Bland and D.G. Altman, Ultrasound Obstet. Gynecol. 22, 85 (2003).

${ }^{31}$ M. Chapman, M. Mullen, E. Novoa-Ortega, M. Alhasani, J.F. Elman, and W.B. Euler, J. Phys. Chem. C 120, 8289 (2016). 


\title{
MANUSCRIPT - II \\ Prepared for submission to Langmuir
}

\section{Evolution of secondary convective instabilities during spin-coating reduces interfacial roughness in thin films}

\begin{abstract}
Navid Chapman, Mingyu Chapman, and William B. Euler
Chemistry, University of Rhode Island, Kingston, RI, USA
\end{abstract}

Corresponding Author: William B. Euler, Ph.D.

Chemistry

University of Rhode Island

140 Flagg Road

Kingston, RI, 02881, USA

Email address: wueler@chm.uri.edu 


\begin{abstract}
The morphology of sub-micron polymethyl methacrylate (PMMA) films coated to glass supports by spin coating from toluene are examined using surface profilometry. Wrinkled surfaces with local quasi-sinusoidal periodicity were seen on the surfaces of films with thicknesses larger than $75 \mathrm{~nm}$. The surface wrinkles had large aspect ratios with wavelengths in the tens of microns and amplitudes in the tens of nanometers. Wrinkles formed during spin-coating are attributed to surface perturbations caused by Rayleigh-Bénard-Marangoni convective instabilities. The effects of film thickness, coating solution concentration, and drying rate on the thin film surface morphology are investigated.
\end{abstract}




\section{INTRODUCTION}

Fluorescence signal enhancement can be achieved with a three-layered sensor design comprised of spin-coating a vertical thin film stack on a substrate, first with a sub-micron-layer of polymer, and topped with a fluorophore monolayer. We have shown that a thin film layer of optical polymer can appreciably enhance fluorescence emission and its sensing applications with explosive vapors. ${ }^{1-3}$ To take advantage of this attribute, fundamental research on the thin film formation dynamics should be carried out first.

Spin-coating is a favored technique for forming uniform films with flat surfaces, which offer several performance advantages regarding electronic properties and device stability ${ }^{4,5}$ In the spin-coating technique, the coating material is dissolved in a volatile solvent, the substrate is fixed to a rotor, a droplet of coating solution is deposited on the unheated substrate. The rotor is set into motion, the fluid spreads until resisted by viscous drag, then evaporation drives fluid thinning in the final coating stages. Lasting only a few seconds, spin-coating is an unsteady dynamic process in which evaporation can drive fluid instabilities to roughen a fluid surface. Wrinkled surfaces found on spincast PMMA thin films are vitrified interfacial flow cells driven by gravity and surface tension phenomena. Individual convective cells self-arrange into a semi-organized pattern that resembles a sunflower, with convection rolls radiating from a central cluster of flow cells that share some resemblance to the hexagonal flow cells that Henri Bénard observed with whale oil. ${ }^{6}$ Self-assembled patterned surfaces are taken advantage of in 
many thin film applications, such as microfluidics, stretchable and foldable electronics, and advanced sensing arrays of medical diagnostic equipment. ${ }^{7}$

The research aim is to reduce thin film interfacial roughness with the change of simple spin-coating parameters. In the preceding work, an accepted equation of state for determining thickness of spin-cast films was calibrated for sub-micron polymethyl methacrylate (PMMA) thin films from toluene solutions. Spin-coating parameters of coating solution concentration and spin speed were mapped to the thickness of submicron films. A theoretical assessment of surface roughening provides background for the concepts presented in this paper.

Evaporative cooling at the surface of the spin-coating droplet leads to the development of a temperature-concentration gradient. When solvent evaporation is greater than condensation, non-equilibrium conditions drive interfacial fluid motion. Convective flow can substantially enhance heat and mass transfer during film drying. Surface wrinkling instabilities evolve when tension experienced at the interface exceeds the resistance to deformation. Because the polymer has a higher glass transition in solution, polymer enrichment during film drying brings about a rapid glass transition and mobility is suppressed. The polymer packing arrangement becomes fixed and relaxation to thermodynamic equilibrium conformations is restricted. ${ }^{8}$

A basic description of convective flows lays the framework for the theoretical experiment. In natural convection, also known as Rayleigh convection, gravitational effects are influential and buoyancy forces dominate. Buoyancy force is associated with the dimensionless Rayleigh number $(R a)$ : 


$$
R a=\frac{\alpha g h^{3} \Delta T}{\kappa v}
$$

where $\alpha$ is the expansion coefficient, $g$ is gravity, $h$ is the vertical thickness of the fluid layer, $\Delta T$ is the temperature gradient between the substrate and surface, $\kappa$ is thermal diffusivity, and $v$ is kinematic viscosity.

In stratified fluids, equilibrium conditions require for heavier fluids to exist below lighter fluids. Because density typically varies inversely with temperature, evaporative cooling brings about a vertical temperature-concentration gradient in which a heavier fluid lies above a lighter fluid as shown in Figure 2-1. Gravity can induce heat and mass transport, which will continue until a critical point where stability between thermal diffusion and buoyancy convection exists. The downflow of cooler condensed particles drives the warmer, less dense particles upwards and starts circular fluid convection. ${ }^{9,10}$

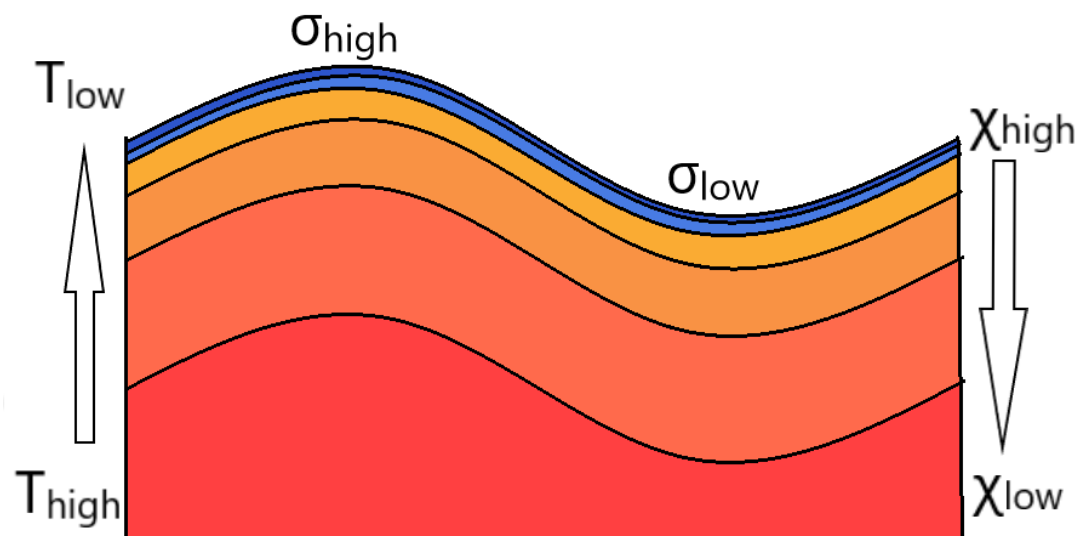

Figure 2-1. Schematic of temperature-concentration gradient on volatile fluid droplets. $\mathrm{T}$ is temperature, $\sigma$ is surface tension, and $\chi$ is polymer mass fraction. Solvent evaporation causes localized cooling at the surface of the spin-coating polymer fluid. Convective instabilities can roughen the surface to decrease surface energy. 
In thermocapillary convection, also known as Marangoni convection, surface tension phenomena are influential. The dimensionless Marangoni number (Ma) describes the rate of thermal transport by diffusion in relation to surface tension driven convection:

$$
M a=-\frac{\partial \sigma}{\partial T} \frac{h \Delta T}{\kappa \eta}
$$

where $\frac{\partial \sigma}{\partial T}$ is the rate of change of surface tension with respect to temperature and $\eta$ is dynamic viscosity.

Like density, surface tension is partly a function of concentration and temperature. Evaporative cooling creates a localized temperature-concentration gradient at the free interface. When the surface tension of the solvent is less than the solute, solvent evaporation will lead to an increase in interfacial free energy. Surface tension driven convective instabilities are known as the 'Marangoni Effect'. In thermocapillary convection, surface tension responds to changes in heat and density. Heat and mass from the relatively warmer droplet edges are transferred along the surface towards to center where subduction occurs inwardly and solvation of the enriched polymer can further reduce free energy. ${ }^{11-13}$

In each of these cases, surface perturbations directly respond to the moderatelyunstable physical state of the interface and correspond to spatial wavelengths of the locally structured surface wrinkles. Spatial wavelengths that describe local surface periodicity tend to a critical value that corresponds to the critical nondimensional number for the observed instability. $R a$ describes the rate of thermal transport by diffusion with respect to buoyancy driven convection. $R a$ is critical when thermal 
transport is equal. Above critical $R a$, the surface is destabilized by buoyancy and convective cells form at the surface. At critical $M a$, an instability causes the surface to roughen and the free energy to decrease. The sign for $\frac{\partial \sigma}{\partial T}$ is based on whether the surface is stabilized or destabilized by evaporation. ${ }^{14-16}$

The prevalence of surface tension effects over buoyancy effects is a unique feature of sub-micron systems. Buoyancy is a body force and by connection through density, it scales by volume. Surface energy scales with the vertical height of the fluid, by the power of one. In a typical fluid environment, surface tension plays a passive role in the transport process. When the fluid height is considerably small, scaling laws are negligible, and interactions at the free surface can become the dominant factor. Because the surface tension of the toluene $(28.52 \mathrm{mN} / \mathrm{m})$ is lower than PMMA $(41 \mathrm{mN} / \mathrm{m})^{17}, \frac{\partial \sigma}{\partial T}$ is positive and evaporation causes the free energy of the surface to increase. $M a$ decreases with evaporation rate and fluid thickness. Because evaporation rate is scaled by the square of spin speed, $M a$ is at a maximum value when the fluid is stationary.

A reduction in PMMA surface wrinkling may be possible by targeting fluid states below instability thresholds and at non-equilibrium transitions between dominant convection modes. For either instability to roughen the surface, thermal transport by convection must be greater than by diffusion alone. Defect free films should be producible at low film heights, which are below threshold conditions for an instability to form. A secondary interfacial instability may evolve at the transition between surface tension and buoyancy driven instabilities. If a moderately-unstable free energy state is formed at the transition between surface tension dominated and buoyancy dominated 
instabilities, two instabilities may converge and produce a secondary instability of lower free energy..$^{18}$
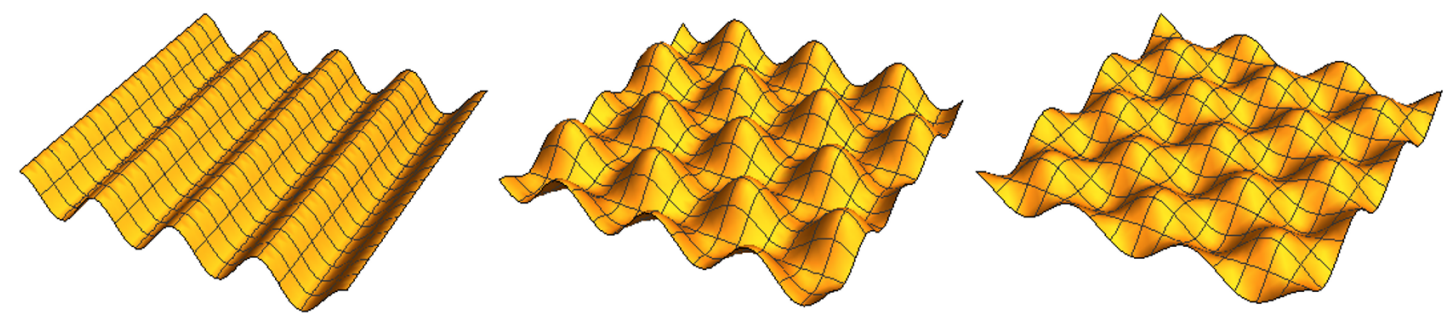

Figure 2-2. Surface plots of commonly observed arrangements of convective flow cells. (Left) Rolls, (Center) hexagonal cells, (Right) square cells.

The geometry of surface wrinkling appears similar to oscillating wave vectors. Figure 2-2 shows algebraic surface plots for three commonly observed arrangements of flow cells. Interfacial rolls are associated with buoyancy driven convection and approximate a sinusoidal profile that can be described by Eq. 2-3.

$$
h(x)=h_{0}+a_{0} \sin \left(\frac{2 \pi x}{\lambda_{0}}\right)
$$

where $h_{0}$ is the mean thickness throughout the extracted region, $a_{0}$ is the wrinkle amplitude, and $\lambda_{0}$ is the wrinkle wavelength.

Hexagonal cells have been considered the most stable morphology of primary instabilities and tend to a triangular super-positioning of three wave vectors that can be described by Eq. 2-4:

$$
h(x)=h_{0}+a_{0}\left[2 \cos \left(\frac{\sqrt{3}}{2} \frac{x}{\lambda_{0}}\right) \cos \left(\frac{1}{2} \frac{y}{\lambda_{0}}\right)+\cos \left(\frac{x}{\lambda_{0}}\right)\right]
$$

Ascending motion towards the center is called (1-) for liquids and descending motion is called (g-) for gas. Buoyancy driven flows manifest as outwardly flowing (1-) 
cells. A different direction of motion is observed with surface tension driven flows. Surface energy can be reduced by downward mass flow and physically expresses as inwardly flowing (g-) cells. Secondary instabilities at non-equilibrium transitions can assemble as the super-positioning of convection rolls vectors that can be described by Eq. 2-5:13,15,19-22

$$
h(x)=h_{0}+a_{0}\left[2 \cos \left(\frac{1}{\sqrt{2}} \frac{x}{\lambda_{0}}\right) \cos \left(\frac{1}{\sqrt{2}} \frac{y}{\lambda_{0}}\right)\right]
$$

In this paper, we compare our theoretical results with what we observe experimentally using phase shifted interferometry. First, a qualitative assessment of PMMA film surface morphology at the spinning center is made. Then, interfacial roughness is characterized by dimension and shape, the parameters for spin-coating flatter films are realized, and relationships between instability flows and roughness morphology are inferred. 


\section{EXPERIMENTAL}

Glass microscope slides $(\sim 1 \mathrm{~mm}$ thick) were cut into 37.5 x $25 \mathrm{~mm}$ sections. Slides were cleaned and treated by submersion in ethanol (EtOH, 95\%, PharmacoAaper), followed by 15 minutes of sonication, then rinsed with purified water, submerged in purified water, sonicated for an added 15 minutes, and dried under $\mathrm{N}_{2}$.

PMMA glassy polymer of 120,000 Mw was obtained from Sigma-Aldrich and used without further purification. A $20 \mathrm{~g} / \mathrm{dL}$ stock solution was prepared in toluene (Honeywell, HPLC grade). Polymer stock solution was sonicated for 8 hours with intermittent shaking to ensure full solvation. Resulting solution was optically clear. Dilutions ranging from 0.75 to $8.00 \mathrm{~g} / \mathrm{dL}$ were prepared directly from the stock.

Sub-micron PMMA films were applied to the glass slides in dry conditions $(<20 \%$ Relative Humidity) by depositing a $250-\mu \mathrm{L}$ aliquot of polymer solution to the center of a slide and then spin-coating for 45 seconds at an acceleration of $1080 \mathrm{~s}^{-2}$ until reaching a maximum rotation speed between 400 and 8000 RPM. Spin-coating was carried out under a constant flow of compressed air. Films were air dried for 15 minutes and then transferred to an oven set at $60^{\circ} \mathrm{C}$ for 2 minutes to facilitate residual solvent removal.

Reflection spectra of polymer films was acquired with a Filmetrics F40 microscope thin film analyzer. Reflectance in the range of 400 - $900 \mathrm{~nm}$ was generated by a tungsten-halogen light source. PMMA thin film optical constants for the refractive index and attenuation coefficient were obtained from literature. ${ }^{23}$ Spectral fitting and film thickness calculations were performed with Filmeasure software. Transmittance spectra of polymer films were collected with a Perkin Elmer Lambda 1050 UV/Vis 
spectrometer. The slit width and integration time were set at $2 \mathrm{~nm}$ and 0.20 seconds respectively. Wavelengths generated from tungsten-halogen and deuterium lamps were collected in the 1100 to $300 \mathrm{~nm}$ range. Three-dimensional surface profiles of dried polymer films were collected with a Filmetrics Profilm3D optical interferometer and then digitally extracted by instrument software. 


\section{RESULTS AND DISCUSSION}

A qualitative assessment of PMMA surface wrinkling was made by examining dry films near the spinning center. Figure 2-3 shows two different magnifications of micrographs for four PMMA films that were spin-cast from different solution concentrations and spin speeds. The lower magnification micrographs provide a view of global surface structure where disordered polygons with local periodicity are clustered around the spinning centers. As distance from the rotor position is increased, the shape of the surface wrinkling transitions from polygons to radiating rolls. The spatial dimensions of polygons and rolls average in the tens of microns for wavelengths and tens of nanometers for amplitudes. The higher magnification micrographs highlight local regions where unit-cells resemble characteristic geometries of common flow cell arrangements. 

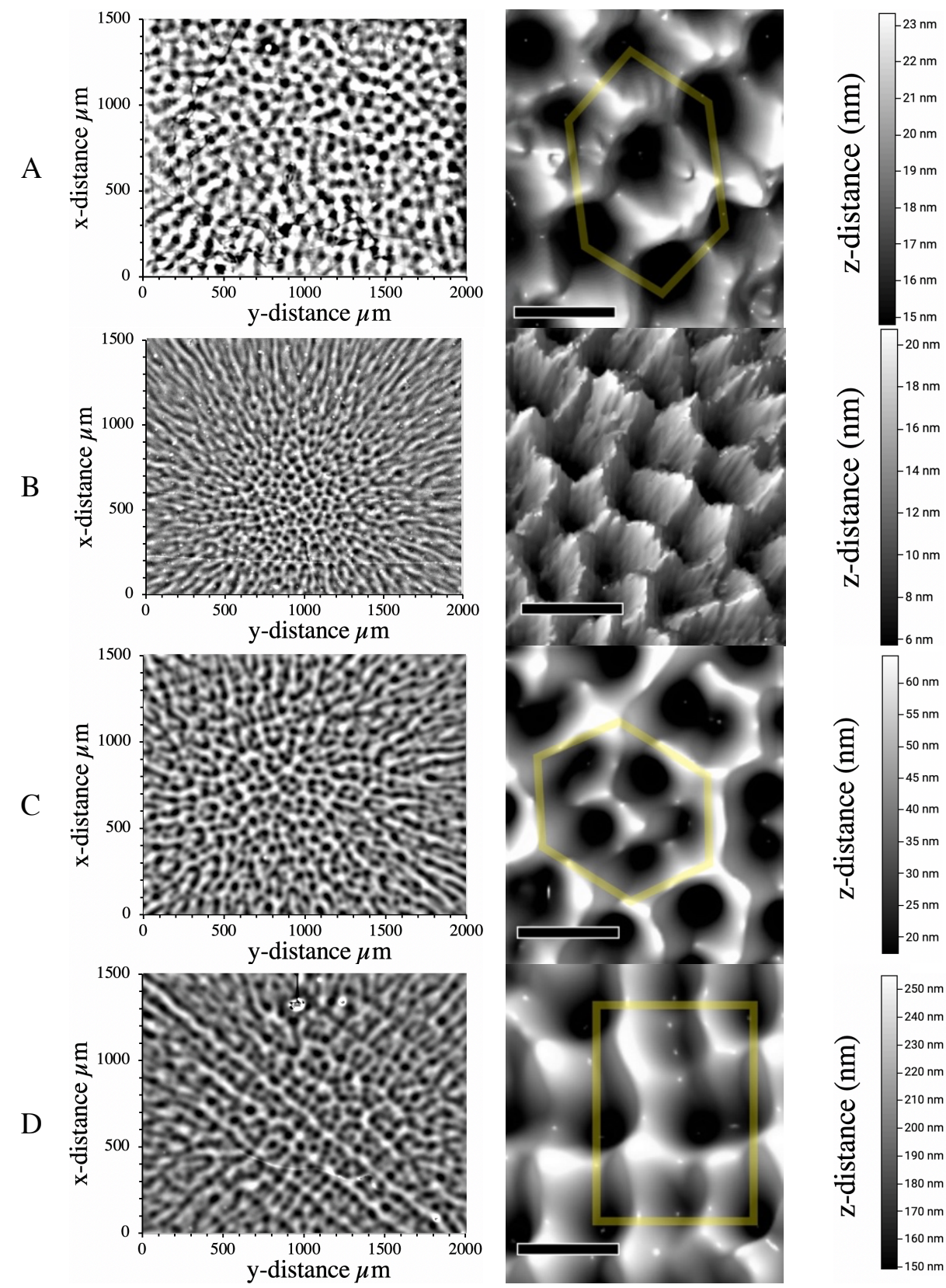

Figure 2-3. Optical micrographs showing surface morphology at the spinning center of PMMA films prepared from various concentrations and spin speeds.

(A) Surface profile of 290-nm thick PMMA film cast from a $2.5 \mathrm{~g} / \mathrm{dL}$ solution at 400 RPM. (B) Surface profile of 105-nm thick PMMA film cast from a $2.5 \mathrm{~g} / \mathrm{dL}$ solution at 3000 RPM. (C) Surface profile of 305-nm thick PMMA film cast from a $4.0 \mathrm{~g} / \mathrm{dL}$ solution at 1200 RPM. (D) Surface profile of 550-nm thick PMMA film cast from a 6.0 $\mathrm{g} / \mathrm{dL}$ solution at $1200 \mathrm{RPM}$. Micrographs on the left show a lower magnification than the micrographs in the middle. The scalebar for the micrographs in the middle is 100 $\mathrm{nm}$. The gray-scale $\mathrm{z}$-scale on the right applies to both micrograph magnifications. 
Figure 2-3 (A) shows a film generated from parameters $2.5 \mathrm{~g} / \mathrm{dL}$ and $400 \mathrm{RPM}$. The lower magnification view shows a disordered arrangement of round depressions. A closer look shows that some local structuring of $\left(\mathrm{g}_{-}\right)$hexagons is present. This type of inward flow is associated with surface tension driven instabilities. ${ }^{12}$ Figure 2-3 (B) shows how the surface changes when drying rate is increased by $\sim 2.7$ times. The lower magnification shows that the transition between rolls and polygons occurs at a closer distance to the spinning center. The higher magnification shows sharper peaks with smaller amplitudes and wavelengths. No local unit cells were seen. The higher disorganization at the increased drying rate is expected as increased air flow is known to promote surface defects. ${ }^{24}$ Figure 2-3 (C) shows a film generated from parameters 4.0 g/dL and 1200 RPM. Disorganized clusters of hexagonal (g-) flow cells that subdivide into five cells of shallower roughness can be seen at both magnifications.

Figure 2-3 (D) shows that when spin speed is held constant and polymer concentration is increased by $2 \mathrm{~g} / \mathrm{dL}$, the polygon clusters change from hexagons to squares. Square flow cells were the least common geometry observed at the spinning center. Square cells were mainly found on films cast at 1200 RPM and sometimes appeared together with large (1-) hexagons on PMMA films thicker than $550 \mathrm{~nm}$. Square flow cells appear to have an equal inward and outward flow. They have been associated as a secondary instability of buoyancy and surface tension. Non-equilibrium phase transitions between moderately-unstable modes can be triggered by internal fluid motion..$^{25}$ 

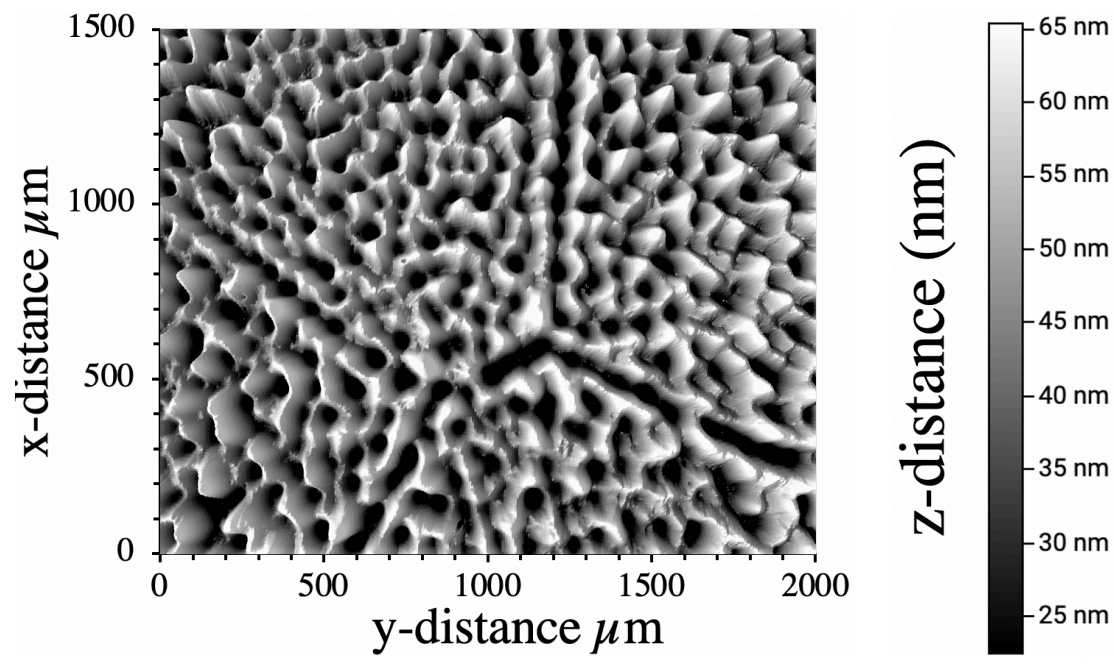

Figure 2-4. Optical micrograph showing surface morphology at the spinning center of PMMA film produced from $8.0 \mathrm{~g} / \mathrm{dL}$ and $1000 \mathrm{RPM}$.

Figure 2-4 shows a centrally positioned digital surface profile with both inwardly and outwardly flowing hexagons. Most of the surface roughness consists of inwardly flowing (g-) disorganized polygons that look similar to surface of the fastdrying film in figure 2-3 (B). A second and much larger hexagon appears superimposed and flowing in the opposite direction. Films cast from concentrated solutions, such as $8.0 \mathrm{~g} / \mathrm{dL}$, have segments of large 1-type hexagonal cells which more closely resemble the whale oil convection cells of Bénard. ${ }^{6}$ Surface wrinkle amplitude was similar for both the (g-) and (1-) hexagons. The super-imposed (g-) and (1-) hexagons may suggest a non-equilibrium 'dual-instability' mode with large buoyancy driven wavelengths and small surface tension dominated wavelengths. This type of dual-instability surface wrinkling was only found on PMMA films thicker than $360 \mathrm{~nm}$.

Next, a quantitative assessment was approached by measuring the dimensions of surface rolls. Surface morphology was characterized with dimensions of wrinkle 
amplitude and wavelength. Three-dimensional surface profiles of dried polymer films were collected by optical profilometry. Roughness scale surface profiles were filtered and characterized by Fast Fourier Transform (FFT).

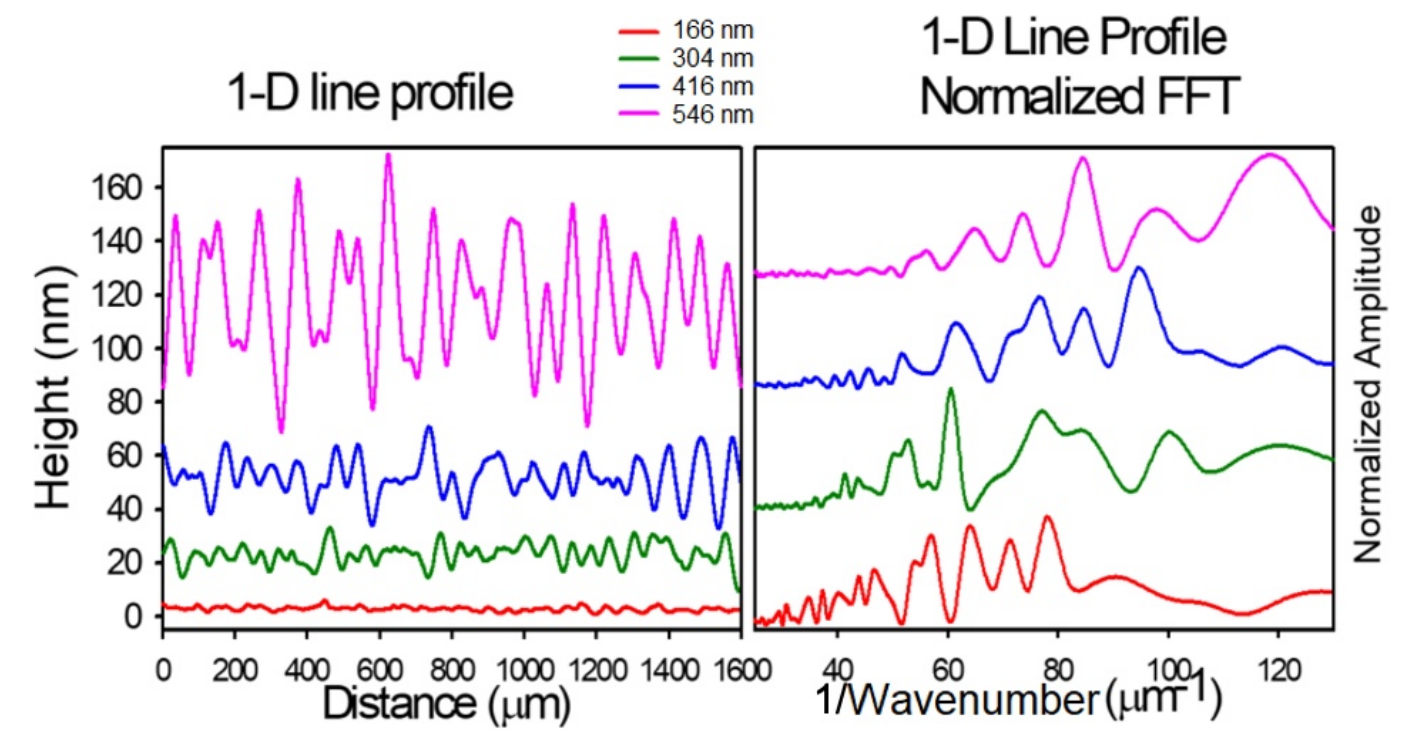

Figure 2-5. One-dimensional line profiles of PMMA surfaces at locations where convection rolls are present.

(A) PMMA surface profiles. (B) Height normalized FFT of (A). Films were cast using 2.5, 4.0, 5.0, and $6.0 \mathrm{~g} / \mathrm{dL}$ solutions spun at $1200 \mathrm{RPM}$.

Figure 2-5 (A) shows one-dimensional line profiles of PMMA thin films generated from different solution concentrations at a constant spin speed. Each of the line profiles were taken in the direction perpendicular to the surface lay at a distance of $\sim 7.50 \mathrm{~mm}$ from the spinning center, which is in the region of convection rolls (wrinkles) for each of the films. Figure 2-5 (B) shows a height normalized FFT magnitude plot of the line profiles in Figure 2-5 (A). Film thickness and the wrinkle amplitude both increase with casting solution concentration. From the FFT plot, the wavelength spacing 
of surface wrinkles is shown to increase with concentration, but to a lesser degree than wrinkle amplitude. Local segments of line profiles were discretely fit to oscillating wave vectors. An approximate fit can be obtained by Eq. 2-3. Examples of the fits are shown in the supplementary information (Figures 2-S1 and 2-S2). Therefore, the wrinkle amplitude and wavelength can be determined by fitting this sinusoidal function to the filtered surface profile.

A series of PMMA films spin-cast at speeds between 400 to 8000 RPM using a range of solution concentrations from $2.5-8.0 \mathrm{~g} / \mathrm{dL}$. First, wrinkle amplitude and wavelength measurements were generated from one-dimensional surface profile sinusoidal fittings. A second set of measurements was made from two-dimensional areal parameters of root-mean-square (RMS) roughness and autocorrelation length (ACL), which were calculated by instrument software. 

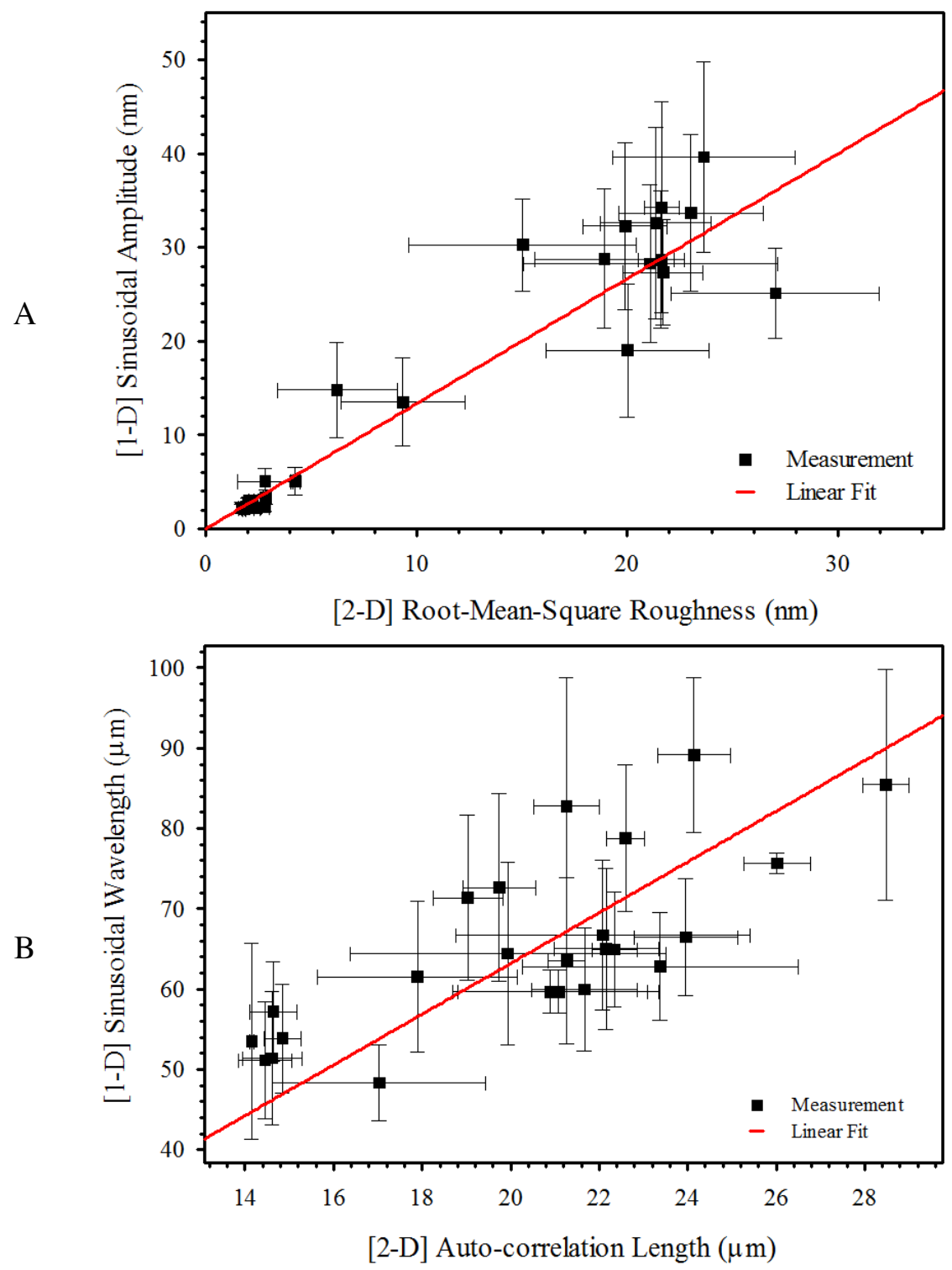

Figure 2-6. Scatterplot comparing PMMA wrinkle measurements by one- and twodimensional analysis methods.

(A) PMMA surface wrinkle amplitude determinations made by one-dimensional sinusoidal fits and two-dimensional RMS roughness. Vertical and horizontal error bars represent a standard deviation of at least ten sinusoidal fits and four RMS roughness measurements. The slope and standard error are $1.34 \pm 0.06$. (B) Wrinkle wavelength determinations made by one-dimensional sinusoidal fits and two-dimensional ACL. Vertical and horizontal error bars represent a standard deviation of at least ten sinusoidal fits and four ACL measurements. The slope and standard error are 3.16 0 0.08. 
Scatterplots in figure 2-6 describe the relationship between one- and twodimensional measurements. The fits show that one- and two-dimensional measurement techniques are closely related by equations 2-6 and 2-7.

$$
\begin{aligned}
& \text { Wrinkle Amplitude } \approx R M S \times \sqrt{2} \\
& \text { Wrinkle Wavelength } \approx A C L \times \pi
\end{aligned}
$$

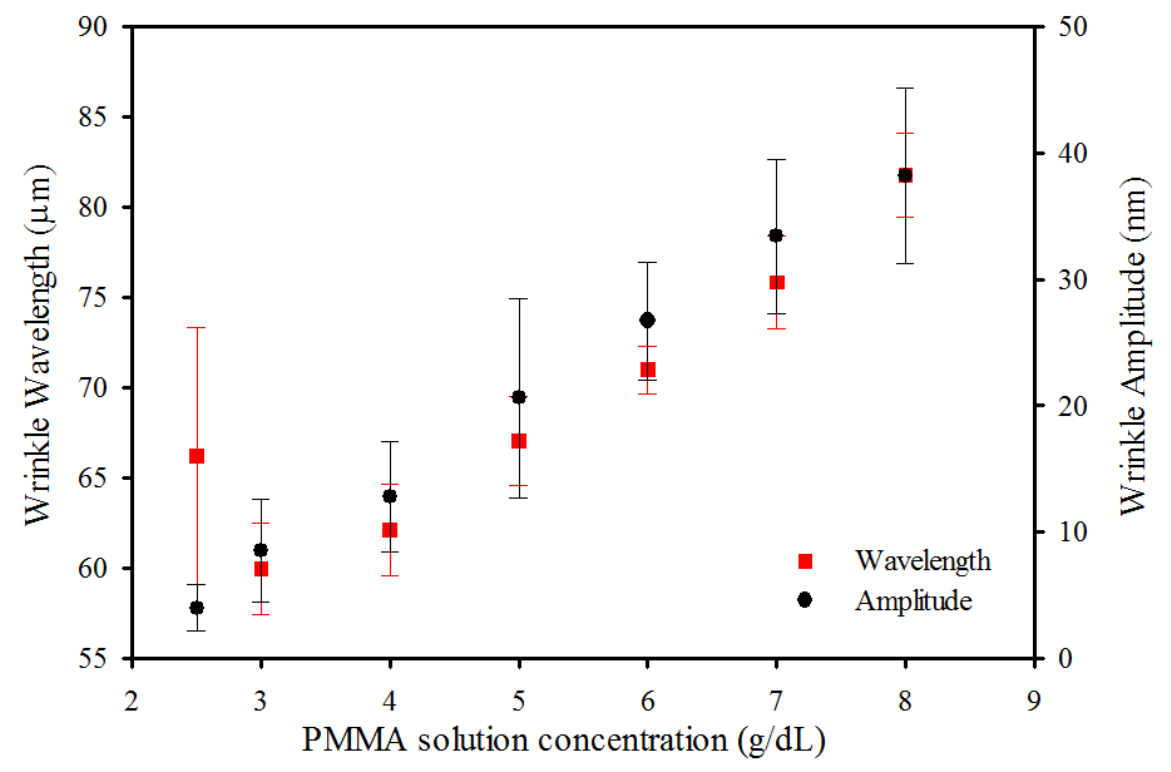

Figure 2-7. Surface wrinkle wavelengths (red squares, left axis) and amplitudes (black circles, right axis) formed on PMMA films cast from different concentrations at a constant spin speed of 1200 RPM.

The error bars represent the standard deviation of four different RMS roughness and ACL determinations generated from micrographs at distances of 3.75, 7.50, 11.25, and $15.00 \mathrm{~mm}$ away from the spinning center.

Figure 2-7 shows a scatterplot of wrinkle wavelengths and amplitudes observed on PMMA thin films cast from different solutions concentrations and constant spin speed. Films prepared from the lowest solution concentration of $2.5 \mathrm{~g} / \mathrm{dL}$ formed the smallest amplitudes of $57 \mathrm{~nm}$ and the widest range of wavelengths averaged near $66 \mu \mathrm{m}$. As concentration is increased to $3.0 \mathrm{~g} / \mathrm{dL}$, the wrinkle amplitude increases by $\sim 5 \mathrm{~nm}$ and 
the wavelength range narrows with the mean wavelength decreasing by $\sim 7 \mu \mathrm{m}$. As concentration is incrementally increased to $8 \mathrm{~g} / \mathrm{dL}$, the average amplitude and wavelength increase linearly. The paired increase of wrinkle wavelength and amplitude with increasing concentration has also been reported for polystyrene thin films spin-cast from toluene. ${ }^{16}$ The aspect ratios (width/depth) of these interfacial wrinkle structures are in the thousands. Similar aspect ratios observed with polystyrene thin films cast from binary solvents $\mathrm{THF}$ and $\mathrm{DMF}{ }^{26}$ 

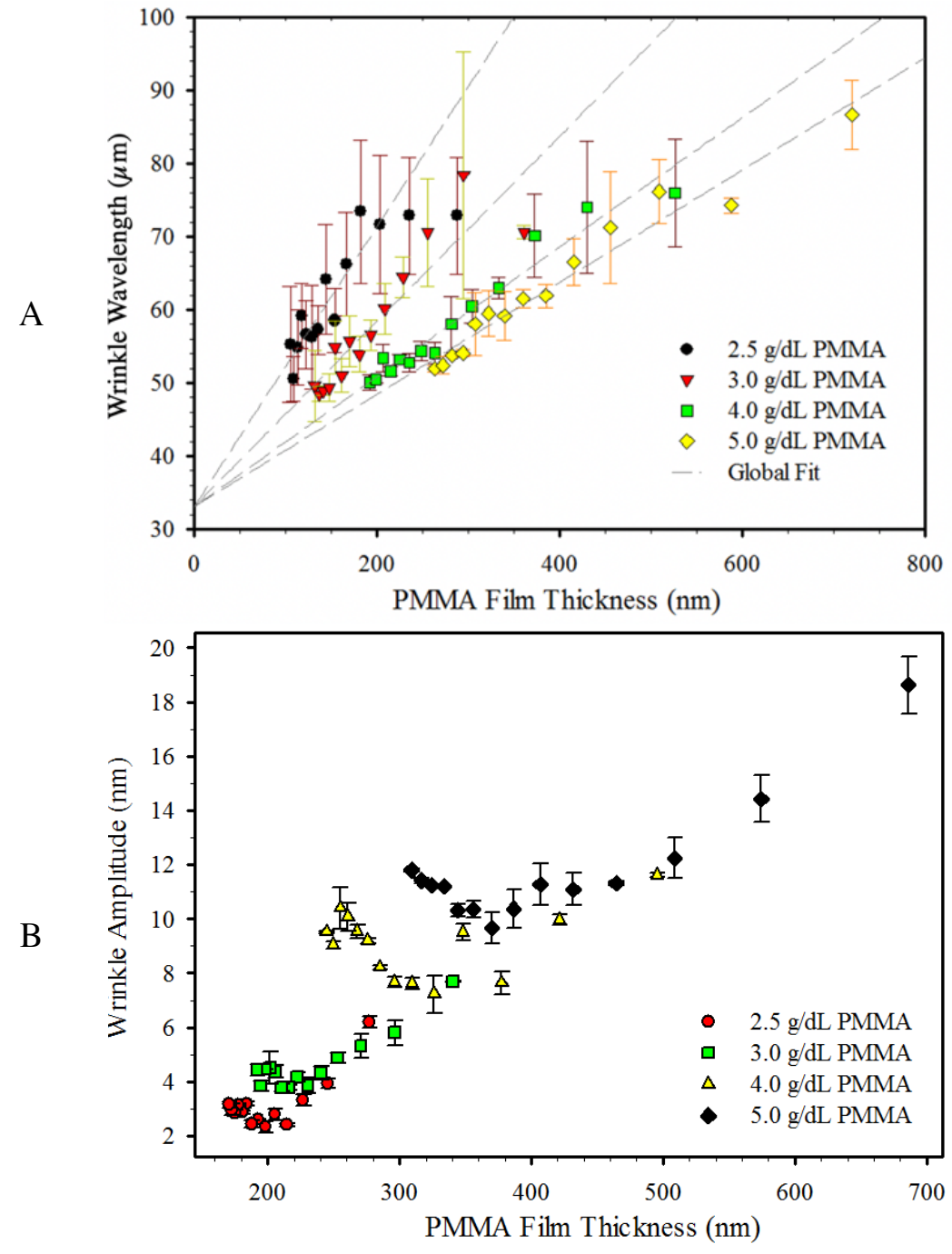

Figure 2-8. PMMA surface wrinkle wavelength (A) and wrinkle amplitude (B) as a function of final film thickness.

PMMA thin films were cast from 2.5, 3.0, 4.0, and 5.0 g/dL solutions spun at speeds from 400 to 3000 RPM. The error bars represent the standard deviation of four different ACL and RMS roughness determinations taken at increments of 3.75, 7.50, 11.25, and $15.00 \mathrm{~mm}$ from the center of each film.

Figure 2-8 shows wrinkle wavelengths different PMMA thicknesses grouped by casting solution concentration. Wrinkled surfaces with local periodicity were seen on the surfaces of films with thicknesses larger than $75 \mathrm{~nm}$, which is likely the critical film thickness for either instability to roughen the surface. A critical wrinkle wavelength of 
$\sim 45 \mu \mathrm{m}$ is observed on the thinnest films produced from each of the four solution concentrations and suggests that surface wavelengths are largely unaffected by coating solution concentration. The observed linear correlation between wrinkle wavelength and average film thickness is an associated characteristic of these instabilities ${ }^{10,16,27}$ The data in Figure 2-8 (A) are global fit to the equation $\lambda=\lambda_{0}+a \times h_{f}$, where $a$ is the concentration dependent slope and $\lambda_{0}$ is the shared parameter for wavelength-intercept. The slope of each fit increases with decreasing casting solution concentration. The shared vertical intercept was found at $35.3 \pm 1.4 \mu \mathrm{m}$ (shown in supporting information Table 2-S1). To the best of our knowledge, a common intercept for instability wavelength has not been published. Figure 2-8 (B) shows a plot of wrinkle amplitude as a function of average film height. In the scatter plot, films applied from the same coating solution concentration differ by spin speed. For films cast from a constant concentration, wrinkle amplitude appears to have a parabolic relationship with film thickness. Average wrinkle amplitude is seen to first decrease and then increase with increasing film thickness. Since surface tension is partly a function of concentration and temperature, evaporative cooling during spin casting creates a localized temperatureconcentration gradient at the free interface. With the growth of temperature gradients, film vertical height increases, surface tension driven instabilities decrease, and buoyancy driven instabilities increase. The relationships shown in figure 2-8 (B) may portray the balance between these instabilities. 


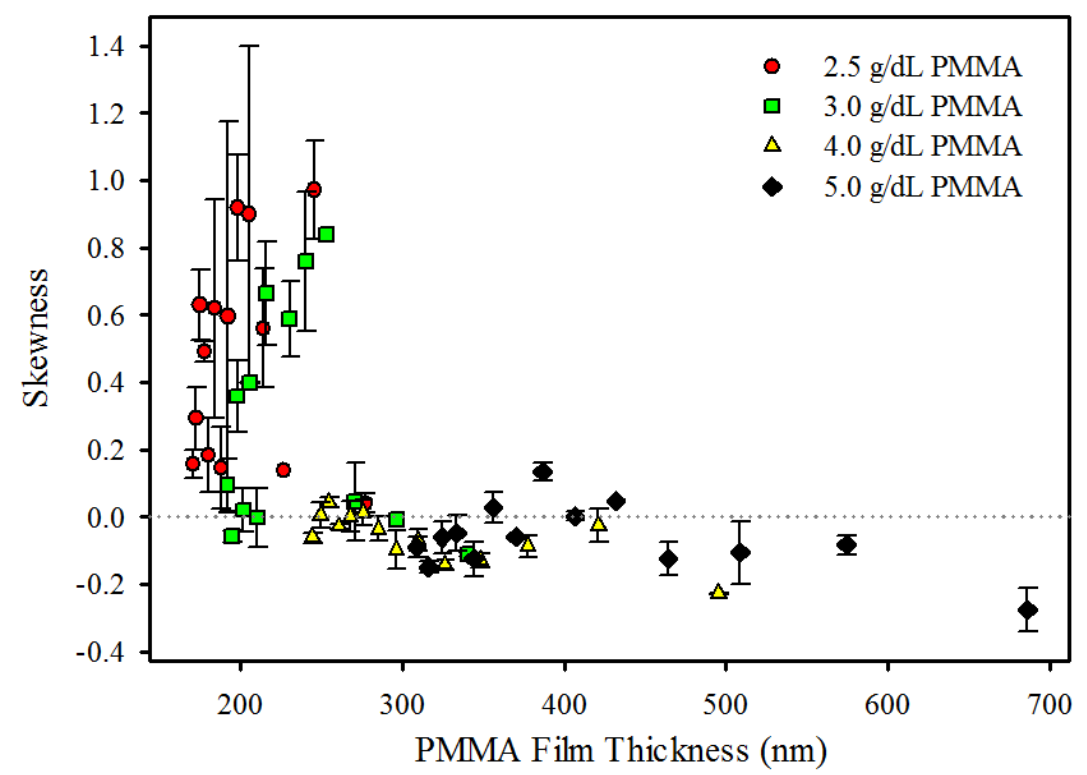

Figure 2-9. PMMA surface skewness as a function of final film thickness.

Films were cast using 2.5, 3.0, 4.0, and $5.0 \mathrm{~g} / \mathrm{dL}$ solutions spun at speeds from 400 to 3000 RPM.

Figure 2-9 shows the skewness of the wrinkles compared to the thickness of dry PMMA films. A horizontal dashed line has been drawn at zero skewness, where an even distribution of wrinkle peaks and valleys would lie. The error bars represent the standard deviation of four different skewness measurements collected at increments of 3.75, 7.50, 11.25, and $15.00 \mathrm{~mm}$ from the center of each film. The surface of some PMMA thin films with thicknesses between 170 and $250 \mathrm{~nm}$ show a positive skew indicating wrinkles with sharp peaks and shallow valleys. PMMA films between 250 and $500 \mathrm{~nm}$ have vertically symmetrical wrinkles with a Gaussian character. This change in skewness as a function of casting solution concentration may be related to the hydrodynamic radius of the polymer existing when the film was vitrified. A possible explanation for the clear cutoff in skewness at $\sim 250$ may suggest a casting solution 
concentration threshold for globular folding/unfolding. The changing wrinkle skewness at lower thicknesses may also be influenced by shear-flow effects from spin speed. ${ }^{28}$

The total drying rate during spin-coating is related to solvent static evaporation rate $(\mathbb{e})$ and the square root of spin speed $(\omega) .{ }^{29}$ Therefore, the drying rate can be calculated from equation 2-8.

Drying Rate $\quad E=e \omega^{1 / 2}$

The static evaporation rate for toluene was calibrated with the film thickness model and found to be $\sqrt{\omega} \times 140 \mathrm{~nm} / \mathrm{s}^{1 / 2}$.

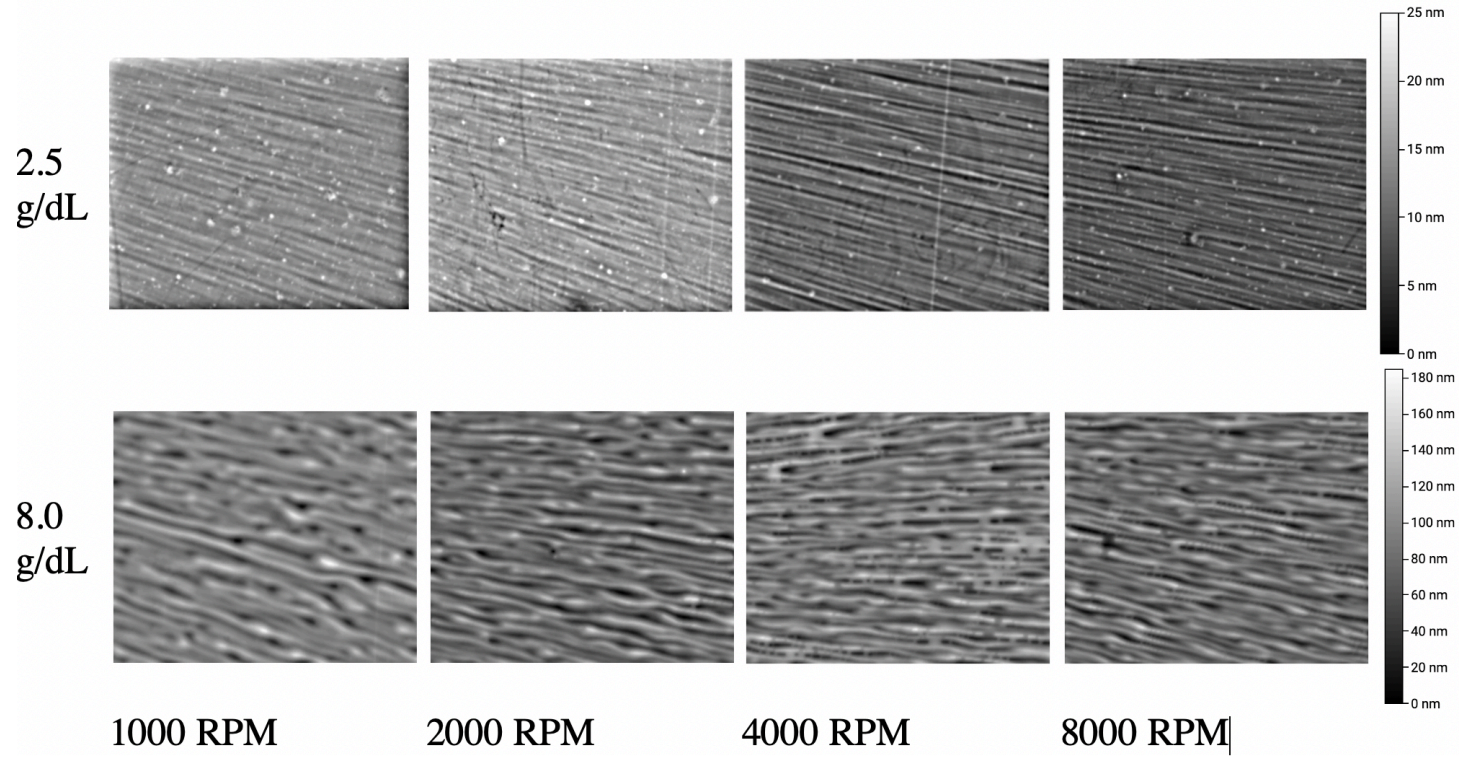

Figure 2-10. Optical micrographs of PMMA thin films cast at different spin speeds from chosen solution concentrations.

The link between surface structures and drying rate has been established..$^{30-32}$ As we reported with polystyrene, faster drying rates lead to more uniform wavelengths, and slower drying rates produce a larger range of wavelengths. ${ }^{26}$ This trend can also be seen 
in thicker PMMA films, as shown in Figure 2-10. As spin speed increases, the wrinkle wavelengths appear more uniform for the films produced from a $8.0 \mathrm{~g} / \mathrm{dL}$ solution.
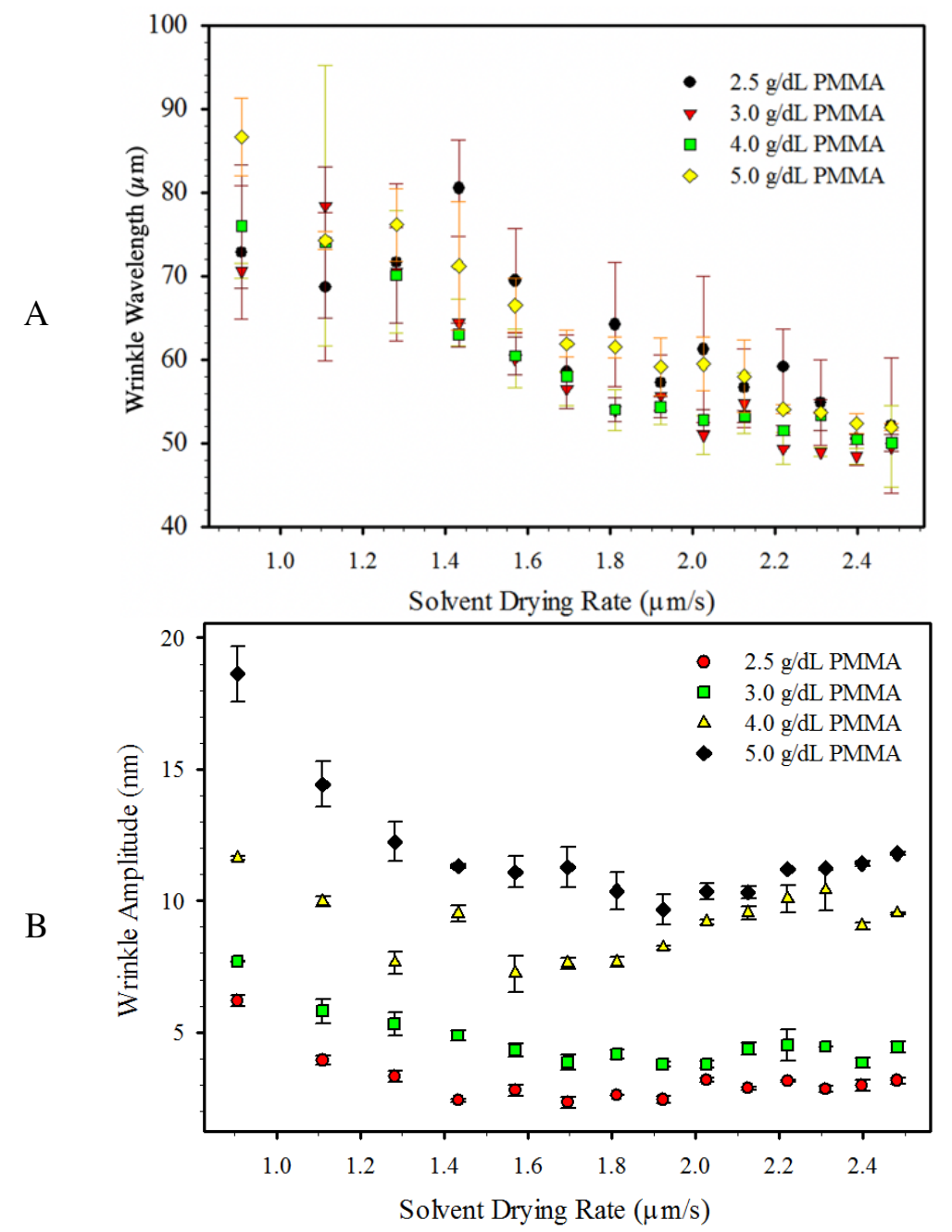

Figure 2-11. PMMA surface wrinkle wavelength (A) and wrinkle amplitude (B) as a function of solvent drying rate.

Films were cast using 2.5, 3.0, 4.0, and $5.0 \mathrm{~g} / \mathrm{dL}$ solutions spun at speeds from 400 to 3000 RPM. The error bars represent the standard deviation of four different ACL and RMS roughness measurements taken at incremental distances of $3.75,7.50,11.25$, and $15.00 \mathrm{~mm}$ away from the spinning center.

The effect of solvent drying rate on wrinkle wavelength is shown in Figure 2-11 (A). When the drying rate is at $0.9 \mu \mathrm{m} / \mathrm{s}$, the average wrinkle wavelength is between 65 
and $90 \mu \mathrm{m}$ for films cast from each of the concentrations. As drying rate is increased to $2.5 \mu \mathrm{m} / \mathrm{s}$, the wrinkle wavelength decreases to $\sim 52 \mu \mathrm{m}$. As seen in Figure 2-11 (B), the spin-casting solution concentration appears to affect wrinkle amplitude, but not wavelength. At the same drying rate, films cast from higher solution concentrations form wrinkles with larger amplitude.

Since film height is scaled by the inverse square root of spin speed, smaller films are formed with faster drying rates and larger temperature gradients. ${ }^{27}$ Surface tension driven instabilities decrease, and buoyancy driven instabilities increase with growth of temperature-gradients and increasing film thickness height. The relationships near 1.6 $\mu \mathrm{m} / \mathrm{s}$ shown in figure 2-8(B) and 2-11(B) may describe non-equilibrium transitions between dominant convection modes. 


\section{CONCLUSION}

Surface morphology of spin-cast PMMA films have been examined using phase shifted interferometry. The experimental results demonstrate that roughness can be modulated from casting solution concentration and solvent drying rate. Local regions with hexagon and square unit-cells were observed near the spinning centers, but longrange periodic structure was lacking. Relatively flat surfaces were found on films with thicknesses below $75 \mathrm{~nm}$. Interfacial wrinkles can be minimized by targeting solvent drying rates between 1.4 to $1.7 \mu \mathrm{m} / \mathrm{s}$. A deeper understanding of fluid flows and surface tension phenomenon has been attained. Insights into the spin-coating process were gained, such as faster drying rates on the thinner films results in rougher surfaces, wrinkle amplitude can increase or decrease with film thickness, and that average wrinkle wavelength decreases with increasing drying rate. A critical wavelength for roughening of the surface by convection instabilities was observed around 45 microns.

This research strengths are the large sampling populations and robust analytical techniques. The sample population was large enough to model spin-coating parameters for generated smooth films and films with reduced. Study limitations included flow complexity and lack of surface energy measurements inhibit direct comparison by nondimensional ratios common to fluid dynamics. The swift transition from a thinning liquid droplet to a glassy film preserves convection pathways through the fluid surface. The points in the spin-coating process for the evolution and vitrification of flow cells are unknown. 


\section{ACKNOWLEDGEMENT}

This material is based upon work supported by Rhodes Pharmaceuticals L.P. and by the U.S. Department of Homeland Security's Science and Technology

Directorate. The views and conclusions contained in this document are those of the authors and should not be interpreted as necessarily representing the official views and policies, either expressed or implied, of Rhodes Pharmaceuticals L.P. or any of its affiliates, or the U.S. Department of Homeland Security. 


\section{CONFLICT OF INTERESTS}

All authors declare no conflicts of interest in this paper. 


\section{SUPPORTING INFORMATION}
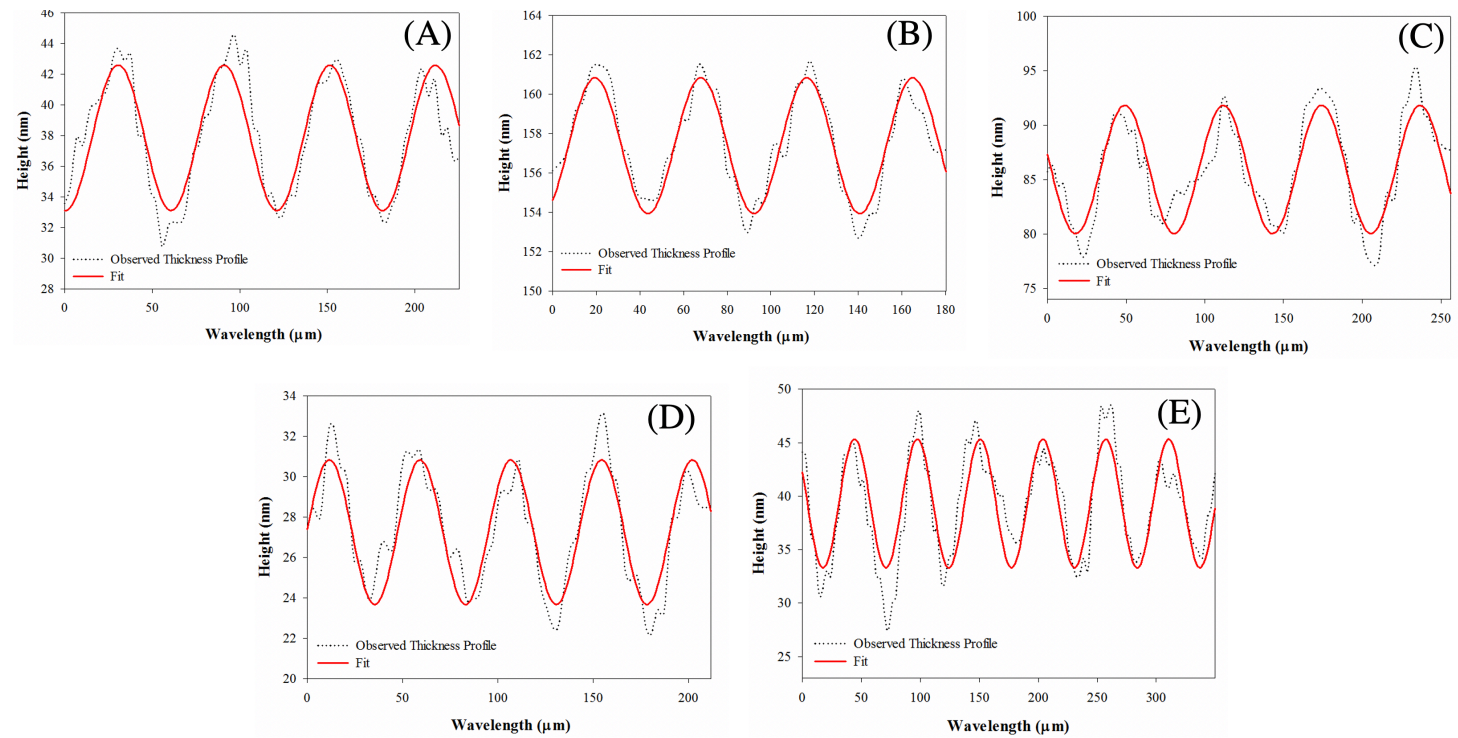

Figure 2-S1. Line scan profiles of the wrinkled PMMA surfaces for films cast from $2.5 \mathrm{~g} / \mathrm{dL}$.

Taken in the direction perpendicular to the surface lay. Black lines are observed thickness profile data and the red lines are fits. $2.5 \mathrm{~g} / \mathrm{dL}$ PMMA, (A) $\omega=2000 \mathrm{RPM}, \mathrm{a}_{0}$ $=4.7 \pm 0.3 \mathrm{~nm}, \lambda_{0}=60.4 \pm 0.5 \mu \mathrm{m}$; (B) $\omega=3000 \mathrm{RPM}, \mathrm{a}_{0}=3.5 \pm 0.2 \mathrm{~nm}, \lambda_{0}=48.6 \pm$ $0.3 \mu \mathrm{m}$; (C) $\omega=5000 \mathrm{RPM}, \mathrm{a}_{0}=5.9 \pm 0.3 \mathrm{~nm}, \lambda_{0}=62.5 \pm 0.4 \mu \mathrm{m}$; (D) $\omega=7000 \mathrm{RPM}$, $\mathrm{a}_{0}=3.6 \pm 0.2 \mathrm{~nm}, \lambda_{0}=47.6 \pm 0.4 \mu \mathrm{m} ;(\mathrm{E}) \omega=8000 \mathrm{RPM}, \mathrm{a}_{0}=6.0 \pm 0.3 \mathrm{~nm}, \lambda_{0}=53.3$ $\pm 0.2 \mu \mathrm{m}$. Uncertainties are the standard error of the estimated fit. 

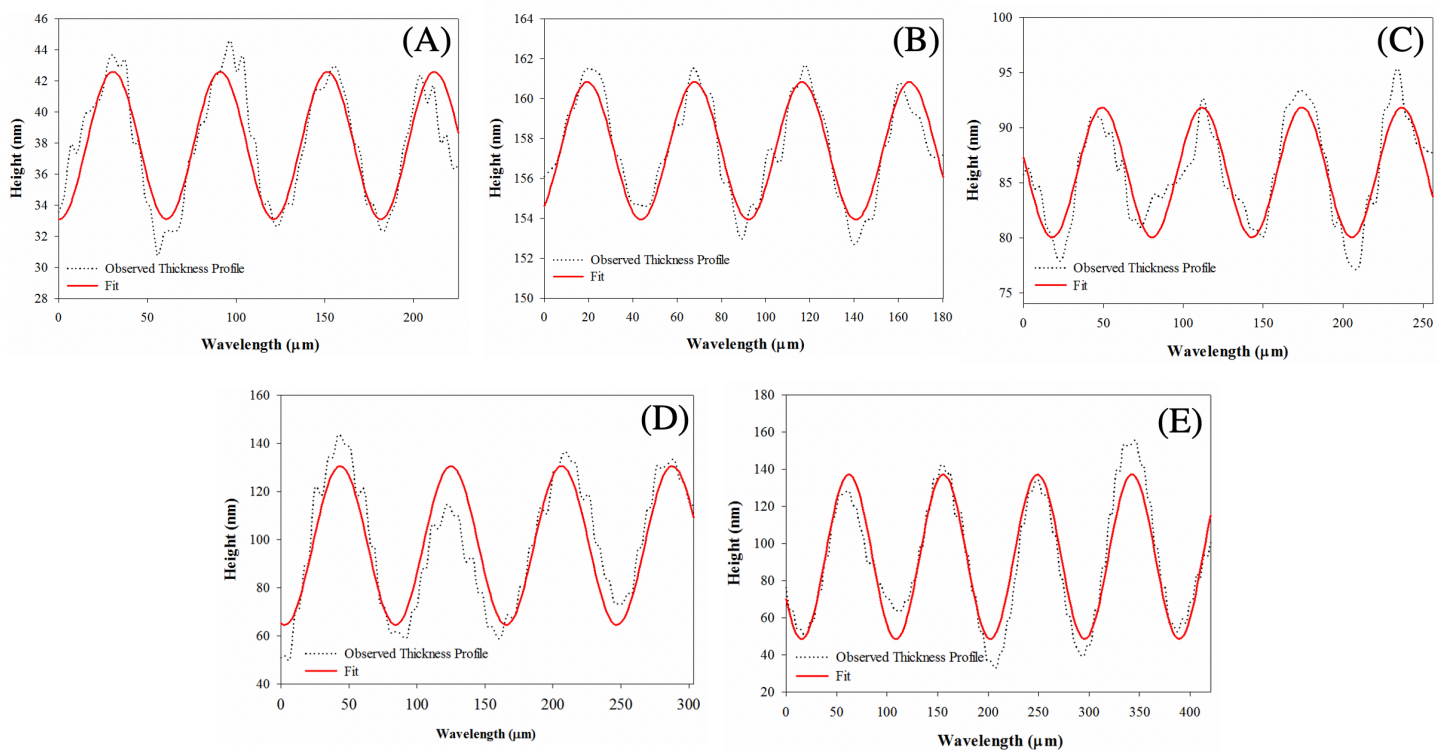

Figure 2-S2. Line scan profiles of the wrinkled PMMA surfaces for films cast at 2000 RPM.

Taken in the direction perpendicular to the surface lay. Black lines are observed thickness profile data and the red lines are fits. $\omega=2000 \mathrm{RPM}(\mathrm{A}) 3 \mathrm{~g} / \mathrm{dL}$ PMMA, $\mathrm{a}_{0}=$ $22.2 \pm 0.9 \mathrm{~nm}, \lambda_{0}=74.8 \pm 0.4 \mu \mathrm{m}$; (B) $4 \mathrm{~g} / \mathrm{dL}$ PMMA, $\mathrm{a}_{0}=19.6 \pm 0.9 \mathrm{~nm}, \lambda_{0}=76.1 \pm$ $0.3 \mu \mathrm{m}$; (C) $5 \mathrm{~g} / \mathrm{dL}$ PMMA, $\mathrm{a}_{0}=34.3 \pm 1.4 \mathrm{~nm}, \lambda_{0}=68.9 \pm 0.3 \mu \mathrm{m}$; (D) $6 \mathrm{~g} / \mathrm{dL}$ PMMA, $\mathrm{a}_{0}=33.0 \pm 1.7 \mathrm{~nm}, \lambda_{0}=81.4 \pm 0.6 \mu \mathrm{m} ;\left(\right.$ E) $7 \mathrm{~g} / \mathrm{dL}$ PMMA, $\mathrm{a}_{0}=44.3 \pm 1.4 \mathrm{~nm}, \lambda_{0}=$ $93.4 \pm 0.3 \mu \mathrm{m}$. Uncertainties are the standard error of the estimated fit.

\begin{tabular}{ccc} 
Concentration g/dL & Slope + error & $\mathbf{R}^{2}$ \\
2.5 & $0.167 \pm 0.010$ & 0.69 \\
3.0 & $0.117 \pm 0.008$ & 0.83 \\
4.0 & $0.082 \pm 0.005$ & 0.95 \\
5.0 & $0.072 \pm 0.004$ & 0.95 \\
\multicolumn{2}{c}{ Overall Global Fit } & 0.87
\end{tabular}

Table 2-S1. Slope, slope error, and $\mathrm{R}^{2}$ of global fit from figure 2-8 (A). 


\section{REFERENCES}

(1) Latendresse, C. A.; Fernandes, S. C.; You, S.; Zhang, H. Q.; Euler, W. B. Analytical Methods Military Explosives and IED Materials $\dagger$. Anal.Methods 2013, 5 (2), 5457-5463. https://doi.org/10.1039/c3ay40293b.

(2) Zhang, H. Q.; Euler, W. B. Sensors and Actuators B : Chemical Detection of GasPhase Explosive Analytes Using Fluorescent Spectroscopy of Thin Films of Xanthene Dyes. Sensors Actuators B. Chem. 2016, 225, 553-562. https://doi.org/10.1016/j.snb.2015.11.098.

(3) Matoian, M. A.; Sweetman, R.; Hall, E. C.; Albanese, S.; Euler, W. B. Light Trapping to Amplify Metal Enhanced Fluorescence with Application for Sensing TNT. J Fluoresc 2013, 23 (5), 877-880. https://doi.org/10.1007/s10895-0131232-8.

(4) Tippo, T.; Thanachayanont, C.; Muthitamongkol, P.; Junin, C.; Hietschold, M.; Thanachayanont, A. The Effects of Solvents on the Properties of Ultra-Thin Poly ( Methyl Methacrylate ) Fi Lms Prepared by Spin Coating. Thin Solid Films 2013, 546, 180-184. https://doi.org/10.1016/j.tsf.2013.05.022.

(5) Richardson, H.; Carelli, C.; Keddie, J. L.; Sferrazza, M. Structural Relaxation of Spin-Cast Glassy Polymer Thin Films as a Possible Factor in Dewetting. Stress Int. J. Biol. Stress 2004, i (2003), 437-441. https://doi.org/10.1140/epje/e200400013-8.

(6) Bénard, H. Les Tourbillions Cellulaires Dans Une Nappe Liquid. Rev. Gén. Sci. pures appl. 1900, 11, 1261-1271 \& 1309-1328.

(7) Rodríguez-Hernández, J. Wrinkled Interfaces: Taking Advantage of Surface Instabilities to Pattern Polymer Surfaces. Prog. Polym. Sci. 2015, 42, 1-41. https://doi.org/10.1016/j.progpolymsci.2014.07.008.

(8) Chung, J. Y.; Chastek, T. Q.; Fasolka, M. J.; Ro, H. W.; Stafford, C. M. Quantifying Residual Stress in Nanoscale Thin Polymer Films via Surface Wrinkling. ACS Nano 2009, 3 (4), 844-852. https://doi.org/10.1021/nn800853y.

(9) Lord Rayleigh. On Convection Currents in a Horizontal Layer of Fluid, When the Higher Temperature Is on the under Side. Philos. Mag. 1916, 32, 529-546.

(10) Pearson, J. R. A. A.; On Convection Cells Induced by Surface Tension. J. Fluid Mech. 1958, 4 (5), 489-500. https://doi.org/10.1017/S0022112058000616.

(11) Scriven, L. E.; Sternling, C. V. The Marangoni Effects. Nature 1960, 187 (4733), 
$186-188$.

(12) Chao, D. F.; Zhang, N. Effects of Evaporation and Thermocapillary Convection on Volatile Liquid Droplets. J. Thermophys. Heat Transf. 2001, 15 (1-4), 416420. https://doi.org/10.2514/2.6644.

(13) Scriven, L. E.; Sternling, C. V. On Cellular Convection Driven by SurfaceTension Gradients: Effects of Mean Surface Tension and Surface Viscosity. $J$. Fluid $\quad$ Mech. $\quad \mathbf{1 9 6 4}, \quad 19 \quad$ (3), 321-340. https://doi.org/10.1017/S0022112064000751.

(14) Chandrasekhar, S. S. Hydrodynamic and Hydromagnetic Stability; Oxford: Clarendon Press: Oxford, 1961.

(15) Cloot, A.; Lebon, G. A Nonlinear Stability Analysis of the Benard-Marangoni Problem. J. Fluid Mech 1984, 145, 447-469. https://doi.org/10.1017/S0022112084003013.

(16) Bassou, N.; Rharbi, Y. Role of Bénard-Marangoni Instabilities during Solvent Evaporation in Polymer Surface Corrugations. Langmuir 2009, 25 (1), 624-632. https://doi.org/10.1021/la802979a.

(17) Brandrup, J.; Immergut, E. H.; Grulke, E. A.; Abe, A.; Bloch, D. R.; Wlley, J.; Chichester, N. Y.; Brisbane, W.; Toronto, S. Polymer Handbook, 4th ed.; WileyInterscience, 1999.

(18) Carisier, P.; Jamand, C. Stability of Roll and Hexagonal Patterns in BenardMarangoni Convection. Phys. Fluids 1987, 30, 954.

(19) Petrov, O. V.The Earth's Dissipative Structures: Fundamental Wave Properties of Substance; Springer Nature, 2019.

(20) Getling, A. V. Formation of Spatial Structures in Rayleigh-Bénard Convection. Sov. Phys. Uspekhi 1991, 34 (9), 737.

(21) Block, M. J. Surface Tension as the Cause of Bénard Cells and Surface Deformation in a Liquid Film. Nature 1956, 178 (4534), 650-651. https://doi.org/10.1038/178650a0.

(22) Eckert, K.; Bestehorn, M. Square Cells in Surface-Tension-Driven Benard Convection: Experiment and Theory. J. Fluid Mech. 1998, 356, 155-197. https://doi.org/10.1017/S0022112097007842.

(23) Penzkofer, A.; Drotleff, E.; Holzer, W. Optical Constants Measurement of Single-Layer Thin Films on Transparent Substrates. Opt. Commun. 1998, 158 (1-6), 221-230. https://doi.org/10.1016/S0030-4018(98)00535-5. 
(24) Maroto, J. A.; Pérez-Mũuzuri, V.; Romero-Cano, M. S. Introductory Analysis of Bénard-Marangoni Convection. Eur. J. Phys. 2007, 28 (2), 311-320. https://doi.org/10.1088/0143-0807/28/2/016.

(25) Eckert, K.; Thess, A. Secondary Instabilities in Surface-Tension-Driven BénardMarangoni Convection. In Dynamics of Spatio-Temporal Cellular Structures: Henri Bénard Centenary Review; Mutabazi, I., Wesfreid, J. E., Guyon, E., Eds.; Springer New York: New York, NY, 2006; pp 163-176. https://doi.org/10.1007/978-0-387-25111-0_9.

(26) Tang, C.; Mullen, M.; B. Euler, W. Influence of Solvent and Molecular Weight in Wrinkle Formation in Spin-Cast Polystyrene Thin Films. AIMS Mater. Sci. 2020, 7 (1), 60-74. https://doi.org/10.3934/matersci.2020.1.60.

(27) Fowler, P. D.; Ruscher, C.; Mcgraw, J. D.; Forrest, J. A.; Dalnoki-Veress, K. Controlling Marangoni Induced Instabilities in Spin-Cast Polymer Films: How to Prepare Uniform Films.

(28) Alexander-Katz, A.; Schneider, M. F.; Schneider, S. W.; Wixforth, A.; Netz, R. R. Shear-Flow-Induced Unfolding of Polymeric Globules. Phys. Rev. Lett. 2006, 97 (13), 138101. https://doi.org/10.1103/PhysRevLett.97.138101.

(29) Meyerhofer, D. Characteristics of Resist Films Produced by Spinning. Cit. J. Appl. Phys. 1978, 49, 3993. https://doi.org/10.1063/1.325357.

(30) Min, X.; Orignac, X.; Almeida, R. M. Striation-Free, Spin-Coated Sol-Gel Optical Films. J. Am. Ceram. Soc. 1995, 78 (8), 2254-2256. https://doi.org/10.1111/j.1151-2916.1995.tb08650.x.

(31) Strawhecker, K. E.; Kumar, S. K.; Douglas, J. F.; Karim, A. The Critical Role of Solvent Evaporation on the Roughness of Spin-Cast Polymer Films [1]. Macromolecules. July 3, 2001, pp 4669-4672. https://doi.org/10.1021/ma001440d.

(32) Haas, D. E.; Birnie, III, D. P. Evaluation of Thermocapillary Driving Forces in the Development of Striations during the Spin Coating Process. J. Mater. Sci. 2002, 37 (10), 2109-2116. https://doi.org/10.1023/A:1015250120963. 
MANUSCRIPT - III

Prepared for submission to Journal of Physical Chemistry C

Interfacial Effects of the Photophysics of Rhodamine 6G Ultra-Thin Films on a Polymethyl Methacrylate Surface

Navid Chapman, Mingyu Chapman, and William B. Euler

Chemistry, University of Rhode Island, Kingston, RI, USA

Corresponding Author: William B. Euler, Ph.D.

Chemistry

University of Rhode Island

140 Flagg Road

Kingston, RI, 02881, USA

Email address:wueler@chm.uri.edu 


\begin{abstract}
The absorbance, excitation, and emission spectra of ultra-thin films of Rhodamine 6G (Rh6G) on polymethyl methacrylate (PMMA) coated glass slide are examined to better understand a perceived emission enhancement. Multiple fluorescence species were observed by changing Rh6G thickness (sub-monolayer to multi-layer) similar to what was observed on glass. However, in comparison with Rh6G on a glass substrate, the fluorescence signal of Rh6G is blue-shifted and enhanced by six times when a sub-micron layer of PMMA was added. Time-resolved emission spectra (TRES) supported to confirm predictions that three emissive species were observed, which are monomers, excimers of oblique dimers, and excitons. Here we show that PMMA surface roughness can help enhance fluorescence by disrupting weakly the formation of oblique dimers and molecular aggregates that would normally exist with the same Rh6G thickness on a glass substrate and that internal reflection of light trapped with the PMMA layer promotes photon re-absorption at the polymer-dye interface.
\end{abstract}




\section{INTRODUCTION}

The principles of fluorescence detection are simple; the fluorescence signal is taken before and after exposure to analyte, then changes in emission are categorized related to unique analyte-fluorophore interactions, such as quench, enhance, or no effect.

In our earlier work, we assembled a liquid state array of different fluorophores dissolved in dimethylformamide and characterized emission responses after exposure to small quantity of explosive analytes. We selected xanthene dyes as the fluorophore for their low cost, high quantum yield, and long wavelength absorption and emissions. ${ }^{1}$ We demonstrated that an array of xanthene dyes produced unique responses sufficient for generating analyte profiles. Most emission responses showed a changed of $10 \%$ or less. ${ }^{1}$ Later, we tested a solid-state sensor prepared by coating ultra-thin layers of Rh6G on a solid support. We reported enhanced emission responses after exposure to $\sim 1 \mathrm{ppb}$ vapor pressure of trinitrotoluene. ${ }^{2}$ When a couple hundred nanometers of transparent polymer between the fluorophore and substrate, we observed a spectral blue shift and emission enhancement by $10^{3}$. The thickness of the polymer layer could change the emission response between quench and enhance. ${ }^{3}$ The thickness of the polymer layer could change the emission response between quench and enhance. We proposed that the blueshift likely because of the reduced dielectric of the polymer and light trapping is likely responsible for the signal enhancement..$^{2,4}$ The scope of this paper is to use a common xanthene dye, Rhodamine 6G (Rh6G), to study the interfacial properties of polymethyl methacrylate (PMMA) substrates. 


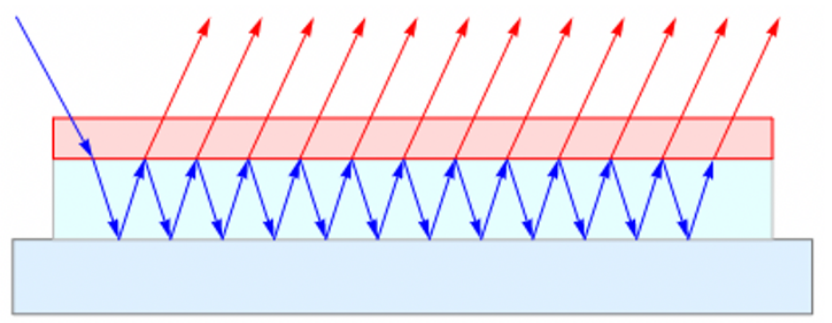

\section{Rhodamine 6G}

PMMA

Glass

Figure 3-1. Scheme for three-layer sensor.

Monomer of Rh6G on sub-micron PMMA on glass support. Light trapping within the PMMA layer promotes photon re-absorption by the fluorophore.

In this study, we investigate the perceived Rh6G signal enhancement that was reported for PMMA substrate. ${ }^{2,3}$ A three-layer sensor comprises up to 1 micron of PMMA deposited by spin-coating onto a cleaned glass surface followed by dye a layer having the thickness of a few nanometers. Spin-coating parameters were used to modulate PMMA film thickness and surface morphology. The absorption, excitation, and emission spectra of Rh6G are investigated at changing dye thickness, polymer thickness, and polymer surface roughness. Two sources contributed to Rh6G emission enhancement. Polymer surface roughness reduces fluorophore molecular aggregation and light trapping promotes photon re-absorption. Schematic of the sensor and light trapping is shown in Figure 3-1. 


\section{EXPERIMENTAL}

Glass microscope slides $(\sim 1 \mathrm{~mm}$ thick) were cut into 37.5 x $25 \mathrm{~mm}$ sections. Slides were then submerged in ethanol (EtOH, 95\%, Pharmaco-Aaper), sonicated for 15 minutes, rinsed with purified water, submerged in purified water, sonicated for an additional 15 minutes, and dried under $\mathrm{N}_{2}$. Polymethyl methacrylate (PMMA) of 120,000 Mw was obtained from Sigma-Aldrich and used without further purification. A $20 \mathrm{~g} / \mathrm{dL}$ stock solution was prepared in toluene (Honeywell, HPLC grade). Polymer stock solution was sonicated for 8 hours with intermittent shaking to ensure full solvation. Resulting solution was free flowing and optically clear. Dilutions ranging from 0.75 to $8.00 \mathrm{~g} / \mathrm{dL}$ were prepared directly from the stock. Rhodamine $6 \mathrm{G} \mathrm{HCl}$ (Rh6G, 99\%) was obtained from Acros and was used as received. Rh6G solutions were prepared in ethanol in the 1 to $100 \mu \mathrm{M}$ range. Flasks were wrapped in aluminum foil to protect solutions from photodegradation.

Sub-micron PMMA films were applied to the glass slides by the static spincoating of a $250-\mu \mathrm{L}$ polymer solution aliquot at a chosen speed between 400 to 8000 RPM for 45 seconds (acceleration of $1080 \mathrm{~s}^{-2}$ ). Spin-coating was carried out under a constant flow of compressed air to reduce the effects of humidity and vapor saturation on film formation. Films were air dried for 15 minutes and then transferred to an oven set at $60{ }^{\circ} \mathrm{C}$ for 2 minutes to facilitate residual solvent removal. Rh6G films were spincast at 1200 RPM for 45 seconds (acceleration of $1080 \mathrm{~s}^{-2}$ ) and air dried. Rh6G films were coated to a set of bare glass slides and a set of polymer coated glass slides. 
Reflection spectra of polymer films was acquired with a Filmetrics F40 microscope thin film analyzer. Reflectance in the range of 400 - $900 \mathrm{~nm}$ was generated by a tungsten-halogen light source. PMMA thin film optical constants for the refractive index and attenuation coefficient were obtained from literature. ${ }^{5}$ Spectral fitting and film thickness calculations were performed with the Filmeasure software. Transmittance spectra of polymer films were collected with a Perkin Elmer Lambda $1050 \mathrm{UV} / \mathrm{Vis}$ spectrometer. The slit width and integration time were set at $2 \mathrm{~nm}$ and 0.20 seconds respectively. Wavelengths generated from tungsten-halogen and deuterium lamps were collected in the 1100 to $300 \mathrm{~nm}$ range. Three-dimensional surface profiles of dried polymer films were collected with a Filmetrics Profilm3D optical interferometer and then digitally extracted by instrument software.

Absorption spectra of dye covered polymer films was also obtained with the Lambda 1050 spectrometer. The slit width set at $2 \mathrm{~nm}$, integration time at 2.00 seconds, and wavelength collection range from 600 to $450 \mathrm{~nm}$. Spectral baseline correction was performed by Peakfit v4.12 software using a cubic automatic baseline subtraction.

Fluorescence steady state excitation and emission spectra of the dye were collected from a Horiba (Jobin Yvon) Fluorolog spectrometer with a xenon arc lamp light source. Emission spectra were excited at the wavelength of maximum absorption, with slit width of $2 \mathrm{~nm}$ and wavelength collection from 700 to $535 \mathrm{~nm}$. For the excitation spectra, two separate measurements were made with excitation wavelengths of 534 and $554 \mathrm{~nm}$. A slit width of $2 \mathrm{~nm}$ was used and wavelengths from 650 to $400 \mathrm{~nm}$ were collected. The dye coated slide was positioned at a $60^{\circ}$ angle and all measurements were made at the 
same location on the slide. Spectral baseline correction was performed by Peakfit software using a linear automatic baseline subtraction.

All absorption, excitation, and emissive spectra were global fit to Gaussian lineshapes with the minimum number of peaks possible using $a$, $\tilde{v}_{\max }\left(\mathrm{cm}^{-1}\right)$, and $\Gamma\left(\mathrm{cm}^{-1}\right)$ for peak amplitude, peak wavenumber, and peak full width half maximum (FWHM).

$$
f(\widetilde{v})=a \exp \left(\frac{-\left(\widetilde{v}-\widetilde{v}_{\max }\right)^{2}}{2 \Gamma^{2}}\right)
$$

Global fitting used $\tilde{v}_{\max }\left(\mathrm{cm}^{-1}\right)$ and $\Gamma\left(\mathrm{cm}^{-1}\right)$ as shared parameters. Peak amplitude was used as the only independent variable.

Time-resolved emission spectra (TRES) measurements were generated with a Horiba Fluorohub time-correlated single photon counting (TCSPC) system. The light source used was a Horiba NanoLED N-460 pulsed diode laser, wavelength $\lambda=464 \mathrm{~nm}$, repetition rate $1.0 \mathrm{MHz}, 160$ pico-second pulse duration, and approximate power output of 7 pico-Joules per pulse. 


\section{RESULTS AND DISCUSSION}

A series of sub-micron PMMA films were applied to glass slides by spin-coating from toluene solutions. Film thickness was manipulated by adjusting coating parameters of casting solution concentration and spin speed. Polymer film thickness was calculated by fitting Fresnel equations to fringing patterns observed in the transmission and reflectance spectra. PMMA film thicknesses were measured in the range between 60 nanometers $(\mathrm{nm})$ to 1 micron. The dataset of thickness measurements was employed to calibrate spin-coating parameters to an established model for polymer thickness which can be used empirically to prepare films of a prescribed thickness within standard error of $\pm 30 \mathrm{~nm}$.

Surface morphology of the PMMA films were analyzed by phase shifting interferometry. For very thin films of fewer than $75 \mathrm{~nm}$, the surfaces were nearly flat. On the surfaces of thicker films are structural large aspect ratio cellular unit. These surface deformations are vitrified Rayleigh-Bénard-Marangoni convective instabilities that arise during the film drying portion of the spin-coating process. ${ }^{6}$ These disorganized surface formations can be modulated by adjusting casting solution concentration and spin speed. Nano-inclusions, such as holes, indentations, and flaws, are observed to a lesser extent. Quasi-periodicity of rough PMMA surfaces can be described in terms of sinusoidal amplitude and wavelength, which are derived from root-mean-square roughness and autocorrelation length. Wavelengths were calculated in the tens of microns while amplitudes were in the tens of nanometers. 
Ultra-thin layers of Rhodamine $6 \mathrm{G}$, of only a few nanometers or fewer, were deposited on top of the PMMA coated glass slides by spin-coating from ethanol. Because PMMA is not soluble in ethanol, the polymer surface is not expected to change during dye deposition. Rh6G film thickness was adjusted by solution concentrations over four orders of magnitude, from $10^{-7}$ to $10^{-3} \mathrm{M}$. Spin-coating speed was maintained at a constant 1200 RPM. Because of the low casting solution viscosity, Rh6G thickness does not change much with spin speed. Because the amplitude of the polymer wrinkles were at least three-times larger than the thickness of the dye layer, direct measurements of Rh6G thickness were not possible with reflectance spectroscopy. Rh6G thickness measurements were made by taking the background-subtracted absorption spectra of the dye and using the equations reported by our group to estimate $\mathrm{Rh} 6 \mathrm{G}$ thickness as a function of maximum absorbance. ${ }^{7}$ An error of $\pm 10 \%$ can apply to Rh6G thickness estimations as a consideration for measurement uncertainty related to polymer surface roughness. Monolayer film thickness is $1.4 \mathrm{~nm}$ and dependent on the orientation of molecules, surface polarity, and surface area of the underlying substrate. ${ }^{4}$ Above the monolayer, film thickness is a function of maximum absorbance. Below a monolayer, film thickness is a function of total surface coverage. Sub-monolayer thicknesses should be interpreted as a fraction of total surface coverage, for instance, $0.7 \mathrm{~nm}$ can be half surface coverage. 


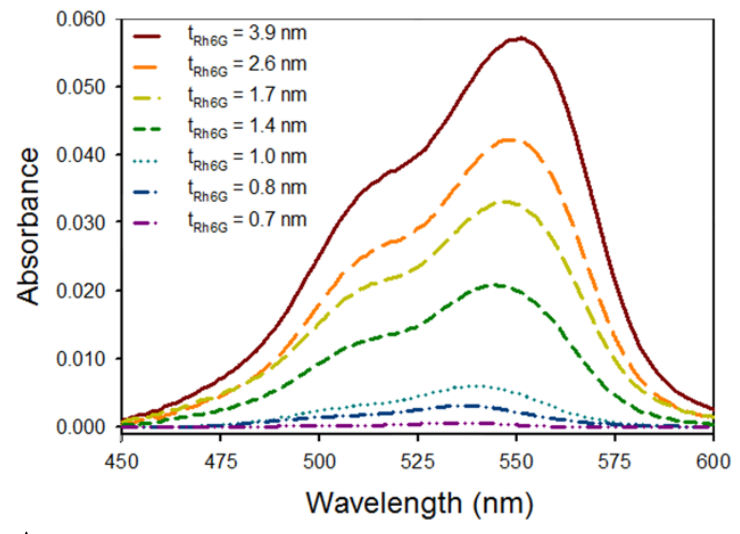

A

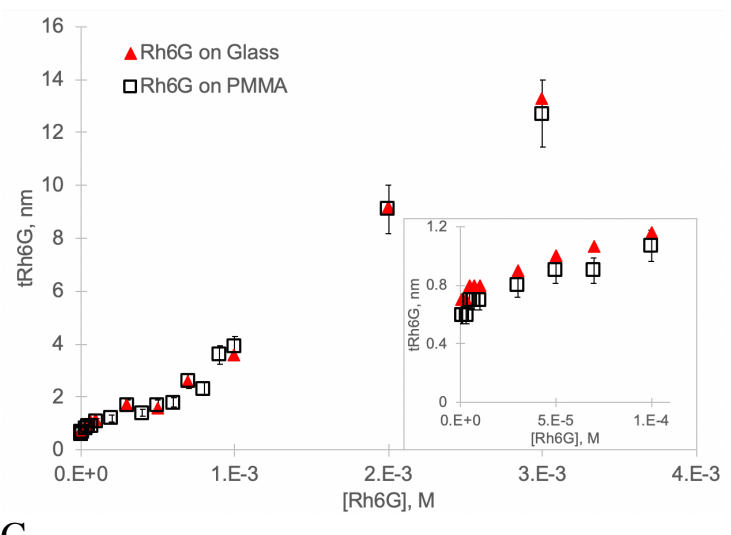

$\mathrm{C}$

Figure 3-2. (A) Absorption spectra of different Rh6G on constant PMMA substrate, $\mathrm{t}_{\text {PMMA }}=318 \pm 30 \mathrm{~nm}$; (B) Height normalized plot of (A); (C) Scatterplot of Rh6G thickness as a function of casting solution concentration for glass and PMMA supports; inset shows the lower concentration range; (D) Scatterplot of absorbance maximum wavelength and Rh6G thickness for Rh6G on PMMA substrate; Rh6G thickness error is $10 \%$. Wavelength measurements have a two-sigma measurement error $\pm 2 \mathrm{~nm}$ slit width.

Figure 3-2 (A) shows the absorption spectra of Rh6G thin films of changing thickness on PMMA substrates of constant thickness. Figure 3-2 (B) shows height normalized spectra of Figure 3-2 (A). Figure 3-2 (C) shows a scatterplot comparing Rh6G film thickness and Rh6G casting solution concentration. The inset shows the smaller concentration range, $[\mathrm{Rh} 6 \mathrm{G}] \leq 10^{-4} \mathrm{M}$. Figure 3-2 (D) shows a scatterplot of the 
maximum absorbance wavelength as a function of Rh6G film thickness. Films prepared from the lowest dye concentration, $10^{-6} \mathrm{M}$, formed layers of half surface coverage, the absorption has a maximum at $535 \mathrm{~nm}$ and a smaller peak at $\sim 501 \mathrm{~nm}$. When spin-coating solution concentration is increased over two orders of magnitude, the film thickness increases to $\sim 1 \mathrm{~nm}$, the absorption broadens, the maximum is further red shifted to 538 $\mathrm{nm}$, and the peak at $\sim 501 \mathrm{~nm}$ grows. As Rh6G approaches bi-layer thickness $(\sim 1.7 \mathrm{~nm})$, the absorption broadens further, and a new peak appears near $565 \mathrm{~nm}$. As Rh6G thickness is further increased, the intensity of the peak at $\sim 501 \mathrm{~nm}$ does not change relative to the maximum intensity, which suggests that the state associated with peak at $\sim 501 \mathrm{~nm}$ is no longer affected by the surrounding environment. At this higher thickness range, the absorption maximum continues moving towards a lower energy as a function of thickness. Compared to the sub-monomer range, the size of the red shift is greatly reduced. Increasing Rh6G film thickness reduces the peak at $\sim 535 \mathrm{~nm}$ and increases the peak at $\sim 565 \mathrm{~nm}$, which suggests that state associate with peak at $\sim 535 \mathrm{~nm}$ is reacting to form the state associated with the peak at $\sim 565 \mathrm{~nm}$, likely the formation of excitons and molecular aggregation..$^{7-9}$ Minimal change in peak shape and gradual red shift of peak maxima suggest that the relative proportions of absorbing species are similar throughout the studied thickness region with a slight decrease in monomeric population countered by an increase in aggregate species. Rh6G films on PMMA, that were cast from very dilute solutions, tended to an angstrom smaller in thickness than films cast to glass supports. This may be related to the difference in polarity between the two substrate materials. 
Deconvolution of absorption spectra by Gaussian line-shape parameters as shown in Table 3-1 and in the supporting information. Rh6G film thickness strongly influences the wavelengths and intensity of Rh6G absorption on PMMA substrate. The absorption spectra of sub-monolayer and monolayer films could be deconvoluted by four peaks.

$\begin{array}{cccc}\text { Peak } & \tilde{v}_{\max }\left(\mathrm{cm}^{-1}\right) ; \lambda_{\max }(\mathrm{nm}) & \Gamma\left(\mathrm{cm}^{-1}\right) & \mathrm{t}_{\mathrm{Rh} 6 \mathrm{G}}(\mathrm{nm}) \\ 1 & 19648(56) ; 509(3) & 756(26) & 0.6-12.7 \\ 2 & 18599(68) ; 538(4) & 405(60) & 0.6-12.7 \\ 3 & 18309(35) ; 546(2) & 586(10) & 0.6-12.7 \\ 4 & 17753(45) ; 563(3) & 410(21) & 1.7-12.7\end{array}$

Table 3-1. Deconvolution Gaussian Peaks for the Absorption Spectra. Parenthetical values are standard error of estimate.

$$
f(\tilde{v})=a \exp \left(\frac{-\left(\tilde{v}-\tilde{v}_{\max }\right)^{2}}{2 \Gamma^{2}}\right)
$$

For the $0.6 \mathrm{~nm}$ and $0.7 \mathrm{~nm}$ ultra-thin Rh6G films, the main peak at $538 \pm 4 \mathrm{~nm}$ is assigned to isolated monomers. Vibrational transitions of individual Rh6G molecules may be partly responsible for the peak at $509 \pm 3 \mathrm{~nm} .{ }^{10}$ The small peak at $509 \pm 3 \mathrm{~nm}$ and the smaller peak at $546 \pm 2 \mathrm{~nm}$ can potentially be assigned to the oblique exciton dimer, which follows exciton theory and is formed in the excited state by two molecular dipoles arranged at an angle to each other., ${ }^{4,7,8,11,12}$ The angle $\theta$ between the two was estimated from the peak intensity ratio of the two dimer peaks as $\sim 58^{\circ}\left( \pm 8^{\circ}\right)$. Exciton structure is dependent on substitution of nitrogen atoms in the xanthene ring. Rhodamine $6 \mathrm{G}$ has each nitrogen is singly substituted which means that exciton structure is oblique dimer, with coupling at an angle. ${ }^{79}$ While $\mathrm{H}$ and $\mathbf{J}$ dimers are associated with excitons, similar structural features likely exist with excimers. 
A new lower energy peak is required for absorption spectra deconvolution when Rh6G thickness is increased beyond the monolayer range. This thickness dependent longer wavelength absorption has been associated with excitons and molecular aggregation..$^{78}$ The absorption peak at $563 \pm 3 \mathrm{~nm}$ appears when the surface density of Rh6G molecules is large enough to support aggregation.

For multi-layer films of Rh6G on PMMA substrates, the relative proportions of different absorbing species do not largely vary with increasing Rh6G thickness. This is in contrast to Rh6G on glass substrates, where monomeric peak decreases and aggregate peak increases with increasing Rh6G thickness. The percentage of aggregate absorbing species with increasing Rh6G thickness is reduced for PMMA substrate, as compared to glass. A similar trend for reduced aggregation was reported for Rh6G on PVDF substrate and is likely related to the increased surface area of the rough polymer surfaces. ${ }^{4}$ 

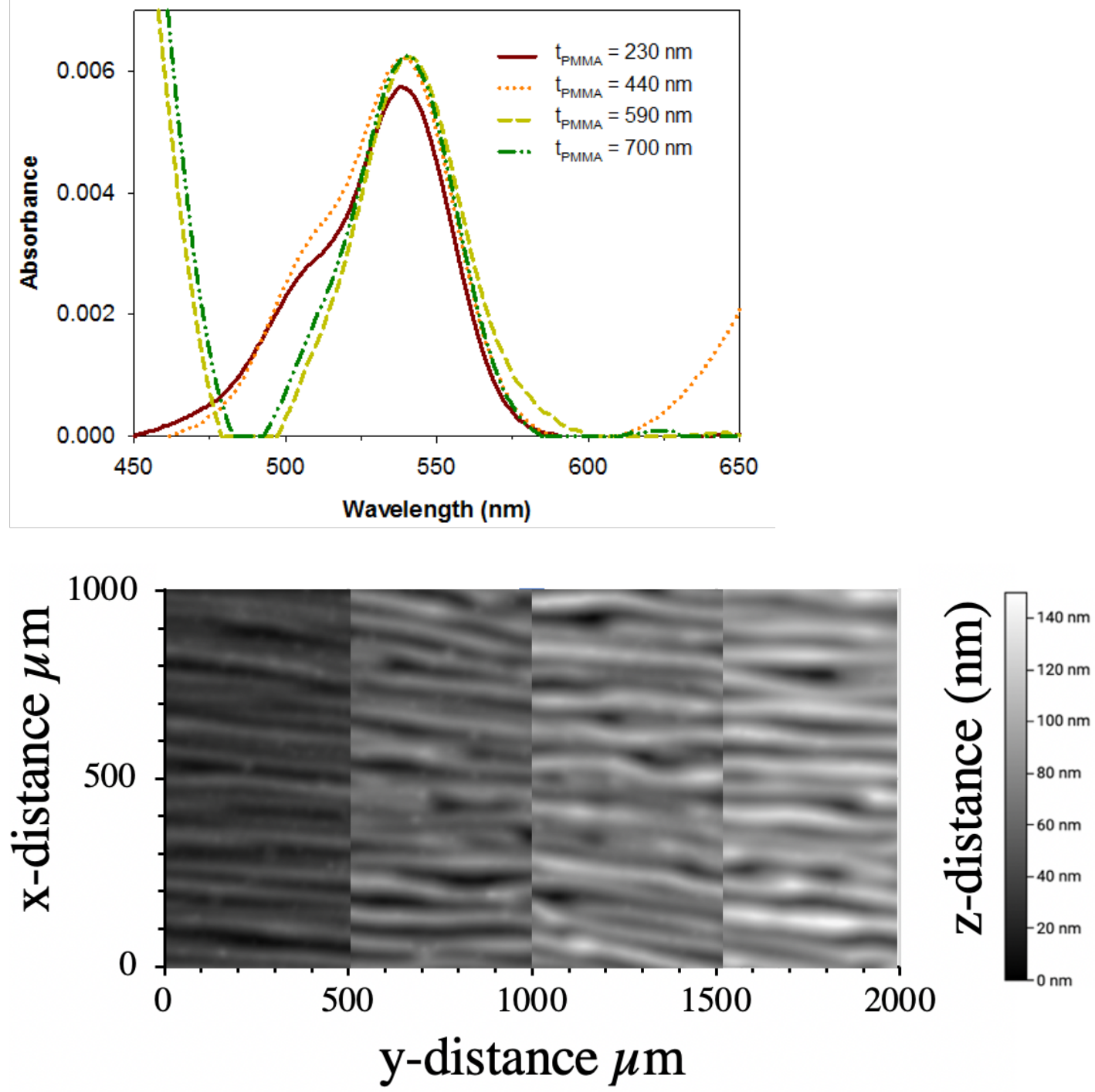

Figure 3-3. Absorption spectra of Rh6G monolayer on PMMA (Top) substrates of changing thickness. $\mathrm{t}_{\mathrm{Rh} 6 \mathrm{G}}=1.0 \pm 0.1 \mathrm{~nm}$; (Bottom) from left to right, surface morphology of $230 \mathrm{~nm}, 440 \mathrm{~nm}, 590 \mathrm{~nm}$, and $700 \mathrm{~nm}$ thick PMMA films. Films were spin-cast at 1200 RPM. Horizontal and vertical units for the surface figures are measured microns and the gray-scale on the right describes film thickness.

Figure 3-3 (top) shows absorption spectra of a Rh6G monolayer on changing PMMA thickness. Each of the Rh6G films were prepared from a single casting solution, $10^{-4}$ M. Figure 3-3 (bottom) shows a bird's-eye view of polymer surfaces for different film thicknesses. Absorption spectra of other thicknesses of Rh6G are shown in the 
supporting information. The same parameters were used for deconvolution of Rh6G absorption spectra on all thickness of PMMA. At the thinnest PMMA film of $230 \mathrm{~nm}$, the Rh6G absorption spectra has a maximum at $538 \mathrm{~nm}$ and a smaller peak at $509 \mathrm{~nm}$. As PMMA thicknesses is increased from 230 to $440 \mathrm{~nm}$, Rh6G absorption intensity increases but the peak maximum does not change position. The intensity increase is likely caused by the increased surface area of the $440 \mathrm{~nm}$ PMMA substrate, which would place more molecules in the path of the incident light. As the thickness of the PMMA layer is increased from $440 \mathrm{~nm}$ to $590 \mathrm{~nm}$, the $\mathrm{Rh} 6 \mathrm{G}$ absorption maximum remains at $538 \mathrm{~nm}$, intensity does not change, the peak at $509 \mathrm{~nm}$ is reduced, and the baseline increases dramatically. 


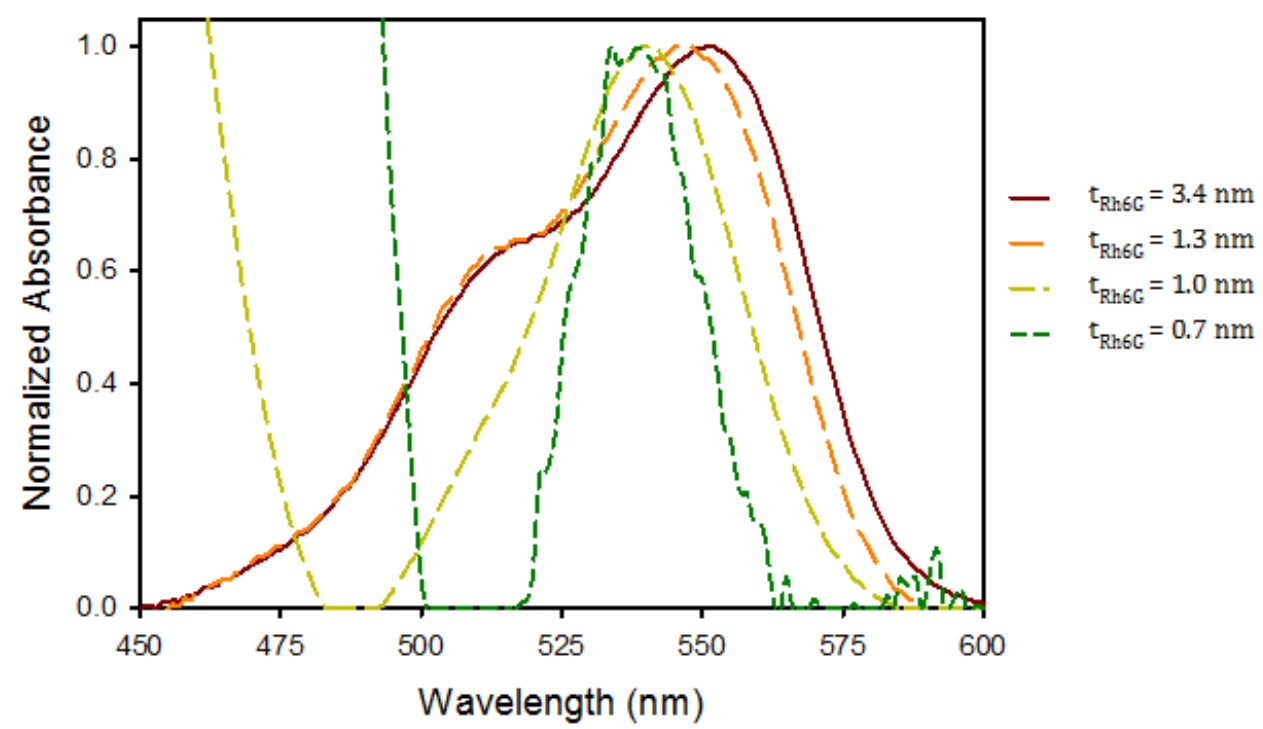

Figure 3-4. Absorption spectra of different Rh6G on constant PMMA substrate, $\mathrm{t}_{\mathrm{PMMA}}=$ $780 \pm 30 \mathrm{~nm}$.

Figure 3-4 shows the absorption spectra of different Rh6G thicknesses on constant thickness of PMMA, $\mathrm{t}_{\mathrm{PMMA}}=780 \mathrm{~nm}$. The sub-monomer absorption spectra show the major peak at $538 \mathrm{~nm}$, which is associated with monomeric structures, and the small peak at $546 \mathrm{~nm}$ associated with aggregate structure. Comparing to the submonomer absorption spectra on $318 \mathrm{~nm}$ PMMA, the absorption maximum wavelength does not change, but the $509 \mathrm{~nm}$ peak is absent. As the films become thicker, the dye molecules aggregate in the excited state. ${ }^{7}$ One explanation is that surface roughness of thicker PMMA films impose structural changes on $\mathrm{Rh} 6 \mathrm{G}$ that disrupt excimer and exciton formation. The absorption peak at $509 \mathrm{~nm}$ may also be hidden by light scattering off the rough PMMA surface. Film thicknesses $t_{\text {Rh6G }}>1.0$, do not appear affected by baseline problems. Full Rh6G surface coverage changes the reflective properties of the PMMA surface. ${ }^{1}$ 

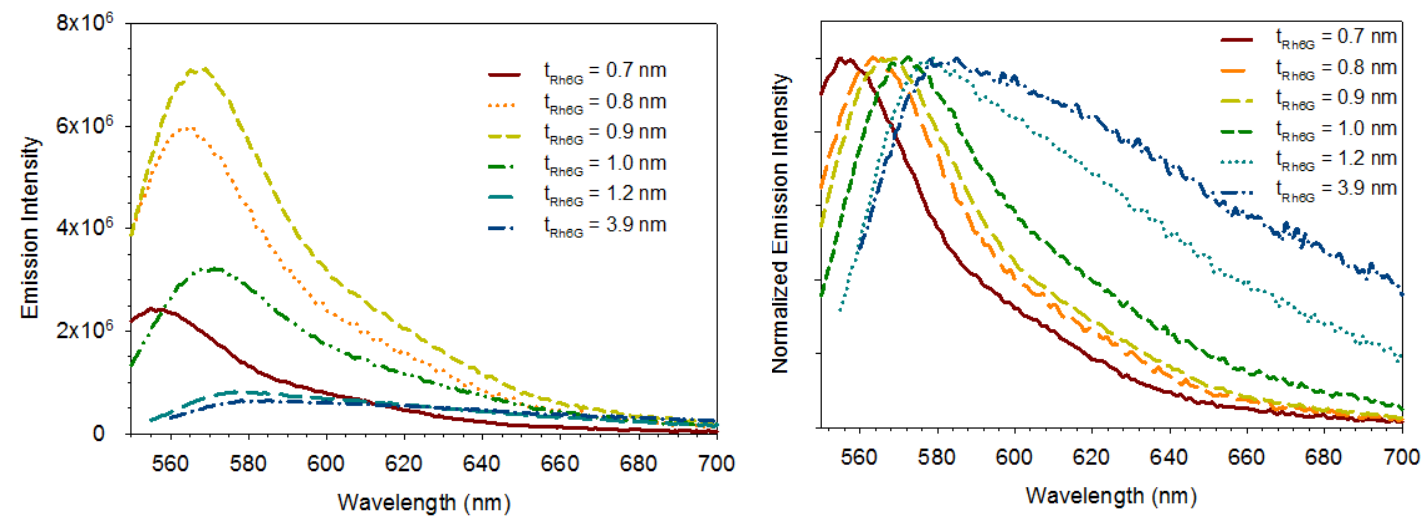

A

B

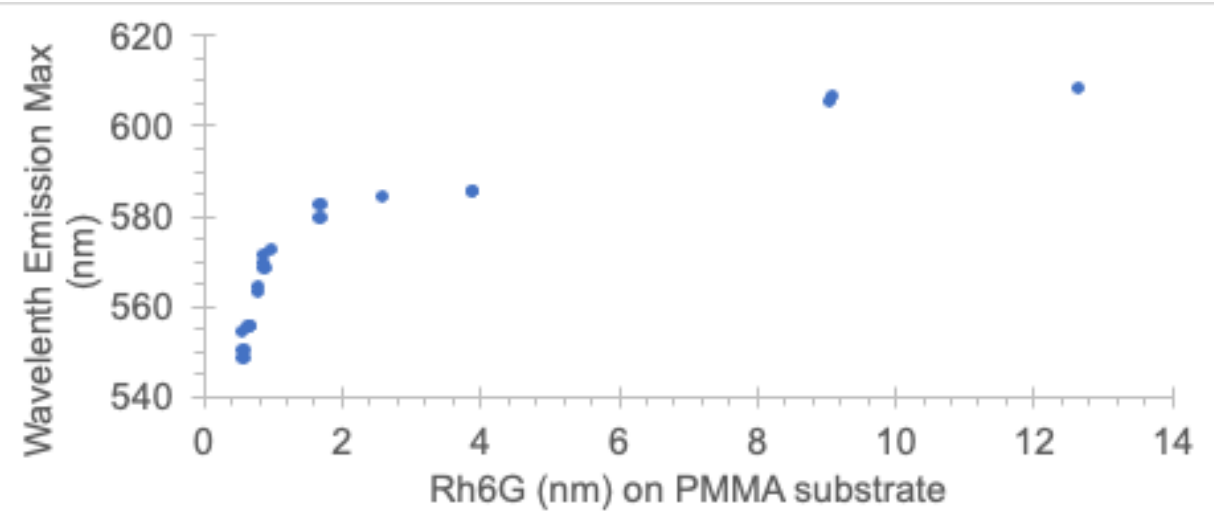

$\mathrm{C}$

Rh6G (nm) on PMMA substrate

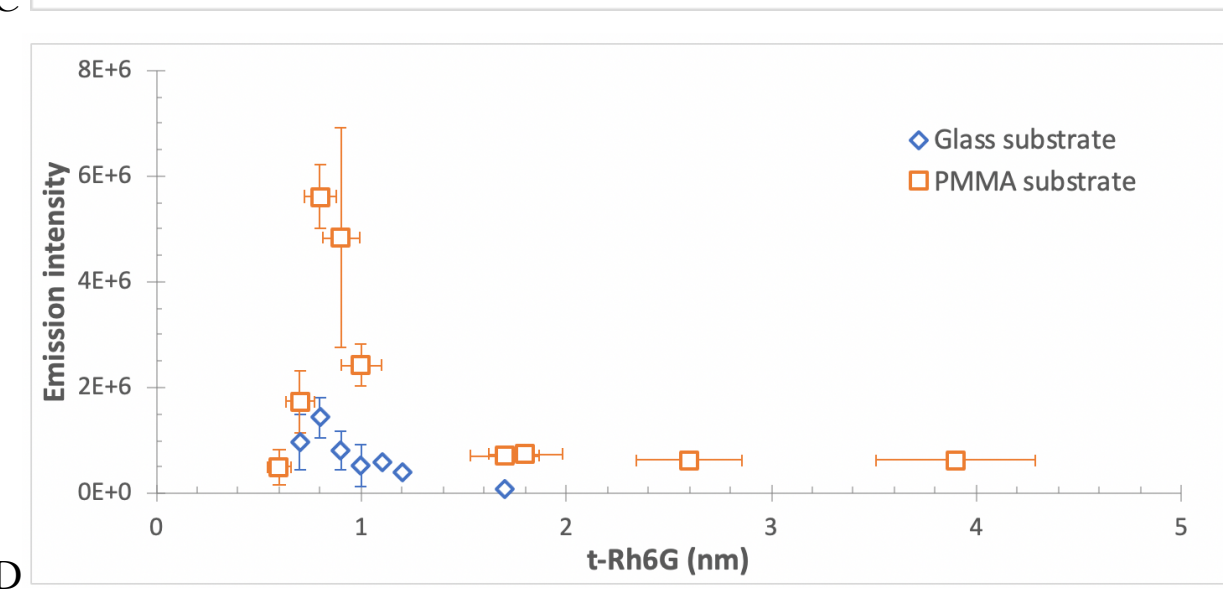

Figure 3-5. (A) Steady state emission spectra of Rh6G on PMMA, tPMMA $=318 \pm$ $30 \mathrm{~nm}$. (B). Height normalized plot of (A). (C) Scatterplot comparing emission maximum wavelength with Rh6G thickness on a PMMA substrate of constant thickness. (D) Non-integrated emission intensity as a function of tRh6G for glass and PMMA substrates. Excited at wavelength for maximum absorbance for each tRh6G. Horizontal error bars are $10 \%$ for measurement error. Vertical error bars are standard deviation of two or more measurements for each thickness. 
Figure 3-5 (A) shows steady state emission spectra for different Rh6G thicknesses on constant PMMA thickness. Figure 3-5 (B) shows height normalized Figure 3-5 (A). Figure 3-5 (C) shows emission maximum wavelength as a function of Rh6G thickness. Figure 3-5 (D) shows the non-integrated emission intensity as a function of Rh6G film thickness and compares PMMA and glass substrates. At the lowest fluorophore thickness, $\mathrm{t}_{\mathrm{Rh} 6 \mathrm{G}}=0.7 \mathrm{~nm}$, the emission maximum is at $555 \mathrm{~nm}$ and a smaller peak is near $\sim 598 \mathrm{~nm}$. As film thickness is increased to $0.8 \mathrm{~nm}$, the emission intensity triples and peak maximum red shifts to $564 \mathrm{~nm}$. Increasing Rh6G thickness another fraction of a nanometer and the emission is further enhanced by another million counts and the peak maximum red shifts to $568 \mathrm{~nm}$. As Rh6G thickness is increased to $1.0 \mathrm{~nm}$, the emission intensity is quenched and redshift to $572 \mathrm{~nm}$. Increasing Rh6G thickness to $1.2 \mathrm{~nm}$, the emission intensity continues to decrease, but now the emission broadens. As Rh6G thickness is further increased, emission continues quenching and broadening towards longer wavelengths. Similar line-shape changes were also seen in the absorption spectra and assigned with molecular aggregation. As compared to Rh6G on glass substrate, Rh6G absorption and emission spectra on PMMA substrate are blue shifted and emission is enhanced by six times. The peak positions and magnitude of fluorescence emission are inversely affected by the polarity of the surrounding environment; and the polarity of PMMA is less than glass. PVDF has an even lower polarity and we reported an emission enhancement significantly greater than PMMA. ${ }^{2-}$ ${ }^{4}$ Emission intensity approximates a log-normal distribution function of Rh6G surface density on both PMMA and glass. We have reported this trait for thin films of several rhodamines..$^{7,9}$ 

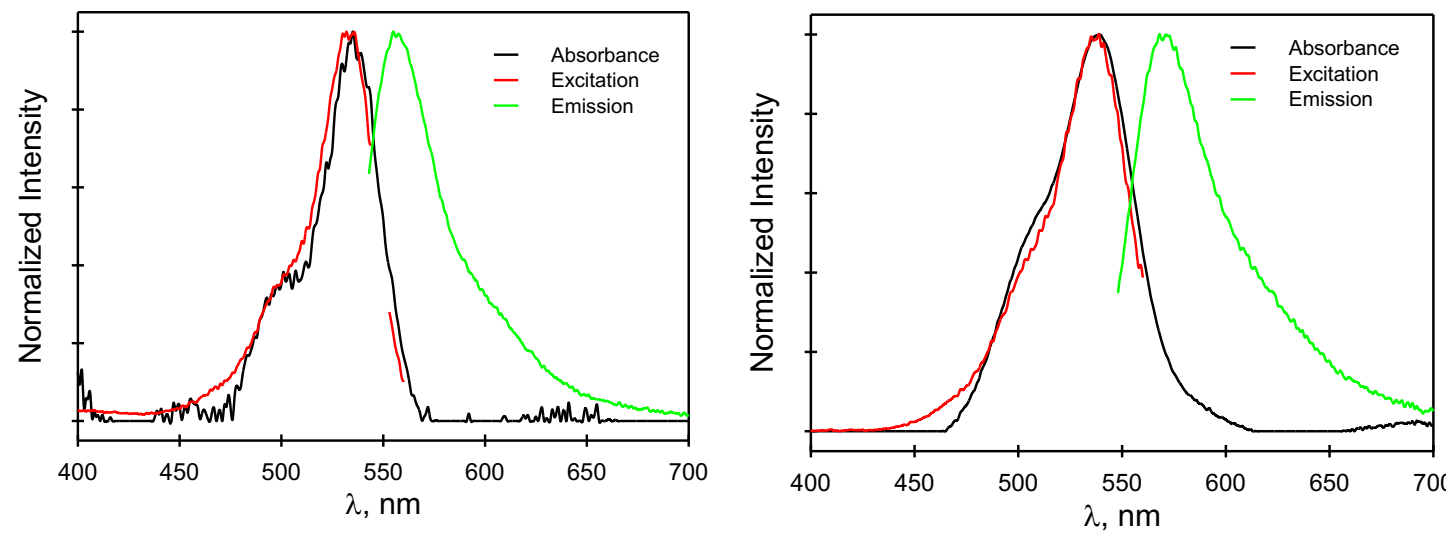

A

B
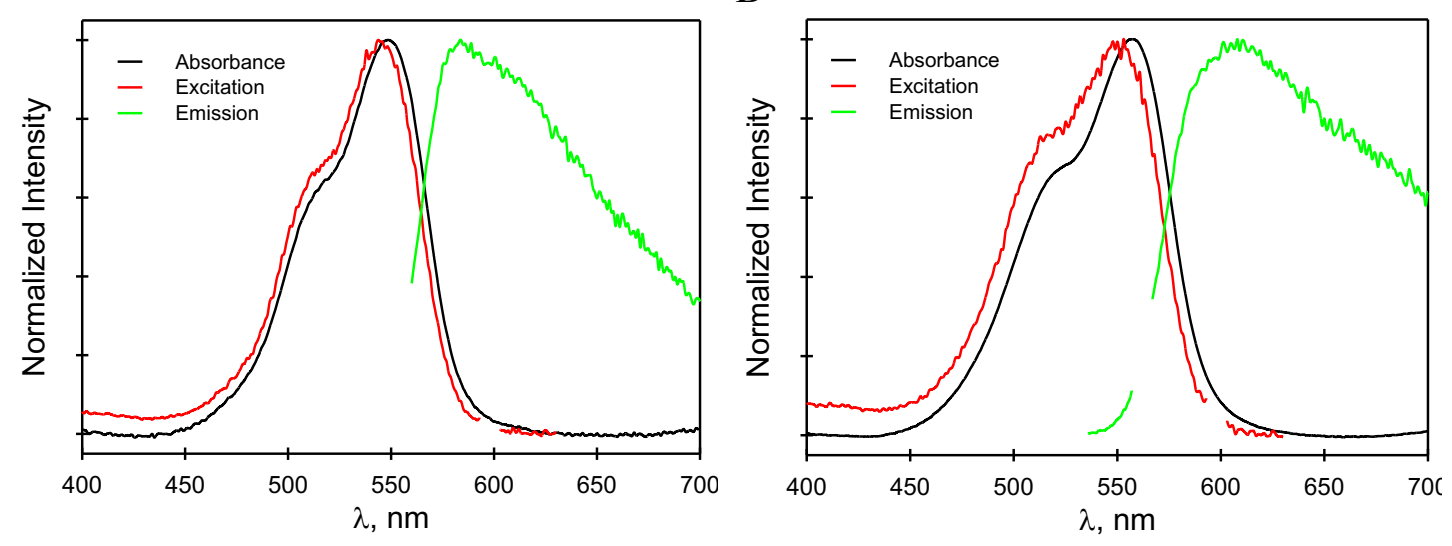

$\mathrm{D}$

$\mathrm{C}$

Figure 3-6. Normalized absorbance (black), excitation (red), emission (green) spectra of different Rh6G thicknesses on PMMA of constant thickness, tPMMA $=318 \pm 30$ nm. (A) tRh6G = $0.7 \mathrm{~nm}$; (B) tRh6G = $1.1 \mathrm{~nm}$; (C) $\mathrm{tRh} 6 \mathrm{G}=2.6 \mathrm{~nm}$; (D) $\mathrm{tRh} 6 \mathrm{G}=$ $12.7 \mathrm{~nm}$.

Figure 3-6 shows normalized spectra of absorption, emission, and excitation for Rh6G of different thickness on PMMA substrate of constant thickness. The absorption and excitation spectra of $0.7 \mathrm{~nm} \mathrm{Rh} 6 \mathrm{G}$ films look the same and are mirror images of the emission spectra. As Rh6G thickness increases to $1.1 \mathrm{~nm}$, the absorption and excitation spectra no longer match at the high energy side. A non-emissive species formed with the absorption at $501 \mathrm{~nm}$. When Rh6G thickness is increases to $2.6 \mathrm{~nm}$, the absorption 
and excitation spectra no longer match, and the lower energy portion of the emission broadens. The higher energy portions of excitation and absorption spectra always match, but the excitation maximum of thicker films is blue shifted relative to the absorption spectra as the lower energy portion of the excitation spectra is missing peaks. The effect is more pronounced with thicker dye films and is likely influenced by the higher proportion of non-emissive aggregate species. The excitation and emission line-shapes were the consistent at all excitation wavelengths.

$\begin{array}{cccc}\text { Peak } & \tilde{v}_{\max }\left(\mathrm{cm}^{-1}\right) ; \lambda_{\max }(\mathrm{nm}) & \Gamma\left(\mathrm{cm}^{-1}\right) & \mathrm{t}_{\text {Rh6G }}(\mathrm{nm}) \\ 1 & 18208(14) ; 549(1) & 475(10) & 0.6-12.7 \\ 2 & 17610(9) ; 568(1) & 445(10) & 0.6-12.7 \\ 3 & 16733(56) ; 598(4) & 923(28) & 0.6-12.7 \\ 4 & 16045(98) ; 623(8) & 1646(35) & 1.7-12.7\end{array}$

Table 3-2. Deconvolution Gaussian Peaks for the Emission Spectra of Rh6G on PMMA. Parenthetical values are standard error of estimate.

$f(\tilde{v})=a \exp \left(\frac{-\left(\tilde{v}-\tilde{v}_{\text {max }}\right)^{2}}{2 \Gamma^{2}}\right)$

Deconvolution of excitation spectra gave the same parameters as the absorption spectra (Table 3-1). Deconvolution of the emission spectra is shown in Table 3-2. Like absorption, deconvolution of excitation and emission spectra each required 4 peaks to get a fit. When Rh6G thickness is at $0.6 \mathrm{~nm}$, three absorption peaks are present: $538 \pm$ $4 \mathrm{~nm}, 509 \pm 3 \mathrm{~nm}$ and $546 \pm 2 \mathrm{~nm}$. The maximum emission wavelength is at $545 \mathrm{~nm}$ and the emission spectrum consists a major peak at $549 \pm 1 \mathrm{~nm}$, followed by $598 \pm 4$ $\mathrm{nm}$ and $568 \pm 1 \mathrm{~nm}$. As Rh6G thickness increases, monomer absorption at $538 \pm 4 \mathrm{~nm}$ and emission at $568 \pm 1$ are reduced, and the emission peaks at $568 \pm 1 \mathrm{~nm}$ and $598 \pm 4$ $\mathrm{nm}$ increase as the emission maximum shifts to longer wavelengths. Assignments for emissive species at $549 \pm 1 \mathrm{~nm}$ and $623 \pm 8 \mathrm{~nm}$ are for monomer and aggregates. The 
emissive species at $598 \pm 4 \mathrm{~nm}$ is the dimeric structure, the emissive species at $568 \pm 1$ $\mathrm{nm}$ is the excimer. Further increase in Rh6G thickness starts aggregation with the absorption peak at $566 \pm 1 \mathrm{~nm}$ and successive emission at $623 \pm 8 \mathrm{~nm}$.
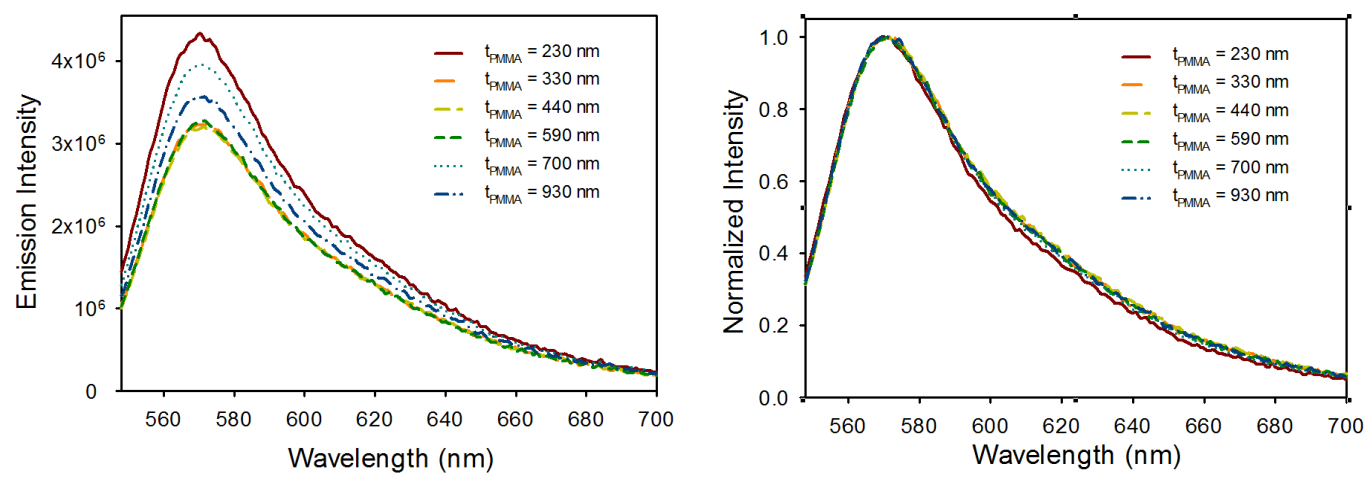

A

$\mathrm{B}$

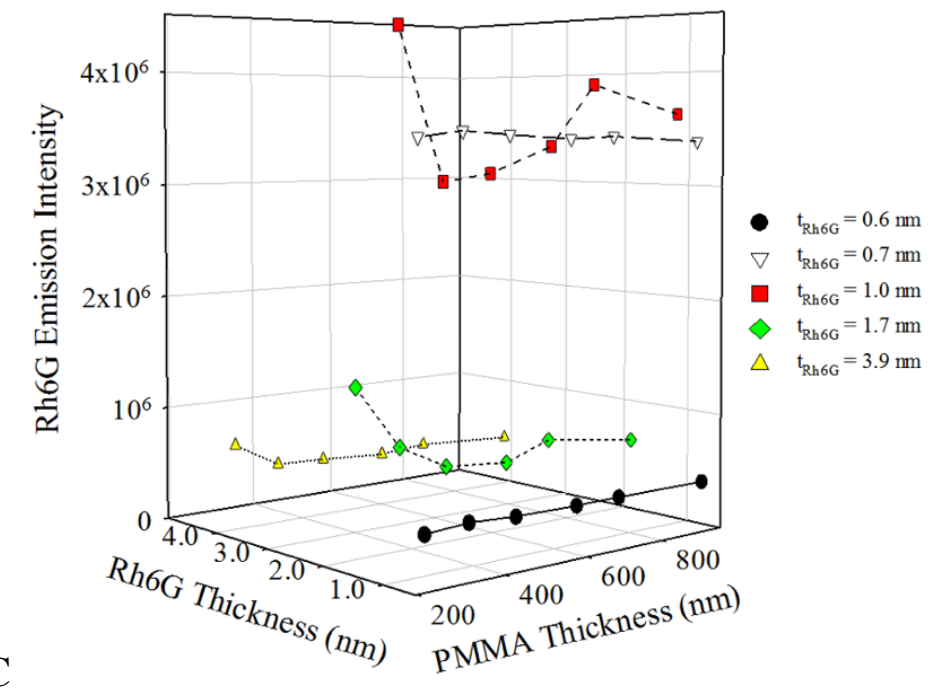

Figure 3-7. (A) Rh6G steady state emission spectra on PMMA of changing thickness, $\mathrm{tRh} 6 \mathrm{G}=1.0 \mathrm{~nm}$. (B) Rh6G emissive wavelength dependence of PMMA thickness. (C) Rh6G Emission intensity as a function of Rh6G thickness and PMMA thickness.

Figure 3-7 (A) shows the effect of changing PMMA thickness on Rh6G emission spectra. Emission intensity changes with PMMA thickness. The normalized spectra in Figure 3-7 (B) show that the change is not in wavelength, but only in intensity. 
Deconvolution parameters for each of the emission peaks are the same, which suggests that the species is unchanged. A scatterplot of Rh6G emission intensity as a function of PMMA thickness is shown in Figure 3-7 (C). It shows at the $0.6 \mathrm{~nm}$ Rh6G film, where monomeric structure is the major component because of the extreme low dye density, the emission intensity appears unaffected by PMMA thickness. The increase in the Rh6G emission intensity results from the light trapping within the PMMA layer. The intensities of $\mathrm{t}_{\mathrm{Rh} 6 \mathrm{G}} 1.0,1.7$, and $3.9 \mathrm{~nm}$ appear to be affected by PMMA thickness $(\mathrm{nm})$. The magnitude of the effect appears proportional to signal intensity, and the effect is strongest for the $1.7 \mathrm{~nm}$ Rh6G film. The change of emission intensity with PMMA thickness follows the expected quarter wavelength interference by Fresnel equations. This fringing pattern does not appear until a full Rh6G monolayer is formed.
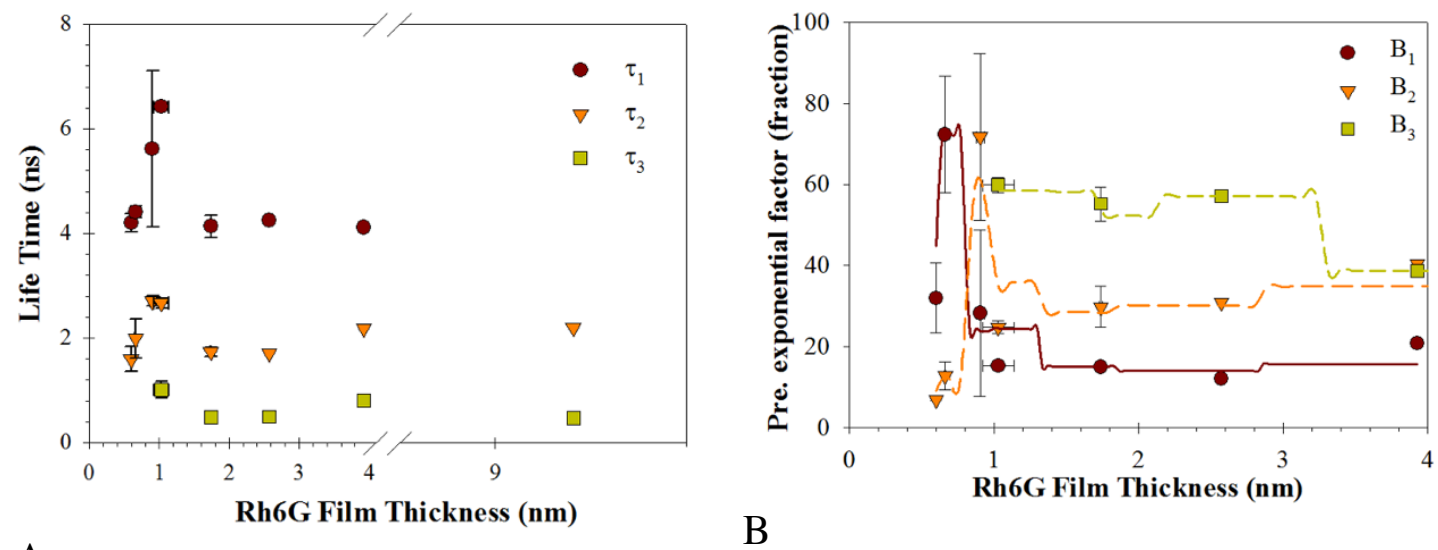

\section{A}

Figure 3-8. (A) Lifetime emission of different thicknesses of Rh6G on PMMA of constant thickness; tPMMA $=318 \mathrm{~nm}$. (B). Pre-exponential factor as a function of Rh6G thickness.

Time-resolved emission spectroscopy (TRES) was performed to obtain photophysical information that was lost with time averaged absorbance and 
fluorescence steady state emission. All decay curves deconvoluted into 2 or 3 exponential fits: $I(t)=+B_{1} e^{-t / \tau_{1}}+B_{2} e^{-t / \tau_{2}}+B_{3} e^{-t / \tau_{3}} \cdot \tau$ is the fluorescence lifetime in nanoseconds and $B$ is the pre-exponential factor, which provides information about the relative population of each fluorescent species.

Figure 3-8 (A) shows the excited state lifetimes for radiative decay as a function of fluorophore thickness for Rh6G films on a PMMA substrate of chosen thickness. Figure 3-8 (B) shows the pre-exponential factor of life decay as a function of Rh6G thickness. At low dye concentrations between 0.6 to $0.9 \mathrm{~nm}$ in thickness, only two species observed, however, three peaks were required for deconvolution of absorbance and steady state emission. $\tau_{1}=4.0 \pm 0.6, \tau_{2}=1.9 \pm 0.4 \mathrm{~ns}$. Monomeric structures are the dominant fluorescent species. Lifetime of solvated monomers in different solvents ranged from 3.8 to $4.4 \mathrm{~ns}$, with the higher lifetimes in more polar solvents. ${ }^{13}$ The dielectric constant of PMMA is sufficiently low that even shorter monomer life times are expected, which suggests that $\tau_{2}$ belongs to monomers. The longer of the two lifetimes goes to excimers as it is the only other emissive species that comes from monomer absorption. When Rh6G thickness is increased to $1.0 \mathrm{~nm}$, three lifetime species with different radioactive decays are observed, $\tau_{1}=6.4 \pm 0.1, \tau_{2}=2.7 \pm 0.6$, and $\tau_{3}=0.8 \pm 0.2 \mathrm{~ns}$. We know from the since the absorption, excitation, and emission spectra could all be deconvoluted from the same parameters, that $\tau_{1}$ and $\tau_{1}$ are likely the same species, but with extended lifetimes at this Rh6G thickness. The very short lifetime of the third species is consistent with molecular aggregation. Aggregate species becomes dominant, dimer proportion increases, and monomer has smallest proportion. 
The extended lifetime of monomer and excimer species suggests increased stability of the excited monomer state and increases the probability of forming additional excited state excimers. Further increases of Rh6G thickness, the formation of strongly quenched aggregate species destabilizes the excited state of monomer. When Rh6G thickness is increased to $1.7 \mathrm{~nm}$ and greater, three lifetime species are observed, $\tau_{1}=4.0 \pm 0.6, \tau_{2}$ $=1.9 \pm 0.4$, and $\tau_{3}=0.8 \pm 0.2 \mathrm{~ns}$. The lifetime assignments are consistent with what we observed on glass. ${ }^{7}$ The extended lifetimes at a narrow region of dye thickness is undetermined. 


\section{CONCLUSION}

The scope of this study was to investigate the perceived signal enhancement for Rh6G that was reported with using PMMA substrates. Rh6G steady state emission intensity approximated a log-normal distribution function with Rh6G layer thickness in which the largest emissions were observed at the Rh6G monolayer thickness. While the same trend was observed with glass substrate, Rh6G emission was increased by six times with PMMA. Two sources likely contribute to Rh6G emission enhancement. First, PMMA surface roughness can disrupt weakly emissive molecular aggregation. For multi-layer films of Rh6G on PMMA substrates, the relative proportions of different absorbing species do not largely vary with increasing Rh6G thickness, which is different from Rh6G on glass substrate where monomer species decreased, and aggregate species increased as a function of Rh6G thickness. Correlations between PMMA surface roughness and Rh6G fluorescence emission intensity suggest that interfacial roughness disrupts the formation of oblique dimers and molecular aggregates that would normally exist with the same Rh6G thickness on a glass substrate. Second, internal reflection of light trapped with the PMMA layer promotes photon re-absorption at the Rh6G interface. This effect was only observed at the Rh6G monolayer thickness, $\mathrm{t}_{\mathrm{Rh} 6 \mathrm{G}} \sim 1.0 \mathrm{~nm}$, and is proportional to signal intensity. Rh6G emission intensity can be described by a dampened sine function of PMMA thickness with oscillations that follow quarter wavelength PMMA thicknesses calculated with elementary Fresnel equations. Since surface roughness increases with increasing PMMA thickness, it's likely that cause for emission decay is light scattering at the PMMA-Rh6G interface. Using TRES, we were 
able to confirm predictions that three emissive species were observed, which are oblique dimers, monomers, and aggregate species with respective lifetimes of $\tau_{1}=4.0 \pm 0.6$, $\tau_{2}=1.9 \pm 0.4$, and $\tau_{3}=0.8 \pm 0.2 \mathrm{~ns}$. These lifetimes are similar to what we reported with the glass substrate. When Rh6G thickness is increased to $1.0 \mathrm{~nm}$, the oblique dimer and monomer lifetimes are extended $\left(\tau_{1}=6.4 \pm 0.1, \tau_{2}=2.7 \pm 0.6\right)$ over a short Rh6G thickness region and return to their previous lifetimes by Rh6G thickness of $1.7 \mathrm{~nm}$. 


\section{ACKNOWLEDGEMENT}

This material is based upon work supported by Rhodes Pharmaceuticals L.P. and by the U.S. Department of Homeland Security's Science and Technology

Directorate. The views and conclusions contained in this document are those of the authors and should not be interpreted as necessarily representing the official views and policies, either expressed or implied, of Rhodes Pharmaceuticals L.P. or any of its affiliates, or the U.S. Department of Homeland Security. 


\section{CONFLICT OF INTERESTS}

All authors declare no conflicts of interest in this paper. 


\section{SUPPORTING INFORMATION}
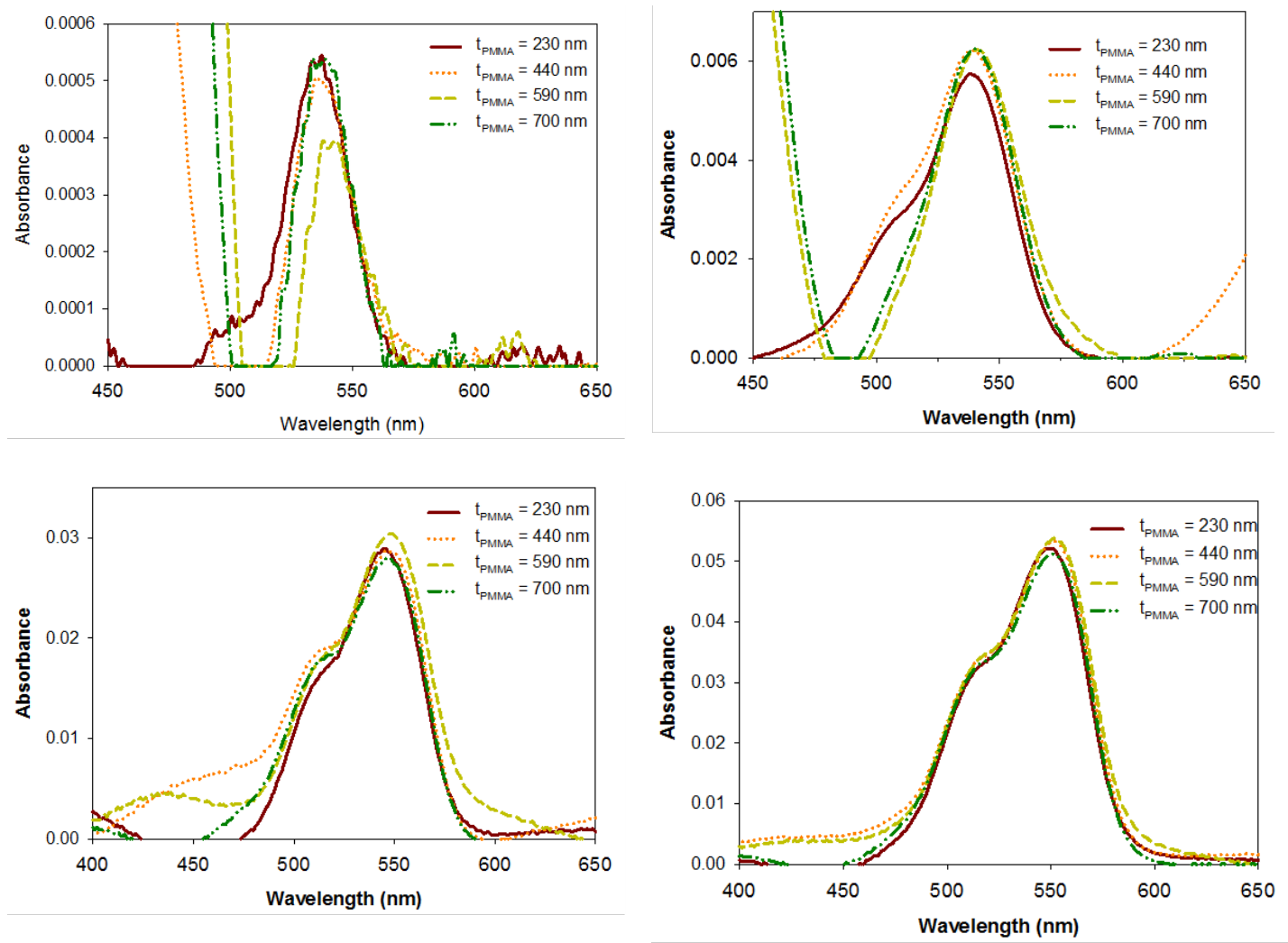

Figure 3-S1. Absorption spectra of constant Rh6G thickness on different PMMA

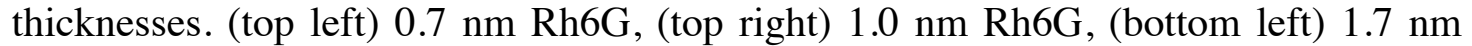
Rh6G, (bottom right) $3.9 \mathrm{~nm}$ Rh6G. 

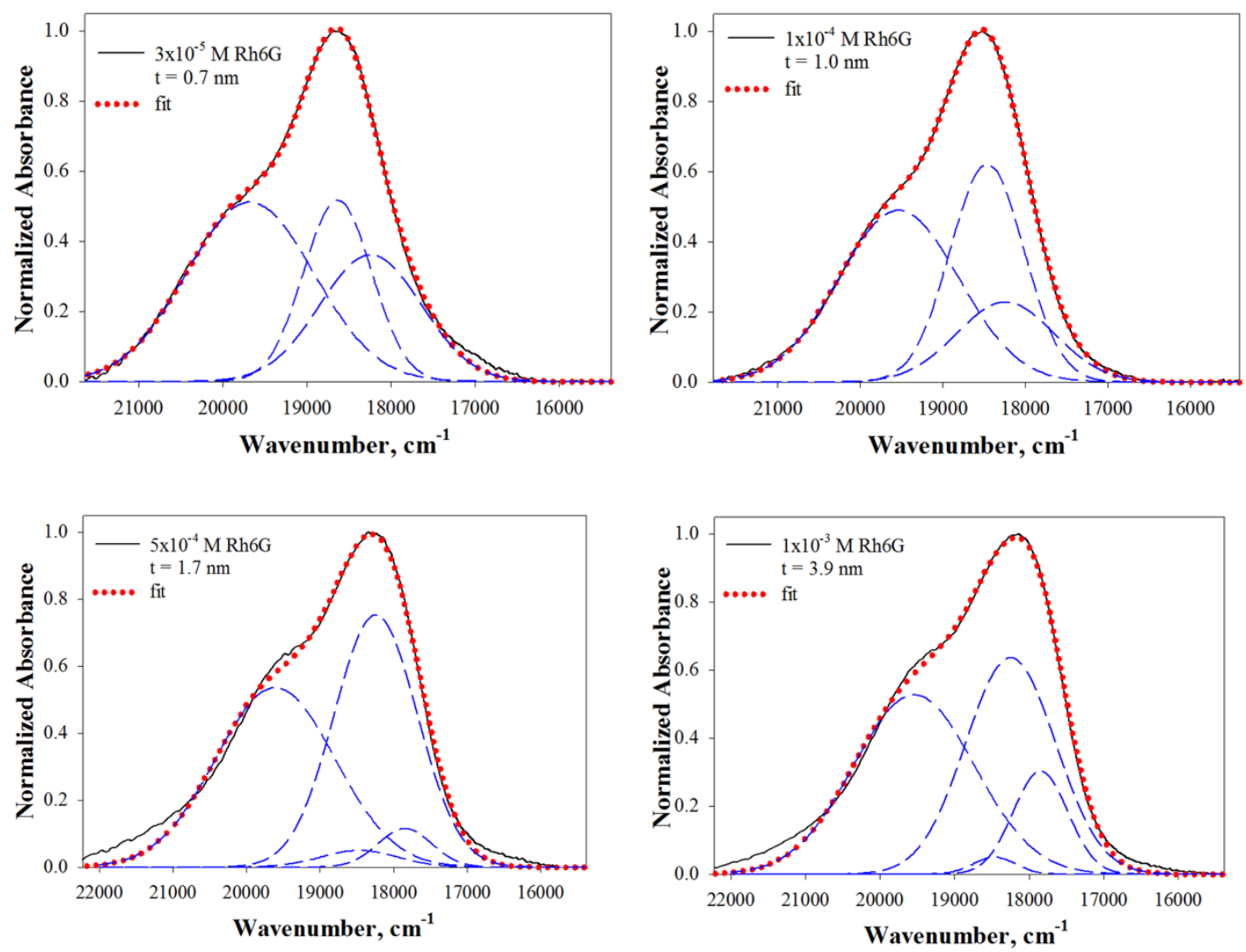

Figure 3-S2. Example fit for deconvolution of Rh6G spectral absorption. 

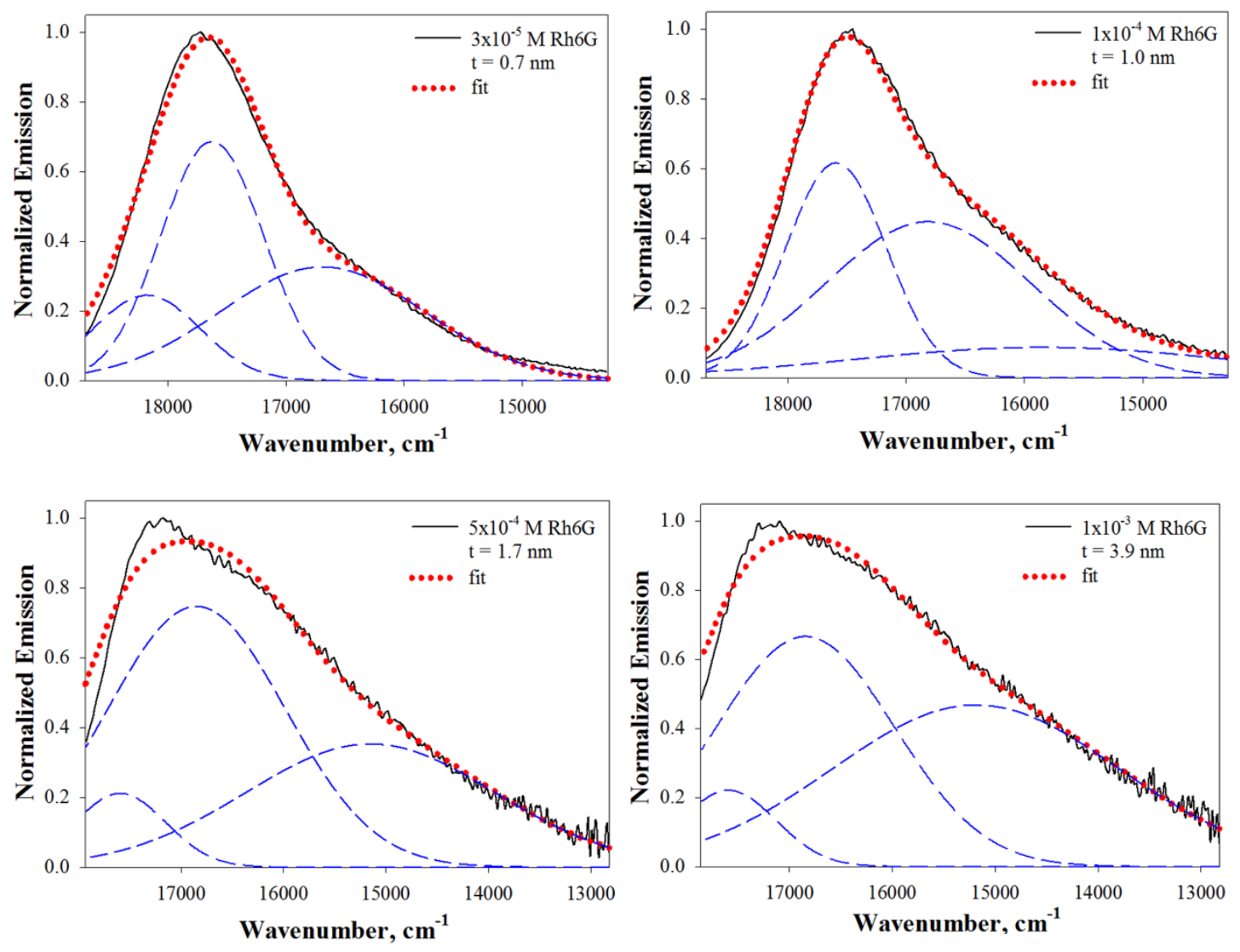

Figure 3-S3. Example fit for deconvolution of Rh6G spectral emission. 


\section{REFERENCES}

(1) Latendresse, C. A.; Fernandes, S. C.; You, S.; Zhang, H. Q.; Euler, W. B. A Fluorometric Sensing Array for the Detection of Military Explosives and IED Materials. Anal. Methods 2013, 5 (20), 5457-5463. https://doi.org/10.1039/c3ay40293b.

(2) Matoian, M. A.; Sweetman, R.; Hall, E. C.; Albanese, S.; Euler, W. B. Light Trapping to Amplify Metal Enhanced Fluorescence with Application for Sensing TNT. J Fluoresc 2013, 23 (5), 877-880. https://doi.org/10.1007/s10895-0131232-8.

(3) Zhang, H. Q.; Euler, W. B. Sensors and Actuators B : Chemical Detection of GasPhase Explosive Analytes Using Fluorescent Spectroscopy of Thin Films of Xanthene Dyes. Sensors Actuators B. Chem. 2016, 225, 553-562. https://doi.org/10.1016/j.snb.2015.11.098.

(4) Mullen, M.; Euler, W. B. The Influence of Interfacial Effects on the Photophysics of Rhodamine 6G Thin Films on a Poly(Vinylidene Fluoride) Surface. Langmuir 2017, 33 (9), 2194-2204. https://doi.org/10.1021/acs.langmuir.7b00144.

(5) Penzkofer, A.; Drotleff, E.; Holzer, W. Optical Constants Measurement of Single-Layer Thin Films on Transparent Substrates. Opt. Commun. 1998, 158 (1-6), 221-230. https://doi.org/10.1016/S0030-4018(98)00535-5.

(6) Haas, D. E.; Birnie, III, D. P. Evaluation of Thermocapillary Driving Forces in the Development of Striations during the Spin Coating Process. J. Mater. Sci. 2002, 37 (10), 2109-2116. https://doi.org/10.1023/A:1015250120963.

(7) Chapman, M.; Mullen, M.; Novoa-Ortega, E.; Alhasani, M.; Elman, J. F.; Euler, W. B. Structural Evolution of Ultrathin Films of Rhodamine $6 \mathrm{G}$ on Glass. J. Phys. Chem. C 2016, 120 (15), 8289-8297. https://doi.org/10.1021/acs.jpcc.6b01669.

(8) Kasha, M. Energy Transfer Mechanisms and the Molecular Exciton Model for Molecular Aggregates. Radiat. Res. 1963, 20 (1), 55-70. https://doi.org/10.2307/3571331.

(9) Novoa-Ortega, E.; Dubnicka, M.; Euler, W. B. Structure-Property Relationships on the Optical Properties of Rhodamine Thin Films. J. Phys. Chem. C 2020, 124 (29), 16058-16068. https://doi.org/10.1021/acs.jpcc.0c05139.

(10) On, C.; Tanyi, E. K.; Harrison, E.; Noginov, M. A. Effect of Molecular Concentration on Spectroscopic Properties of Poly(Methyl Methacrylate) Thin Films Doped with Rhodamine 6G Dye. Opt. Mater. Express 2017, 7 (12), 4286. 
https://doi.org/10.1364/ome.7.004286.

(11) Kasha, M.; Rawls, H. R.; Ashraf El-Bayoumi, M. The Exciton Model in Molecular Spectroscopy. Pure Appl. Chem. 1965, 11 (3-4), 371-392. https://doi.org/10.1351/pac196511030371.

(12) Chapman, M.; Euler, W. B. Rhodamine 6G Structural Changes in Water/Ethanol Mixed Solvent. J. Fluoresc. 2018, 28 (6), 1431-1437. https://doi.org/10.1007/s10895-018-2318-0.

(13) Magde, D.; Wong, R.; Seybold, P. G. Fluorescence Quantum Yields and Their Relation to Lifetimes of Rhodamine 6G and Fluorescein in Nine Solvents: Improved Absolute Standards for Quantum Yields. Photochem. Photobiol. 2002. https://doi.org/10.1562/0031-8655. 


\section{BIBLIOGRAPHY}

Alexander-Katz, A., Schneider, M. F., Schneider, S. W., Wixforth, A., \& Netz, R. R. (2006). Shear-Flow-Induced Unfolding of Polymeric Globules. Physical Review Letters, 97(13), 138101. https://doi.org/10.1103/PhysRevLett.97.138101

Bassou, N., \& Rharbi, Y. (2009). Role of Bénard-Marangoni instabilities during solvent evaporation in polymer surface corrugations. Langmuir, 25(1), 624-632. https://doi.org/10.1021/la802979a

Bénard, H. (1900). Les tourbillions cellulaires dans une nappe liquid. Rev. Gén. Sci. Pures et Appl., 11, 1261-1271 \& 1309-1328.

Bistac, S., \& Schultz, J. (1997). Study of solution-cast films of PMMA by dielectric spectroscopy: Influence of the nature of the solvent on $\alpha$ and $\beta$ relaxations. International Journal of Adhesion and Adhesives, 17(3), 197-201. https://doi.org/10.1016/S0143-7496(97)00001-8

Bland, J. M., \& Altman, D. G. (2003). Applying the right statistics: Analyses of measurement studies. In Ultrasound in Obstetrics and Gynecology (Vol. 22, Issue 1, pp. 85-93). https://doi.org/10.1002/uog.122

Block, M. J. (1956). Surface tension as the cause of Bénard cells and surface deformation in a liquid film. Nature, 178(4534), 650-651. https://doi.org/10.1038/178650a0

Brandrup, J., Immergut, E. H., Grulke, E. A., Abe, A., Bloch, D. R., Wlley, J., Chichester, N. Y., Brisbane, W., \& Toronto, S. (1999). Polymer Handbook (4th ed.). Wiley-Interscience.

Carisier, P., \& Jamand, C. (1987). Stability of roll and hexagonal patterns in BenardMarangoni convection. Physics of Fluids, 30, 954.

Chandrasekhar, S. S. (1961). Hydrodynamic and hydromagnetic stability. Oxford: Clarendon Press.

Chao, D. F., \& Zhang, N. (2001). Effects of Evaporation and Thermocapillary Convection on Volatile Liquid Droplets. Journal of Thermophysics and Heat Transfer, 15(1-4), 416-420. https://doi.org/10.2514/2.6644

Chapman, M., Mullen, M., Novoa-Ortega, E., Alhasani, M., Elman, J. F., \& Euler, W. B. (2016). Structural Evolution of Ultrathin Films of Rhodamine 6G on Glass. Journal of Physical Chemistry C, 120(15), 8289-8297. https://doi.org/10.1021/acs.jpcc.6b01669 
Chung, J. Y., Chastek, T. Q., Fasolka, M. J., Ro, H. W., \& Stafford, C. M. (2009). Quantifying residual stress in nanoscale thin polymer films via surface wrinkling. ACS Nano, 3(4), 844-852. https://doi.org/10.1021/nn800853y

Cloot, A., \& Lebon, G. (1984). A nonlinear stability analysis of the Benard-Marangoni problem. J. Fluid Mech, 145, 447-469. https://doi.org/10.1017/S0022112084003013

Cohn-Ginsberg, E., Fox, T., \& Mason, H. (1962). Properties of dilute polymer solutions II: Light scattering and viscometric properties of solutions of conventional polymethyl methacrylate. Polymer, 3, 97-109. https://doi.org/10.1016/00323861(62)90068-X

Danglad-Flores, J., Eickelmann, S., \& Riegler, H. (2018). Deposition of polymer films by spin casting: A quantitative analysis. Chemical Engineering Science, 179, 257264. https://doi.org/10.1016/j.ces.2018.01.012

Eckert, K., \& Bestehorn, M. (1998). Square cells in surface-tension-driven Benard convection: experiment and theory. Journal of Fluid Mechanics, 356, 155-197. https://doi.org/10.1017/S0022112097007842

Eckert, K., \& Thess, A. (2006). Secondary Instabilities in Surface-Tension-Driven Bénard-Marangoni Convection. In I. Mutabazi, J. E. Wesfreid, \& E. Guyon (Eds.), Dynamics of Spatio-Temporal Cellular Structures: Henri Bénard Centenary Review (pp. 163-176). Springer New York. https://doi.org/10.1007/978-0-38725111-0_9

Emslie, A. G., Bonner, F. T., \& Peck, L. G. (1958). Flow of a Viscous Liquid on a Rotating Disk. Journal of Applied Physics, 29(5), 858-862. https://doi.org/10.1063/1.1723300

Ferriol, M., Gentilhomme, A., Cochez, M., Oget, N., \& Mieloszynski, J. L. (2003). Thermal degradation of poly(methyl methacrylate) (PMMA): Modelling of DTG and TG curves. Polymer Degradation and Stability, 79(2), 271-281. https://doi.org/10.1016/S0141-3910(02)00291-4

Fowler, P. D., Ruscher, C., Mcgraw, J. D., Forrest, J. A., \& Dalnoki-Veress, K. (n.d.). Controlling Marangoni induced instabilities in spin-cast polymer films: how to prepare uniform films.

Gałka, P., Kowalonek, J., \& Kaczmarek, H. (2014). Thermogravimetric analysis of thermal stability of poly(methyl methacrylate) films modified with photoinitiators. Journal of Thermal Analysis and Calorimetry, 115(2), 1387-1394. https://doi.org/10.1007/s10973-013-3446-z

Getling, A. V. (1991). Formation of spatial structures in Rayleigh-Bénard convection. 
Soviet Physics Uspekhi, 34(9), 737.

Haas, D. E., \& Birnie, III, D. P. (2002). Evaluation of thermocapillary driving forces in the development of striations during the spin coating process. Journal of Materials Science, 37(10), 2109-2116. https://doi.org/10.1023/A:1015250120963

Haas, Dylan E., Quijada, J. N., Picone, S. J., \& Birnie III, D. P. (2000). Effect of solvent evaporation rate on skin formation during spin coating of complex solutions. In B. S. Dunn, E. J. A. Pope, H. K. Schmidt, \& M. Yamane (Eds.), Sol-Gel Optics V (pp. 280-284). SPIE. https://doi.org/10.1117/12.384348

Hall, D. B., Underhill, P., \& Torkelson, J. M. (1998). Spin coating of thin and ultrathin polymer films. Polymer Engineering \& Science, 38(12), 2039-2045. https://doi.org/10.1002/pen.10373

Hansen, C., \& Hansen, K. (1988). Solubility Parameter Prediction of the Barrier Properties of Chemical Protective Clothing. In Performance of Protective Clothing: Second Symposium (pp. 197-197-12). ASTM International. https://doi.org/10.1520/STP26285S

Hansen, C. M. (2007). Hansen solubility parameters : a user's handbook (2nd ed.). CRC Press. https://www.crcpress.com/Hansen-Solubility-Parameters-A-UsersHandbook-Second-Edition/Hansen/p/book/9780849372483

Kashiwagi, T., Inaba, A., Brown, J. E., Hatada, K., Kitayama, T., \& Masuda, E. (1986). Effects of weak linkages on the thermal and oxidative degradation of poly(methyl methacrylates). $\quad$ Macromolecules, $19(8), \quad$ 2160-2168. https://doi.org/10.1021/ma00162a010

Lalova, A., Todorov, R., \& Malinowski, A. J. (2015). Optical properties of thin PMMA films for sensor application. In Bulgarian Chemical Communications (Vol. 47). http://www.bcc.bas.bg/BCC_Volumes/Volume_47_Special_B_2015/BCC-47-SIB-5.pdf

Latendresse, C. A., Fernandes, S. C., You, S., Zhang, H. Q., \& Euler, W. B. (2013). Analytical Methods military explosives and IED materials $\dagger$. Anal.Methods, 5(2), 5457-5463. https://doi.org/10.1039/c3ay40293b

Lord Rayleigh. (1916). On convection currents in a horizontal layer of fluid, when the higher temperature is on the under side. Philosophical Magazine, 32, 529-546.

Maroto, J. A., Pérez-Mũuzuri, V., \& Romero-Cano, M. S. (2007). Introductory analysis of Bénard-Marangoni convection. European Journal of Physics, 28(2), 311-320. https://doi.org/10.1088/0143-0807/28/2/016

Martínez, V. M., Arbeloa, F. L., Prieto, J. B., \& Arbeloa, I. L. (2005). Characterization 
of rhodamine $6 \mathrm{G}$ aggregates intercalated in solid thin films of laponite clay. 2 fluorescence spectroscopy. Journal of Physical Chemistry B, 109(15), 7443-7450. https://doi.org/10.1021/jp050440i

Matoian, M. A., Sweetman, R., Hall, E. C., Albanese, S., \& Euler, W. B. (2013). Light Trapping to Amplify Metal Enhanced Fluorescence with Application for Sensing TNT. J Fluoresc, 23(5), 877-880. https://doi.org/10.1007/s10895-013-1232-8

Matsuda, H., Yamano, K., \& Inagaki, H. (1969). Styrene-methyl acrylate copolymers and acrylate homopolymers in solution. Journal of Polymer Science Part A-2: Polymer Physics, 7(4), 609-633. https://doi.org/10.1002/pol.1969.160070403

Matsuoka, S., \& Cowman, M. K. (2002). Equation of state for polymer solution. Polymer. https://doi.org/10.1016/S0032-3861(02)00157-X

Meyerhofer, D. (1978). Characteristics of resist films produced by spinning. Citation: Journal of Applied Physics, 49, 3993. https://doi.org/10.1063/1.325357

Min, X., Orignac, X., \& Almeida, R. M. (1995). Striation-Free, Spin-Coated Sol-Gel Optical Films. Journal of the American Ceramic Society, 78(8), 2254-2256. https://doi.org/10.1111/j.1151-2916.1995.tb08650.x

Mokarian-Tabari, P., Geoghegan, M., Howse, J. R., Heriot, S. Y., Thompson, R. L., \& Jones, R. A. L. (2010). Quantitative evaluation of evaporation rate during spincoating of polymer blend films: Control of film structure through definedatmosphere solvent-casting. Eur. Phys. J. E, 33, 283-289. https://doi.org/10.1140/epje/i2010-10670-7

Moore, W. R., \& Fort, R. J. (1963). Viscosities of dilute solutions of polymethyl methacrylate. Journal of Polymer Science Part A: General Papers, 1(3), 929-942. https://doi.org/10.1002/pol.1963.100010308

Mouhamad, Y., Mokarian-Tabari, P., Clarke, N., Jones, R. A. L., \& Geoghegan, M. (2014). Dynamics of polymer film formation during spin coating. Journal of Applied Physics, 116(12). https://doi.org/10.1063/1.4896674

Patra, N., Barone, A. C., \& Salerno, M. (2011). Solvent effects on the thermal and mechanical properties of poly(methyl methacrylate) casted from concentrated solutions. Advances in Polymer Technology, 30(1), 12-20. https://doi.org/10.1002/adv.20203

Patrone, E., \& Bianchi, U. (1966). Viscosity-molecular weight relationships for low molecular weight polymers. II. Poly(vinyl acetate) and poly(methyl methacrylate). Die Makromolekulare Chemie, 94(1), 52-59. https://doi.org/10.1002/macp.1966.020940106 
Pearson, J. R. A. A., (1958). On convection cells induced by surface tension. Journal of Fluid Mechanics, 4(5), 489-500. https://doi.org/10.1017/S0022112058000616

Peng, J., Yang, F., Chiang, D., \& Lee, S. (2016). Kinetics of Field-Induced Surface Patterns on PMMA. Langmuir, 32(18), 4602-4609. https://doi.org/10.1021/acs.langmuir.6b01304

Penzkofer, A., Drotleff, E., \& Holzer, W. (1998). Optical constants measurement of single-layer thin films on transparent substrates. Optics Communications, 158(16), 221-230. https://doi.org/10.1016/S0030-4018(98)00535-5

Petrov, O. V. (2019). The Earth's Dissipative Structures: Fundamental Wave Properties of Substance. Springer Nature.

Richardson, H., Carelli, C., Keddie, J. L., \& Sferrazza, M. (2004). Structural relaxation of spin-cast glassy polymer thin films as a possible factor in dewetting. Stress: The International Journal on the Biology of Stress, i(2003), 437-441. https://doi.org/10.1140/epje/e2004-00013-8

Rodríguez-Hernández, J. (2015). Wrinkled interfaces: Taking advantage of surface instabilities to pattern polymer surfaces. Progress in Polymer Science, 42, 1-41. https://doi.org/10.1016/j.progpolymsci.2014.07.008

Scriven, L. E., \& Sternling, C. V. (1960). The Marangoni Effects. Nature, 187(4733), $186-188$.

Scriven, L. E., \& Sternling, C. V. (1964). On cellular convection driven by surfacetension gradients: effects of mean surface tension and surface viscosity. Journal of Fluid Mechanics, 19(3), 321-340. https://doi.org/10.1017/S0022112064000751

Strawhecker, K. E., Kumar, S. K., Douglas, J. F., \& Karim, A. (2001). The critical role of solvent evaporation on the roughness of spin-cast polymer films [1]. In Macromolecules (Vol. 34, Issue 14, pp. 4669-4672). https://doi.org/10.1021/ma001440d

Tang, C., Mullen, M., \& B. Euler, W. (2020). Influence of solvent and molecular weight in wrinkle formation in spin-cast polystyrene thin films. AIMS Materials Science, 7(1), 60-74. https://doi.org/10.3934/matersci.2020.1.60

Tippo, T., Thanachayanont, C., Muthitamongkol, P., Junin, C., Hietschold, M., \& Thanachayanont, A. (2013). The effects of solvents on the properties of ultra-thin poly ( methyl methacrylate ) fi lms prepared by spin coating. Thin Solid Films, 546, 180-184. https://doi.org/10.1016/j.tsf.2013.05.022

Van Dyk, J. W., Frisch, H. L., \& Wu, D. T. (1985). Solubility, solvency, and solubility parameters. Industrial \& Engineering Chemistry Product Research and 
Development, 24(3), 473-478. https://doi.org/10.1021/i300019a028

Vashishtha, S. R., Chand, N., \& Hashmi, S. A. R. (2002). Morphology of PS/PMMA blends and their solution rheology. Indian Journal of Chemical Technology, 9(4), 316-323.

Weissberg, S. G., Simha, R., \& Rothman, S. (1951). Viscosity of dilute to moderately concentrated polymer solutions. Journal of Research of the National Bureau of Standards, 47(4), 298-314.

Yamamoto, H. (2009). Hansen Solubility Parameter(HSP) - HSP Application note \#2. https://pirika.com/NewHP/PirikaE/polymer-solvent.html

Zhang, H. Q., \& Euler, W. B. (2016). Sensors and Actuators B : Chemical Detection of gas-phase explosive analytes using fluorescent spectroscopy of thin films of xanthene dyes. Sensors \& Actuators: B. Chemical, 225, 553-562. https://doi.org/10.1016/j.snb.2015.11.098 